\title{
Medical Antihyperglycaemic Treatment of Type 2 Diabetes Mellitus*
}

\author{
Update of the evidence-based guideline of the German Diabetes Association
}

Authors

Published by

Affiliation
S. Matthaei ${ }^{1}$, R. Bierwirth ${ }^{2}$, A. Fritsche ${ }^{3}$, B. Gallwitz ${ }^{3}$, H.-U. Häring ${ }^{3}$, H.-G. Joost ${ }^{4}$, M. Kellerer ${ }^{5}$, Ch. Kloos ${ }^{6}$, T. Kunt ${ }^{7}$, M. Nauck ${ }^{8}$, G. Schernthaner ${ }^{9}$, E. Siegel ${ }^{10}$, F. Thienel

W. A. Scherbaum, T. Haak

Affiliation addresses are listed at the end of the article
Guideline originally published

Guideline last

updated

Bibliography

DOI 10.1055/s-0029-1239559

Exp Clin Endocrinol Diabetes

2009; 117: 522-557

(c) J. A. Barth Verlag in

Georg Thieme Verlag KG

Stuttgart · New York

ISSN 0947-7349

Correspondence

Prof. Stephan Matthaei

Spokesperson for the Panel of Experts

Quakenbrück Diabetes Centre,

DDG clinical diabetes centre

Department of Diabetology,

Metabolism and Endocrinology

at the Christliches Krankenhaus

Academic Teaching Hospital

of the Hannover Medical

University

Danziger Straße10

49610 Quakenbrück

Tel.: ++ 49/5431/15 2830

Fax: ++49/5431/15 2831

S.Matthaei@ckq-gmbh.de

\section{Prof. W. A. Scherbaum}

Chairman of the DDG

Guidelines Committee

Clinic for Endocrinology,

Diabetology and Rheumato-

logy at Düsseldorf University

Hospital WHO Collaborating

Centre for Diabetes European

Training Centre in Endocrino-

logy and Metabolism

Moorenstraße 05

40225 Düsseldorf

Tel.: ++49/211/81 17810

Fax: ++49/211/81 17860

scherbaum@uni-duesseldorf.de

\section{Contents}

$\nabla$$$
1 .
$$

1.1

1.1.1

1.1.1.1

1.1.1.2

1.1.1.3

1.1.1.4

1.1 .2

1.1.2.1

1.1.2.2

1.1.2.3

1.1 .3

1.2.

1.2.1

1.2 .2

1.2.2.1

1.2 .22

1.2.2.3

1.2.2.4

1.2.2.5

1.2.2.6

1.2.2.7

1.2.2.8

2.

2.1

3.

4.

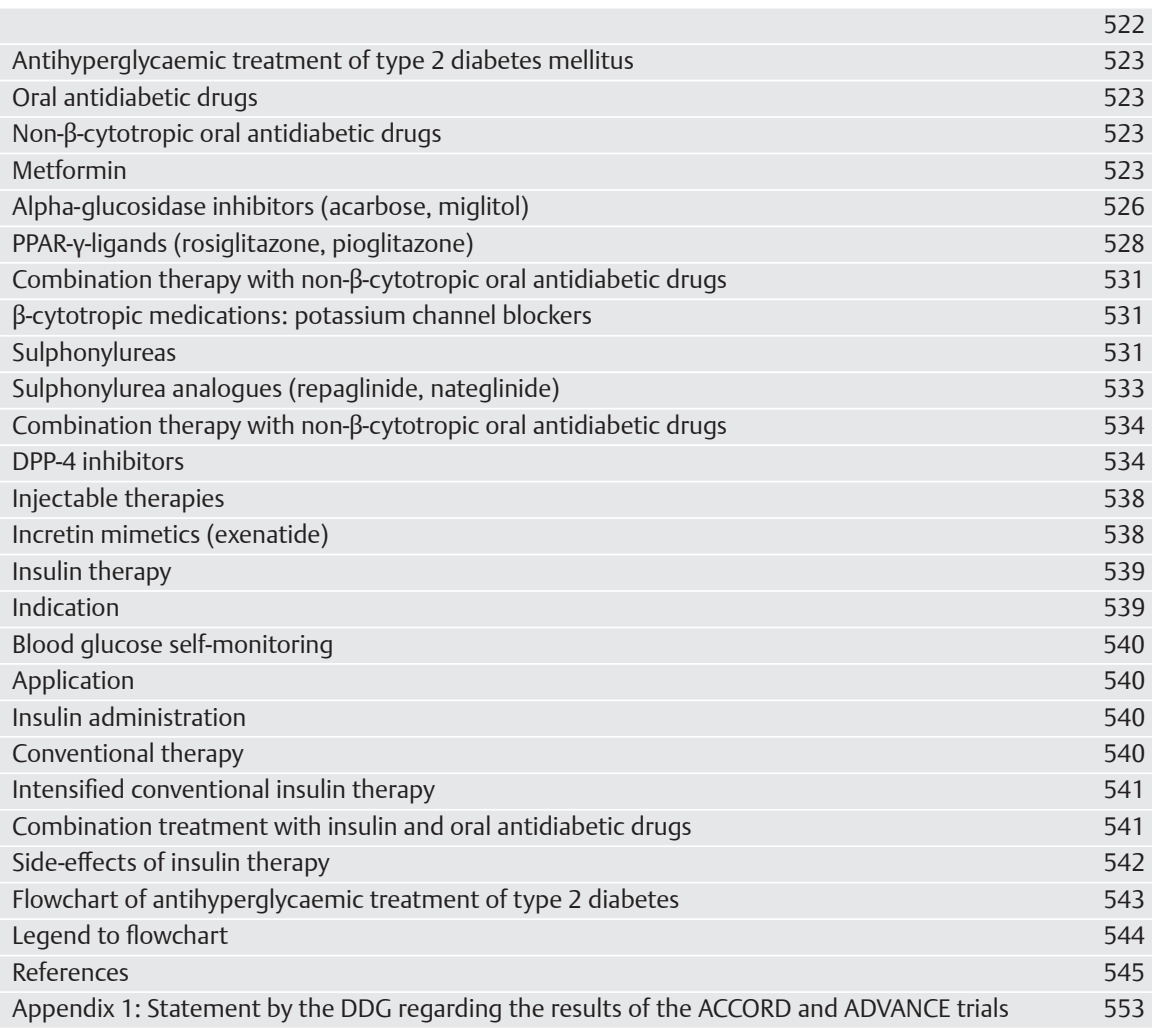

\section{Foreword}

$\nabla$

Type 2 diabetes mellitus is a chronically progressive disease that is characterised by inherited and acquired insulin resistance and an increasing insulin secretion disorder. In order to reduce the morbidity and mortality rates among type 2 diabetics, which are increased significantly by

Note: This updated version takes into account all evidence that was published prior to the end of $06 / 2008$, as well as all new approvals/indications prior to the same date. macro- and microangiopathic complications, besides the antihyperglycaemic therapy discussed here it is also essential to administer the optimum treatment for arterial hypertension (see also DDG guideline "Managing hypertension in patients with diabetes mellitus"), diabetic dyslipidaemia (see also DDG guideline on "Lipid metabolism disorders", in preparation), and hypercoagulopathy that are often associated with type 2 diabetes. The effectiveness of a multifactorial intervention in reducing macro- and microvascular complications Gaede et al., 2003, evidence class (EC) Ib) and also mortality (abso- 
lute risk lowered by $20 \%$ in 13.3 years) (Gaede et al., 2008, EC Ib) has been demonstrated convincingly by the results of the Steno2 study. The favourable effect of an optimised antihyperglycaemic treatment in terms of reducing microvascular complications has been shown equally convincingly in the UKPDS (relative risk reduction $40 \%$ ) (UKPDS 33, 1998, EC Ib) and the ADVANCE study (The ADVANCE Collaborative Group, 2008, EC Ib). Moreover, the 10-year follow-up data from the UKPDS which was published recently attests to the long-term benefits of intensified antihyperglycaemic therapy in reducing macrovascular end points such as myocardial infarction (Holman et al., 2008, EC Ib). A recently published meta-analysis of the effects of antihyperglycaemic therapy on macrovascular results in patients with type 2 diabetes reported a relative risk reduction of 19\% (Stettler et al., 2006, EC Ia).

Because of the chronically progressive nature of the disease, the antihyperglycaemic treatment must be selected according to the pathophysiological phase of the disease at the time the treatment is begun (see also flowchart of "Antihyperglycaemic treatment for type 2 diabetes: [2.0]). At the same time, non-pharmacological therapies (structured patient education, nutrition therapy (see also DDG guideline "Nutrition and diabetes mellitus", as well as exercise therapy) are extremely important in all phases of the disease. In the context of the data from the UKPDS, the UKPDS 10-year follow-up, and ADVANCE, and in accordance with the European Diabetes Policy Group (Desktop Guide to Type 2 Diabetes mellitus) as well as the global IDF guidelines, the target range for $\mathrm{HbA} 1 \mathrm{c}$ recommended in this guideline is $<6.5 \%$. In the light of the recently published results of the ACCORD and ADVANCE studies, however, it is also imperative to avoid adverse side effects such as severe hypoglycaemia and significant weight gain (The Action to Control Cardiovascular Risk in Diabetes Study Group, 2008, EC Ib; The ADVANCE Collaborative Group, 2008, EC Ib). The appendix to this guideline (starting on p.64) includes the position statement of the DDG with respect to both of these studies. This statement has also been posted on the DDG homepage: http://www.deutsche-diabetesgesellschaft.de/redaktion/news/ACCORD_ADVANCE_DDG_ Stellungnahme_2008_07_09.pdf

The conclusions to be drawn from the results of the two studies have been incorporated in the flowchart (see section 2.0) and in the associated legend (see section 2.1).

Endpoint data are available for the following substances in the pharmacological antihyperglycaemic treatment of subjects with type 2 diabetes: metformin, glibenclamide, insulin, pioglitazone, and rosiglitazone. Cardiovascular endpoint data of this kind is not yet available for the other substances listed in this guideline, and there is as yet little long-term information for the newer compounds for obvious reasons.

Antihyperglycaemic treatment of diabetes mellitus type 2 is monitored in the medium to long term range by measuring HbA1c, and as a rule this should be done every three months. Moreover, the treatment is monitored in the short term by measuring blood glucose. This should be carried out in consultation with the treating physician taking into consideration the objectives of treatment, the current metabolic situation, current treatment, and other individual, social and organisational factors. In theory, blood glucose self-measurements should be taken regularly by the patient if therapeutic implications for the short, medium and long terms are derived from the results. The frequency with which the patient should monitor his/her own blood glucose levels is dictated by the individual treatment plan, which in turn is prepared taking into account the treatment objective, quality and stability of metabolic control, and the treatment strategy and other factors. A positive relationship between self-testing and the course of the disease has been shown for example in the ROSSO study (Martin et al., 2006, EC Iib). Accordingly, self-testing is also an integral component in the treatment of type 2 diabetes.

The objective of this guideline for antihyperglycaemic treatment of diabetes mellitus type 2 is to provide treating physicians with assistance when they are selecting the appropriate treatment for each of their patients, and thus reduce the burden not only on the patients but also on their circle of friends and family. In the light of the marked heterogeneity of type 2 diabetes, this guideline is only able to establish a framework and indicate therapeutic options, within which the physician is expected to implement the individualised treatment strategy jointly with the patient. Accordingly, no guideline will claim absolute authority regarding the treatment of all patients, and particularly not of individual problems; however, documented justifications should be provided for deviations from the guidelines.

\section{Antihyperglycaemic treatment of type 2 diabetes mellitus}

$\nabla$

1.1 Oral antidiabetic drugs

1.1.1 Non- $\beta$-cytotropic oral antidiabetic drugs

\subsubsection{Metformin}

Metformin belongs to the class of biguanides, which were introduced into diabetes treatment over 40 years ago (Bailey \& Turner, 1996, EC IV). Metformin improves diabetes control by reducing insulin resistance, mainly in the liver but also in the skeletal muscle, without increasing pancreatic beta-cell secretion (Prager \& Schernthaner, 1983, EC Ib; Perriello et al., 1994, EC IIa; Prager et al., 1986, EC IIa; Matthaei et al., 2000, EC IV; Widen et al., 1992, EC IIa). Metformin reduces free fatty acids and the lipid oxidation rate (Widen et al., 1992, EC Ila). The reduction in hepatic glucose production by metformin may be explained at least in part by the lower rate of lipid oxidation. A recent analysis of 42 clinical studies revealed that the effect of metformin on peripheral insulin resistance might be significantly lower than that of the glitazones (Natali \& Ferrannini, 2006, EC IV).

\subsection{Indication}

Patients with diabetes mellitus type 2 in conjunction with nonpharmacological measures (education, nutrition therapy, increasing physical activity), and for whom there are no contraindications for metformin (Nathan, 2006, IV). The average rate of blood sugar reduction is $20 \%$, and this is not limited to overweight patients; it has also been observed among patients with normal body weight (BMI $24-25 \mathrm{~kg} / \mathrm{m}^{2}$ ).

\subsection{Dosage}

Treatment with metformin should be initiated as described in Table 4. With metformin, there is a clear relationship between dosage and effect, as Garber and associates demonstrated in a placebo-controlled, double-blind study in 1997 (Garber et al., 1997, EC Iia). The effects of metformin doses between $500 \mathrm{mg} /$ day $-2000 \mathrm{mg} /$ day were analysed on a total of 451 patients with type 2 diabetes. The most effective dosage of metformin was $2000 \mathrm{mg} /$ day, which reduced HbA1c levels by as much as $2 \%$ from baseline values of $9 \%$ and lowered fasting blood glucose 


\begin{tabular}{|lll|}
\hline Reported effects & \multicolumn{2}{l}{ Change with respect to starting value } \\
& Range & $\%$ \\
\hline effects on diabetes control & & \\
\hline fasting blood glucose (mmol/L) & $\downarrow 2-4$ & $\downarrow 20-30$ \\
\hline postprandial blood glucose (mmol/L) & $\downarrow 3-6$ & $\downarrow 30-40$ \\
\hline HbA1c (\%) & $\downarrow 1-2$ & $\downarrow 10-25$ \\
\hline effects on insulin concentrations & & $\downarrow 0-20 \%$ \\
\hline fasting plasma insulin concentration ( $\mu \mathrm{U} / \mathrm{mL})$ & $\downarrow 0-3.5$ & \\
\hline effects on lipid metabolism & & $\downarrow 0-30 \%$ \\
\hline serum triglycerides (mmol/L) & $\downarrow 0-1.10$ & $\downarrow 0-10 \%$ \\
\hline serum cholesterol (mmol/L) & $\downarrow 0-0.35$ & $\downarrow 0-25 \%$ \\
\hline serum LDL cholesterol (mmol/L) & $\downarrow 0-1.00$ & $\downarrow 0-39 \%$ \\
\hline serum VLDL cholesterol (mmol/L) & $\downarrow 0-0.60$ & $\downarrow 0-17 \%$ \\
\hline serum HDL cholesterol (mmol/L) & $\downarrow 0-0.16$ & $\downarrow 0-14 \%$ \\
\hline free fatty acids (mmol/L) & $\downarrow 0-0.15$ & No change \\
\hline effect on vascular- and haemostasis parameters & & $\downarrow 10-45$ \\
\hline blood pressure (mmHg) & No change & $\uparrow 0-25$ \\
\hline PAl-1 antigen concentration (ng/ml) & $\downarrow 10-15$ & \\
\hline peripheral blood flow ml/100 ml tissue/min & $\uparrow 0-1.0$ & $\downarrow 0-6$ \\
\hline effect on body weight & & \\
\hline body weight (kg) & $\downarrow 0-4$ & \\
\hline severe hypoglycaemic episodes & & \\
\hline monotherapy & neglegible &
\end{tabular}

Table 1 Effects of metformin on components of insulin resistance. levels by $86 \mathrm{mg} / \mathrm{dl}$ compared with placebo (Garber et al., 1997, EC Ila). $60 \%$ of the maximum hypoglycaemic effect of metformin was observed with a dosage of $1500 \mathrm{mg} /$ day. Increasing the metformin dosage from 2000 to $3000 \mathrm{mg} /$ day only reduced fasting blood glucose levels by a further $5 \%$, while the incidence of gastrointestinal side effects rose sharply.

\subsection{Antihyperglycaemic efficacy}

Two meta-analyses (Hermann et al., 1994, EC Ia; Campbell et Howlett, 1995, EC Ia) of all the prospective and randomised studies that had been conducted between 1957 and 1994 revealed that the effects of metformin and sulphonylureas appear to be identical on HbA1c (decrease of approx. $1.2 \%$ ), fasting blood glucose (decrease of $30-40 \mathrm{mg} / \mathrm{dl}$ ) and postprandial blood sugar values (decrease of approx. $30 \mathrm{mg} / \mathrm{dl}$ ). Even more pronounced effects on fasting blood glucose and HbA1c were observed in studies conducted in the USA, though this may be attributable to the higher starting values in the US studies.

\subsection{Endpoint data with metformin}

The results of the UKPDS study showed unequivocally that improved diabetes control led to a significant reduction in microvascular complications (UKPDS 33, 1998, EC Ib), and that the risk reduction was identical in all therapy groups (sulphonylureas, metformin, insulin). On the other hand, macrovascular complications such as stroke, coronary events and diabetes-related death were only reduced significantly by metformin (UKPDS 34, 1998, EC Ib), though it should be noted that this effect was not observed until after the sixth year of treatment. Since the reduction in HbA1c was comparable for sulphonylureas, metformin and insulin, the macrovascular vasoprotective effect of metformin reported in the UKPDS can only be explained by its activity on other - probably non-traditional cardiovascular - risk factors - or by mechanisms resulting in plaque stabilisation, but not by its activity in lowering blood sugar levels.

\subsection{Effect on other components of the metabolic syndrome}

\subsection{Effect on lipid parameters}

It has been demonstrated in several studies (Johnston et al., 1990 EC Ila) that a significant increase in the HDL cholesterol levels and a fall in VLDL triglycerides are observed during treatment with metformin (see Table 1). In a randomised doubleblind comparative study $(n=1199)$ between metformin and pioglitazone, very different effects on lipid metabolism were observed while the improvement in diabetes control was identical (Schernthaner et al., 2004, EC Ib). The fall in triglycerides $(-19 \%$ vs. $-10 \%$; $<0.001)$ and the increase in HDL cholesterol $(+14 \%$ vs. $+7 \%, \mathrm{p}<0.001)$ were much more pronounced with pioglitazone than with metformin, but the effect on LDL cholesterol was less beneficial with pioglitazone ( $+8 \%$ vs. $-3 \%$; $\mathrm{p}<0.001)$. Concerning the pertinent total cholesterol/HDL cholesterol ratio, identical results were observed for both monotherapies ( $-8 \%$ vs. $-8 \%$; NS). In the combination therapies with various oral antidiabetics too, very different effects on the individual lipid fractions were found despite exactly the same HbA1c-lowering effect, though it is important to note that even combination antidiabetic therapies are rarely capable of regulating complex diabetic dyslipaemia (Schernthaner, 2005, EC IV).

\subsection{Antithrombotic effects}

In 2 studies (Vague et al., 1987; EC Ila; Nagi \& Judkin, 1993, EC Ila), metformin therapy was observed to cause a significant fall in PAI-1, which is associated with reduced triglyceride levels. Metformin was also observed to have a direct effect on PAI-1 synthesis. An additional antithrombotic effect of metformin was observed in its favourable activity against increased thrombocyte aggregation (Gin et al., 1988, EC Ila). Moreover, when metformin was administered to an animal model, a significant reduction of AGE formation was reported, by $25 \%$ with a low dose, and by $72 \%$ with a high dose, respectively (Tanaka et al., 1999). In the DPP study (Diabetes Prevention Program), patients with glucose intolerance showed a reduction in CRP following a year-long course of treatment with metformin; levels were 
reduced by $7 \%$ in men and by $14 \%$ in women (Haffner et al., 2005, EC Ib), though it should be noted that the effect in the group that modified its lifestyle was much more pronounced ( $-23 \%$ and $-33 \%$, respectively). In summary, it seems that the vasoprotective effect of metformin that was demonstrated in the UKPDS is attributable to the fact that the substance has a beneficial effect on several of the known risk factors for atherosclerosis: 1) hyperglycaemia 2) dyslipaemia 3) coagulation disorders 4) endothelial dysfunction 5) chronic vascular inflammation.

\subsection{Combination therapy with metformin and sulpho- nylureas, sulphonylurea analogues, $\alpha$-glucosidase inhibitors, PPAR ligands and insulin}

Since it is often necessary to administer antihyperglycaemic combination therapy, more than $50 \%$ of all patients worldwide receive at least one additional antidiabetic medicine besides metformin. The most thorough information is available for a combination therapy with metformin and sulphonylureas (Hermann et al., 1994; EC Ia; Campbell \& Howlett, 1995, EC Ia). Less well studied is a combination therapy with metformin and resorption inhibitors. A reduction by 0.5 to $2 \%$ ( $1.3 \%$ on average) in HbA1c - depending on the HbA1c baseline value - is described for metformin and sulphonylureas in combination therapy compared with results from monotherapies with these two substance classes (Hermann et al, 1994, EC Ia; Campbell \& Howlett, 1995, EC Ia). Similar findings have also been reported in more recent studies for the combination of metformin with glinides (repaglinide, nateglinide) and glitazones (rosiglitazone, rosiglitazone, pioglitazone). Evaluations of the safety of combination therapy with metformin and sulphonylureas have led to differing results.

In the UKPDS study (UKPDS 34, 1998, EC Ib), a sub-study that was conducted on this combination found a higher mortality rate than for sulphonylurea monotherapy. This was explained by the fact that the patients who were treated with a sulphonylurea in this subgroup had responded exceptionally well (UKPDS 34, 1998, EC Ib). Negative endpoint data was also observed for a combination therapy in a Scandinavian study (Olsson et al., 2000, EC III). However, this statement must be qualified: the patient group receiving combination therapy in this study consisted of a cohort with a longer diabetes duration and was less well controlled (Olsson et al., 2000, EC III). In a 5-year Canadian observational study of 12272 patients who had recently begun treatment with oral antidiabetic drugs (Johnson et al., 2002, EC III), the mortality risk (OR 0.60) was found to be significantly lower with metformin monotherapy $(n=1150)$ than with sulphonylurea monotherapy $(n=3033)$, and this was also demonstrated for the combination therapy of metformin with sulphonylureas ( $\mathrm{n}=4684$ ) (OR 0.66). While the rate of cardiovascular mortality with sulphonylurea monotherapy was $11.6 \%$ during the observation period, the same rate with metformin monotherapy and combination therapy was just $7.0 \%$ and $6.4 \%$, respectively. Likewise in an 8-year Scottish observational study of 5730 patients who had recently begun treatment with oral antidiabetic drugs (Evans et al., 2006, EC III), the overall mortality rate (HR 1.43) and cardiovascular mortality (HR 1.70) were found to be significantly higher with sulphonylurea monotherapy ( $n=3331)$ than with metformin monotherapy $(n=2286)$, though the cardiovascular mortality in combination therapy with both substances $(n=2237)$ in this study was also significantly higher, with RR 1.94 (metformin initially, sulphonylureas later) and RR 3.31 (sulphonylureas initially, metformin later).
Recent studies suggest that the risk of mortality for combination therapy using metformin may be determined by the sulphonylurea that is used. In an Italian observation study of 2002 patients with diabetes mellitus type 2 (Monami et al., 2006, EC III), 696 subjects received a combination therapy of insulin secretagogues with biguanides. Mortality after 3 years was significantly higher for the combination therapy with glibenclamide $(8.7 \%)$ than for repaglinide (3.1\%; $\mathrm{p}=0.002)$, gliclazid $(2.1 \% ; \mathrm{p}=0.001)$ or glimepiride $(0.4 \% ; \mathrm{p}<0.0001)$. Even after adjusting for many influencing factors, the risk of mortality with the metformin-glibenclamide combination was significantly greater, more than doubled (OR 2.09).

In view of the above, the authors do not believe that switching all diabetic patients who are treated with these combinations is indicated, however, they do recommend the application of stricter indication guidelines, particularly for new patients and for those with coronary artery disease.

Particularly favourable results have been described for the combination of insulin and metformin (Yki-Järvinen et al., 1999, EC Ib). Besides marked lowering of HbA1c, by as much as $2.5 \%$, positive effects on body weight as well as an insulin-saving effect were described (Yki-Järvinen et al., 1999, EC Ib).

\subsection{Side effects}

Gastrointestinal side effects, namely nausea, fullness, bloating, diarrhoea and a metallic taste in the palate are side effects that are not uncommon when treatment with metformin is initiated, and in about $5 \%$ of patients these persist, causing treatment to be discontinued. The most common side effects are loss of appetite and fullness, diarrhoea is relatively rare. The most dangerous side effect is lactic acidosis, which is extremely uncommon.

\subsection{Lactic acidosis}

The incidence of lactic acidosis with metformin is $0-0.084$ cases/1 000 patient years (Chan et al., 1998, EC Ila). The risk of death is about a third of this figure. Practically all cases of metformin-associated lactic acidosis occurred in patients for whom clear contraindications existed. Renal insufficiency and cardiac insufficiency are the contraindications that are overlooked most often (Chan et al., 1998, EC Ila). In a recent Cochrane analysis of 206 prospective comparative studies spanning 47846 patient years with metformin and 38221 patient years without metformin, no evidence of an increased risk of lactic acidosis related to metformin was found (Salpeter et al., 2005, EC Ia). The incidence of lactic acidosis with metformin was 6.3 cases per 100000 patient years, whereas the incidence with an antidiabetic therapy that did not include metformin was 7.8 cases per 100000 patient years.

\subsection{Contraindications}

- Impaired renal function (limit value of creatinine clearance: $60 \mathrm{ml} / \mathrm{min}$ )

- Severe liver disease

- Pancreatitis

- Alcoholism

- Consumptive diseases

- Hypoxic states with poor oxygen supply to tissue, respiratory insufficiency, severe cardiac insufficiency (NYHA 3/4). Cardiovascular shock

- Preoperative, perioperative and postoperative state

- Advanced age

- Caloric restrictions (<1000 kcal per day) 


\subsubsection{Advantages and disadvantages of metformin}

\section{Advantages}

- reduction of macrovascular complications

- pathophysiologically orientated therapy

- weight loss

- non- $\beta$-cytotropic

- few episodes of hypoglycaemia

- positive endpoint data (for obese patients)

- other components of the metabolic syndrome are affected favourably

(lipid parameters, CRP, PAI-1, thrombocyte hyperactivity) $\downarrow$ )

\section{Disadvantages}

- many contraindications

- gastrointestinal side effects

- safety of combination therapy with

glibenclamide not established

- increased risk of lactic acidosis if

contraindications are ignored

\subsubsection{Current positioning of metformin}

Metformin was originally approved for treating diabetes in the USA in 1995. In Germany before the UKPDS (1998), metformin could only be used in combination therapy with sulphonylureas, and it should be noted that precisely the combination with glibenclamide that was used frequently then is now associated with possibly unfavourable mortality data. Exactly 50 years after its introduction, metformin is undergoing a renaissance of a kind that is highly unusual and even unprecedented for a drug (Schernthaner, 2007, EC IV). In the ADA-EASD Guidelines, metformin was recommended as a primary pharmacotherapy in combination with lifestyle modification for all patients regardless of their body weight (Nathan et al., 2006, EC IV). In an Australian retrospective observational study, metformin was observed to produce at least equally good results for patients of normal weight as for overweight patients in terms of diabetes control (Ong et al., 2006, EC III). Today, metformin is used in combination with all other available antidiabetic medications (insulin, sulphonylureas, glinides, glitazones, gliptins, GLP-1 agonists), wherein both its efficacy and particularly its contribution to weight control appear attractive. In the ADOPT study (Kahn et al., 2006), patients receiving monotherapy treatment with metformin were compared with those taking rosiglitazone only, and a weight difference of $6.9 \mathrm{~kg}$ was found after just 3 years of treatment. In the QUARTET study as well, the difference in weight between metformin and pioglitazone was $3.9 \mathrm{~kg}$ after just one year (Schernthaner et al., 2004, EC Ib). The anorectic effect of metformin, which has been known for decades, may be at least partly attributable to an inhibiting effect on DPP-4 (Lindsay et al., 2005). The favourable view of metformin is also supported by a new Cochrane analysis (Saenz et al., 2005, EC Ia) as well as by positive reports for patients with cardiac insufficiency (Masoudi et al., 2005, EC III) and in terms of the risk of cancer (Evans et al., 2005, EC III).

\subsubsection{Alpha-glucosidase inhibitors (AGI)}

Alpha-glucosidase inhibitors (AGI) are enzyme inhibitors that prevent di- and oligosaccharides from being hydrolysed to monosaccharides in the intestines. Since only monosaccharides are easily absorbed into the blood from the intestines, a fraction of the oligosaccharides consumed with food remains in the intestines. This reduces the postprandial rise in blood sugar levels and the quantity of sugar absorbed.

Clinical data is available in the literature for three AGIs, acarbose, miglitol and voglibose. Currently, only acarbose and miglitol are approved for use in Germany. Therefore, voglibose is not mentioned in this guideline.

\subsection{Indication}

For patients with diabetes mellitus type 2 in conjunction with non-pharmacological measures (education, nutrition therapy, increased physical activity), for whom an intolerance/ contraindication for metformin exists. Acarbose can be combined with any therapeutic principle that lowers blood glucose, and also contributes to further significant reduction of HbA1c (Chiasson et al., 1994, EC I b; Holman et al., 1999, EC Ib, van de Laar et al. 2005, EC Ia) (recommendation grade A). Miglitol is only approved for the combination therapy with sulphonylureas.

Acarbose can slow the progression of impaired glucose tolerance (IGT) to diabetes mellitus (Chiasson et al., 2002, EC Ib). It has not yet been established beyond doubt whether this actually prevents the patient from developing diabetes mellitus, or whether it is simply slowed. Acarbose is not approved for use in IGT.

\subsection{Dosage}

In the case of both AGIs, acarbose and miglitol, an optimum dosage should be titrated gradually for each patient. Glucosidase activity varies according to each patient's constitution and dietary habits, and this individual dose should be used to determine the extent of the efficacy and side effects. Where meals contained between 30 and $60 \%$ available carbohydrates, there were no demonstrable differences in terms of HbA1c efficacy and tolerability of acarbose (Wolever et al., 1998, EC Ib, recommendation grade B). Both AGIs should be taken at the start of the meal.

Treatment with acarbose is usually begun with a dose of $50 \mathrm{mg}$ once daily, whereby the most suitable meal for taking the prescribed medication is the one with the biggest increase in postprandial blood glucose (breakfast). For patients who are prone to meteorism, treatment may begin with a single dose of $25 \mathrm{mg}$, which already reduces blood glucose levels by $11 \%$ (Fischer et al., 1998; EC Ib). Depending on tolerance and the blood sugar target, this dose may be increased incrementally and every few days. Increasing the dose to more than $100 \mathrm{mg}$ per day $(50 \mathrm{mg} 2 \mathrm{x} / \mathrm{d}$ ) does not further improve HbA1c but aggravates gastrointestinal side effects (van de Laar et al., 2005, EC Ia, Fischer et al., 1998, EC 1b). Increasing the dosage to a total daily dose of more than 100-200 mg does not appear to bring any benefits (recommendation grade $\mathrm{B}$ ). There appears to be no clear relationship between dosage and effectiveness for larger doses of acarbose (>100 mg/d).

Similar titration is also advisable for miglitol. Unlike acarbose, there does appear to be a linear dose-effectiveness relationship for miglitol (van de Laar et al., 2005, EC Ia, recommendation grade $\mathrm{B}$ ). 


\subsection{Antihyperglycaemic efficacy}

The pharmacological principle implies that AGIs act mainly on the postprandial blood glucose concentrations, which are lowered by AGIs, depending on the initial value and in the case of acarbose by $1.65-3.62 \mathrm{mmol} / \mathrm{l}$ (30-65 mg/dl) (miglitol $2.7 \mathrm{mmol} / \mathrm{l}$ (49 mg/dl)) (Lebovitz, 1998, EC I a, Herrman et al., 1998, EC II b, Goto T, 2005, EC Ib, van de Laar et al., 2005, EC Ia) (recommendation grade A). After several weeks, in a secondary, less pronounced phenomenon, the fasting blood glucose concentrations are also lowered by $1.1-2.2 \mathrm{mmol} / \mathrm{l}(20-40 \mathrm{mg} / \mathrm{dl}$ ) (miglitol $0.52 \mathrm{mmol} / \mathrm{l}(9 \mathrm{mg} / \mathrm{dl})$ ) (Hoffmann et al., 1994, EC I b; Lebowitz, 1998, EC Ia; Meneilly et al., 2000, EC Ib, van de Laar et al. 2005, EC Ia). This effect occurs in addition to that of dietary training (Hasche et al., 1999, EC Ib) (recommendation grade B). The power of AGIs to lower blood sugar is retained permanently. Therapy failure in the sense of complete loss of efficacy does not occur (Mertes G, 2001, EC IIb, recommendation grade B). In monotherapy with AGIs, HbA1c can be lowered by $0.5-1.4 \%$ (Baron et al., 1997, EC IIa; Hasche et al., 1999, EC Ib; Braun et al., 1996, EC Ib), and on average by about $0.8 \%$ (Lebovitz, 1998, van de Laar, EC Ia) (recommendation grade A). If HbA1c is higher at baseline, the improvement in HbA1c is more marked. For every one percent elevation of the baseline-HbA1c, the estimated reduction is an additional $0.12 \%$ (van de Laar, EC Ia, recommendation grade A). Over prolonged treatment periods, significantly worse HbA1c efficacy may be reported, and the effect of lowering the HbA1c may be reduced to $0.2 \%$, caused by failure to adhere to the treatment regimen (Holman et al., 1997, EC Ia, recommendation grade A) (see also section 1.1.1.2.5 Side effects).

\subsection{Effect on other metabolic components and hormones}

The effect of AGIs on bodyweight is neutral (Holman et al., 1999, EC I b, van de Laar 2005, EC Ia) (recommendation grade A). Postprandial insulin release is lowered by acarbose (Calle-Pascual et al., 1996, EC IIa, Meneilly et al., 2000, EC Ib, Delgado et al., 2002, EC Ib, Chiasson et al., 1996, EC Ib; Laube et al., 1998, EC IIa, van de Laar EC Ia) (recommendation grade B). However, this does not improve beta-cell function (Chang et al. 2004, EC Ib) (recommendation grade B) or insulin sensitivity (Fischer et al. 2003, EC Iib) (recommendation grade C). A proven effect of AGIs on serum lipids has not been confirmed (van de Laar et al., 2005, EC Ia) (recommendation grade B). Increased release of GLP-1 was not demonstrated (DeLeon et al., 2002, EC Iib) (recommendation grade $\mathrm{B}$ ). Postprandial reduction of $\mathrm{D}$-dimer and prothrombin fragments, and therewith also a possible reduction in the degree of activation of haemostasis was observed in type 2 diabetics receiving acarbose (Ceriello et al., 1996, EC Ib) (recommendation grade $\mathrm{C}$ ). In a population with impaired fasting glucose (IFG), acarbose was not shown to reduce endothelial dysfunction in a substance-specific manner, but rather as a result of reduced hyperglycaemia (Wascher et al., 2005, EC Ib) (recommendation grade $\mathrm{C}$ ).

The clinical relevance of these changes for the patient has not yet been established in any valid studies, so they should not form the primary basis for any decision regarding treatment.

\subsection{Side effects}

Gastrointestinal complaints such as bloating, flatulence, diarrhoea and abdominal pain are the most common side effects of AGIs, and their respective frequency is in the order the complaints are listed. They are caused by fermentation of unused

carbohydrates in the intestine. The complaints occur most often in the first few weeks after treatment starts. The scale and frequency of these side effects are determined by the individual's glucosidase activity, and are clearly dependent on the dosage of AGIs (van de Laar et al., 2005, evidence class Ia) (recommendation grade A). Since the additional antihyperglycaemic effect of high doses of acarbose is weak, high doses should be avoided (see also section 1.1 .1 .2 .2 ). Initially, up to $50 \%$ of patients may experience gastrointestinal side effects with AGIs, compared with $30 \%$ who receive a placebo. It is therefore important to increase the dosage gradually. In this way, the associated intestinal symptoms at start may be reduced to below 30\% (May, 1995, EC IIa) (recommendation grade B) and the discontinuation rate for new patients may be reduced to less than $3 \%$ (Fischer et al., 1998; EC I b) (recommendation grade A). Over a prolonged period, however, some of those patients who experience strong side effects may become less observant of their regimen (Holman et al., 1997, evidence class Ib), (recommendation grade A). Severe side effects seldomly occur with AGIs. Individual case reports of the development of hepatitis and ileus with AGIs have been published. If AGIs are used in combination with insulinotropic medications or insulin, hypoglycaemia can only be treated orally or with glucose and not with oligosaccharides.

\subsection{Contraindications}

AGIs are contraindicated for patients younger than 18 and those who are pregnant. Contraindications also exist for patients with chronic inflammatory intestinal diseases, and also for hernias, spastic colon, ileus and subileus. AGIs should not be administered in the case of severe renal insufficiency (creatinine clearance $<25 \mathrm{ml} / \mathrm{min}$ ).

\subsection{Summary: Advantages and disadvantages of AGls}

AGIs are drugs that lower blood glucose levels by preventing oligosaccharides (di- and oligosaccharides) from being broken down to glucose. As a result, a fraction of the carbohydrates that are consumed in food remains in the intestine and is not made available for resorption. Because of their pharmacologically different mechanism of action, AGIs can be used in combination with other antihypergycaemic compounds and have an additive antiglycaemic effect. An effect on surrogate parameters has been demonstrated, but no endpoint studies are available. Since they only lower HbA1c and blood glucose slightly, AGIs alone are not usually effective enough to achieve the treatment objective of a near- normoglycaemic blood glucose levels. Severe side effects occur rarely, but gastrointestinal side effects are frequent, and they tend to discourage patients from adhering to the treatment regimen. AGIs are drugs that should be used as complementary treatments and after careful consideration of the additional therapeutic effect and benefit expected.

\section{Advantages}

- can be used in combination with all therapy principles (diet, oral antidiabetics, insulin) with added effect

- does not affect weight

- no risk of hypoglycaemia

- life-threatening side effects are extremely rare

\section{Disadvantages}

- no primary endpoint study

- gastrointestinal side effects common

- poor therapy observance due to frequent side effects

- HbA1c lowered only slightly 


\subsubsection{PPAR-y ligands (rosiglitazone, pioglitazone)}

Rosiglitazone and pioglitazone are selective agonists of the PPAR- $\gamma$ receptor (peroxisomal proliferator activated receptor gamma) and belong to the class of thiazolidindiones (glitazones). These substances improve blood glucose control by reducing insulin resistance in adipose tissue, skeletal muscle and liver (Balfour et al., 1999, EC IV; Schatz et al., 2000, EC IV; Matthaei et al., 2000, EC IV; Matthaei et al., 2001, EC IV).

\subsection{Indication}

\subsection{Monotherapy (rosiglitazone, pioglitazone)}

For patients with diabetes mellitus type 2 in conjunction with non-pharmacological measures (education, nutrition therapy, increased physical activity), for whom an intolerance/ contraindication for metformin exists. (Pavo et al., 2003, EC Ib; Schernthaner et al., 2004, EC Ib; Tan et al., 2005, EC Ib; Charbonnel et al., 2004, EC Ib; Tan et al., 2004a, EC Ib; Tan et al., 2004b, EC Ib; Natali et al., 2004, EC Ib; St. John-Sutton, 2002, EC Ib) (recommendation grade $\mathrm{A}$ ).

\subsection{Double combination therapy (rosiglitazone, pioglitazone)}

a) With metformin: for patients whose blood sugar is not sufficiently controlled despite oral monotherapy with the maximum - or maximum tolerable - daily dose of metformin (Matthews et al., 2005, EC Ib; Bailey et al., 2005, EC Ib; Jung et al., 2005, EC Ib). b) With sulphonylureas/sulphonylurea analogues (glinides): only for patients with intolerance or contraindication for metformin whose blood sugar is not sufficiently controlled despite oral monotherapy with sulphonylureas (Hanefeld et al., 2004, EC Ib; Umpierrez et al., 2006, EC Ib; Nagasaka et al., 2004, EC Ib; Rosenstock et al., 2005, EC Ib; Zhu et al., 2003, EC Ib; Kerenyi et al., 2004, EC Ib; Pfützner et al., 2006, EC Ib; Fonseca et al., 2003, EC Ib; Raskin et al., 2004, EC Ib).

\subsection{Triple combination therapy (rosiglitazone)}

For patients whose blood sugar is not sufficiently controlled despite oral double combination therapy with metformin and sulphonylureas (Dailey et al., 2004, EC Ib) and for whom insulin therapy would entail professional limitations (e.g. carriage of passengers). Achievement of the HbA1c therapeutic objective should be realistic with the triple combination therapy. (Technical information on Avandia ${ }^{\circledR}$ March 2008, Technical information on Actos ${ }^{\circledR}$, August 2007).

\subsection{Combination therapy with insulin (pioglitazone)}

For patients whose blood sugar is insufficiently controlled with insulin and for whom metformin is not suitable due to contraindications or intolerance (Technical information on Actos ${ }^{\circledR}$, August 2007).

\subsection{Dosage}

\subsection{Dosage of rosiglitazone}

Rosiglitazone therapy is usually started at $4 \mathrm{mg} /$ daily. This dose can be increased to $8 \mathrm{mg} /$ daily after 8 weeks if necessary. Rosiglitazone can be administered in one or two doses per day, whereby the antihyperglycaemic efficacy is individually greater with two administrations per day than with one, without resulting in a significant difference. In combination with a sulphonylurea, care should be taken when increasing the dosage to $8 \mathrm{mg} / \mathrm{d}$. It should be preceded by an appropriate medical examination to assess the risk of fluid retention occurring. Rosiglitazone can be taken with or without food. For patients of advanced age, the dosage does not need to be adjusted, though particular attention must be paid to cardiac insufficiency and fluid retention. For patients with mild to moderate renal insufficiency (creatinine clearance $>30 \mathrm{ml} / \mathrm{min}$ ), the dosage does not need to be adjusted, in the case of severe renal insufficiency (creatinine clearance $<30 \mathrm{ml} / \mathrm{min}$ ), rosiglitazone should only be used with extreme caution because very few study results are available (Technical information on Avandia ${ }^{\circledR}$ March 2008).

\subsection{Dosage of pioglitazone}

Pioglitazone therapy can be started at a dosage of 15 or $30 \mathrm{mg}$ and increased incrementally up to $45 \mathrm{mg}$, once a day. Pioglitazone can be taken with or without food. In combination with insulin, the prior dosage of insulin can be retained when treatment with pioglitazone begins. If the patient has a history of hypoglycaemia, the insulin dosage should be reduced. For patients of advanced age, the dosage does not need to be adjusted. For patients with impaired renal function (creatinine clearance > $4 \mathrm{ml} / \mathrm{min}$ ), the dosage does not need to be adjusted. No information is available with regard to dialysis patients, so these patients must not receive pioglitazone (Technical information on Actos $^{\circledR}$, August 2007).

\subsection{Antihyperglycaemic efficacy}

The average antihyperglycaemic efficacy of rosiglitazone and pioglitazone in monotherapy is about $1.0 \%$ HbA1c reduction (0.5-1.4\%) (Pavo et al., 2003, EC Ib; Schernthaner et al., 2004, EC Ib; Tan et al., 2005, EC Ib; Charbonnel et al., 2004, EC Ib; Tan et al., 2004a, EC Ib; Tan et al., 2004b, EC Ib; Watanabe et al., 2004, EC Ib; Ebeling et al., 2001, EC Ib; Lawrence, 2004, EC Ib; Ramachandran et al., 2004, EC Ib; Langenfeld et al., 2005, EC Ib; Carey et al., 2002, EC Ib; Natali et al., 2004, EC Ib; Tiikkainen et al., 2004, EC Ib; St. John-Sutton 2002, EC Ib; Yosefy et al., 2004, EC Ib; Fonseca et al., 2000, EC Ib; Kipnes et al., 2001; EC Ib; Einhorn et al., 2000, EC Ib; Derosa et al., 2005a, EC Ib) (recommendation grade A) HbA1c reduction is of a similar magnitude to that achieved with double and triple combination therapies with metformin and/or sulphonylureas or sulphonylurea analogues (0.33-1.9\%) (Matthews et al., 2005, EC Ib; Hanefeld et al., 2004, EC Ib; Hanefeld et al., 2006, EC IIa; Nagasaka et al., 2004, EC Ib, Bailey et al., 2005, EC Ib; Derosa et al., 2005b, EC Ib; Garber et al., 2006, EC Ib; Rosenstock et al., 2005, EC Ib; Zhu et al., 2003, EC Ib; Kerenyi et al., 2004, EC Ib; Pfützner et al., 2006, EC Ib; Fonseca et al., 2003, EC Ib; Raskin et al., 2004, EC Ib; Jung et al., 2005, EC Ib; Dailey et al., 2004 EC Ib; Orbay et al., 2004, EC Iia) (recommendation grade $\mathrm{A}$ ).

Table 1A shows a summary of studies that examined the antihyperglycaemic efficacy of a glitazone therapy compared to other OADs. The results of these studies show that the antihyperglycaemic efficacy of glitazone therapy is comparable to other OADs.

There is a comparison of the sustained therapeutic effect of initial monotherapies for diabetes mellitus type 2 with rosiglitazone, metformin and glyburide (Kahn et al. 2006, ADOPT study, EC Ib). After five years, therapy failure - defined as fasting blood sugar $>180 \mathrm{mg} / \mathrm{dl}$ - was observed in $15 \%$ of patients treated with rosiglitazone, $21 \%$ of patients treated with metformin, and $34 \%$ patients treated with glyburide. The differences were significant. 
Table 1A Studies including examination of the antihyperglycaemic efficacy of glitazone therapy compared to other OADs.

\begin{tabular}{|c|c|c|c|c|c|c|c|}
\hline \multicolumn{8}{|c|}{$\begin{array}{l}\text { Comparison of glitazone } \\
\text { monotherapy with other OADs }\end{array}$} \\
\hline & Author & EC & N & $\begin{array}{l}\text { Therapy dura- } \\
\text { tion [weeks] }\end{array}$ & $\begin{array}{l}\text { Baseline } \\
\text { HbA1c [\%] }\end{array}$ & Ä HbA1c [\%] & $\mathbf{p}$ \\
\hline Rosi vs. Placebo & Carey 2002 & $\mathrm{lb}$ & 33 & 16 & 7.8 vs. 7.1 & -0.7 vs. +0.4 & $<0.05$ \\
\hline Rosi vs. Metf vs. Plac & Natali 2004 & $\mathrm{lb}$ & 74 & 16 & 7.7/7.8/7.6 & $+0.09 /-0.33 /+1.3$ & ns \\
\hline Rosi vs. Metf & Tiikkainen 2004 & Ib & 20 & 16 & 7.0 vs. 6.9 & 0.4 vs 0.7 & ns \\
\hline Rosi vs. Glibenclamid & St.John-Sutton 2002 & $\mathrm{lb}$ & 203 & 52 & 9.1 vs. 9.5 & 1.1 vs. 1.1 & kA \\
\hline Rosi vs. Glibenclamid & Yosefy 2004 & $\mathrm{Ib}$ & 48 & 8 & 7.4 vs. 7.2 & 1.2 vs. 0.9 & ns \\
\hline Pio vs. Metf & Pavo 2003 & $\mathrm{lb}$ & 205 & 32 & 8.6 vs. 8.6 & 1.3 vs. 1.5 & ns \\
\hline Pio vs. Metf & Schernthaner 2004 & $\mathrm{lb}$ & 1199 & 52 & 8.7 vs. 8.7 & 1.41 vs. 1.5 & ns \\
\hline Pio vs. Gliclazid & Charbonnel 2004 & $\mathrm{lb}$ & 1270 & 52 & 8.7 vs. 8.7 & 1.4 vs. 1.4 & ns \\
\hline Pio vs. Glimepiride & Tan 2004 & $\mathrm{lb}$ & 244 & 52 & 8.54 vs. 8.45 & 0.78 vs 0.68 & ns \\
\hline Pio vs. Glibenclamide & Tan 2004 & $\mathrm{lb}$ & 200 & 52 & 8.4 vs. 8.5 & 0.5 vs. 0.4 & ns \\
\hline Pio vs. Glibenclamide & Watanabe 2004 & $\mathrm{lb}$ & 27 & 26 & 6.9 vs. 7.2 & 0.8 vs. 0.9 & nd \\
\hline Pio vs. Glibencl & Ebeling 2001 & $\mathrm{lb}$ & 29 & 26 & 9.1 vs. 8.9 & 1.1 vs. 1.2 & nd \\
\hline Pio vs. Gliclazid vs. Metf & Lawrence 2004 & $\mathrm{lb}$ & 60 & 26 & $7.43 / 7.85 / 8.04$ & 1.2 vs. 1.2 vs. 1.1 & ns \\
\hline Pio vs. Glimepiride & Langenfeld 2005 & $\mathrm{lb}$ & 173 & 24 & 7.52 vs. 7.44 & 0.81 vs. 0.61 & ns \\
\hline
\end{tabular}

Rosi= Rosiglitazone, $\mathrm{Pio}=$ Pioglitazone, Metf=Metformin, Plac=Placebo, EC=Evidence class, $\mathrm{N}=$ No. of study participants, Duration of therapy in weeks, $\mathrm{HbA1}$ in \%, $\mathrm{p}=$ Significance level, $\mathrm{ns}=$ not significant $(\mathrm{p}>0.05), \mathrm{nd}=$ no data

\subsection{Effect on cardiovascular endpoints}

In the ProActive study, after 36 months pioglitazone led to a nonsignificant relative risk reduction of $10 \%$ for the primary endpoint (overall mortality, non-fatal myocardial infarction, stroke, major lower limb amputation, acute coronary syndrome, cardiac intervention (CABG, PCI), revascularisation of arteries of the lower limb) for patients who had a history of a macrovascular event. A significant relative risk reduction of $16 \%$ was observed for the secondary (cardiovascular) endpoint (myocardial infarction, stroke, death). The "number-needed-to-treat" in order to prevent a macrovascular event is 144/year (Dormandy et al., 2005, EC Ib). In the group that was treated with pioglitazone, the fraction of patients who had to begin an insulin therapy fell by $46.9 \%$ compared to placebo. $1.6 \%$ more patients in the pioglitazone group than in the placebo group were hospitalised for cardiac insufficiency. $21.6 \%$ of the patients in the pioglitazone group and $13.0 \%$ of the patients in the placebo group experienced edema.

A meta-analysis by Eurich showed a reduction in overall mortality for glitazone patients with known cardiac insufficiency, but at the same time an increased risk of admission to hospital for decompensation due to cardiac insufficiency (Eurich et al., 2007, EC Ia).

Nissen \& Wolski (2007, EC Ia) published a meta-analysis of 42 studies with rosiglitazone as the study medication, which detected a significant increase in the risk of myocardial infarction (Odds ratio 1.43) when rosiglitazone medication was used compared with control groups (placebo and comparison substances). In this analysis, the risk of mortality from cardiovascular causes was also greater for rosiglitazone therapy (Odds ratio 1.64 ) but just missed the significance level $(p=0.06)$. The associated editorial listed the following weaknesses of this analysis: relatively small number of cardiovascular events; analysis only of summary study data, not of individual patient data, and consequently the time before the event and dose event relationships were not recorded; control groups with placebo and comparison medication were not distinguished; no standard method for diagnosing and securing endpoints. (Psaty \& Furberg 2007, EC IV). Home et al., published an interim analysis of the ongoing RECORD study on a total of 4447 patients who were being treated with the combination of metformin plus sulphonylurea or rosiglitazone plus metformin or sulphonylurea following fail- ure of monotherapy with metformin or sulphonylurea. In this analysis, no significant differences with regard to the risk of myocardial infarction and risk of cardiovascular mortality were found between the rosiglitazone group and the control group after an average observation period of 3.75 years. However, congestive heart failure occurred more frequently with rosiglitazone (Home et al., 2007, EC Ib).

Another meta-analysis of studies with rosiglitazone revealed an increased risk of myocardial infarction, which was, however, not associated with increased risk of death from cardiovascular causes (Singh et al., 2007, EC Ia). This last finding was confirmed in a further meta-analysis (Lago et al. 2007, EC Ia). No reference to increased cardiovascular risk due to rosiglitazone was made in the ACCORD and VADT study.

The position of the Pharmacotherapy Committee of the DDG regarding this issue is set out in detail at the following web address. (http://www.deutsche-diabetes-gesellschaft.de/redak tion/news/rosi_final.doc)

On the basis of the data quoted, the EMEA recognises acute coronary syndromes such as angina pectoris, non-ST-elevation myocardial infarction and ST-elevation myocardial infarction as contraindications for rosiglitazone. The same authority recommends that rosiglitazone not be used for patients with ischaemic coronary disease and/or peripheral arterial occlusive disease (press release EMEA 24.01.08 - Doc.Ref.EMEA/42232/2008). These points have also been incorporated into the current Technical Information Sheet. (Technical information on Avandia ${ }^{\circledR}$ March 2008).

\subsection{Effect on metabolic parameters}

1.1.1.3.4.1 Effect on lipid parameters (Yki-Järvinen 2004, EC IV)

$\begin{array}{lll}\text { LDL cholesterol } & \begin{array}{l}\text { Rosiglitazone } \\ \text { 8 } 8-16 \% \\ \text { shift from small dense to } \\ \text { shift from small dense to }\end{array} & \text { Pioglitazo } \\ \text { large buoyant } & & \mathbf{\Delta} 0-13 \% \\ \text { large buoyant } & & 0 \text { to }-26 \% \\ \text { HDL cholesterol } & \mathbf{\Delta} 5-13 \% & \mathbf{\nabla}\end{array}$

${ }^{*}$ Change relative to starting value compared with placebo 
(Bailey et al., 2005, EC Ib; Wagstaff et al., 2002, EC IV, Goldberg et al., 2005, EC Ib; Freed et al., 2002, EC Ib; Pfützner et al., 2006, EC IV; King et al., 2002, EC III; van Wijk et al., 2005, EC Ib).

\subsection{Effect on blood pressure}

Significant reductions in both diastolic (to $4.2 \mathrm{mmHg}$ ) and systolic (to $6.2 \mathrm{mmHg}$ ) blood pressure was found for rosiglitazone and pioglitazone in several studies (Pavo et al., 2003, EC Ib; St. JohnSutton 2002, EC Ib; Yosefy et al., 2004, EC Ib, Natali et al., 2004, EC Ib).

\subsection{Effect on insulin resistance markers}

Significant improvements in insulin resistance markers such as fasting plasma insulin, postprandial insulin level and HOMA indices were shown for rosiglitazone and pioglitazone compared with other oral antidiabetics (Natali et al., 2004; Bailey et al., 2005; Derosa et al., 2005; Rosenstock et al., 2005; Kerenyi et al., 2004; Pfützner et al., 2006; Pavo et al., 2003; Schernthaner et al., 2004; Charbonnel et al., 2004, Yanagawa et al., 2004; Tan et al., 2004; Nagasaka et al., 2004 - all EC Ib). (HOMA insulin resistance index (HOMAIR): fasting insulin $(\mu \mathrm{U} / \mathrm{ml}) \times$ fasting glucose $(\mathrm{mmol} / \mathrm{l}) / 22,5$; HOMA insulin secretion (HOMA- $\beta): 20 \times$ fasting insulin $(\mu \mathrm{U} / \mathrm{l}) /$ fasting glucose $(\mathrm{mmol} / \mathrm{l})-3.5$ or HOMACalculator at www.dtu.ox.ac.uk).

\subsection{Effect on intima-media thickness of the carotid artery}

Significantly less progression in the intima-media thickness was observed for pioglitazone than with glimepiride (Mazzone et al., 2006, EC Ib). In a smaller study, a regression of the intima-media thickness was described for rosiglitazone compared with metformin (Stocker et al., 2007, EC Ib).

\subsection{Clinically relevant side effects}

\section{Rosiglitazone}

fluid retention edema (3.0-5.4\%)* congestive heart failure $(0.2-0.6 \%$ when combined with OAD)

metabolism weight gain $(1-5 \mathrm{~kg})$

+ metformin $+3.3 \mathrm{~kg}$

+ sulphonylurea

$+5.1 \mathrm{~kg}$

hypoglycaemia when combined with sulphonylureas

gastrointes-

tinal tract haematology

eye diseases diarrhoea, flatulence, obstipation anaemia

occurrence or worsening of macular edema (rare)

\section{Pioglitazone}

edema (6-9\%)* congestive heart failure (by $1 \%$ )

weight gain $(0.7-3.5 \mathrm{~kg})$

+ metformin:

$+1.5 \mathrm{~kg}$

+ sulphonylurea:

$+2.8 \mathrm{~kg}$

hypoglycaemia when combined with sulphonylureas

flatulence

$\mathrm{Hb}$ - and $\mathrm{Hk}$ reduction by approx. $4 \%$ occurrence or worsening of macular edema (not known)

central

Rosiglitazone

headaches

nervous

system

liver and impaired liver impaired liver

biliary function function, mainly function (rare)

caused by elevated

liver enzyme values

skeleton

higher fracture rate of distal upper or lower extremities in female patients of distal upper or lower extremities in female patients

*when glitazones are combined with insulin, oedemas occur in $15 \%$ cardiac insufficiency in $2.5 \%$.

(Technical information on Avandia ${ }^{\circledR}$ March 2008, Technical information on Actos ${ }^{\circledR}$, August 2007, EC IV; Pfützner et al., 2006, EC IV; Hanefeld et al., 2004, EC Ib; Umpierrez et al., 2006, EC Ib; Nagasaka et al., 2004, EC Ib; Rosenstock et al., 2005, EC Ib; Zhu et al., 2003, EC Ib; Kerenyi et al., 2004, EC Ib; Matthews et al., 2005, EC Ib; Bailey et al., 2005, EC Ib; Jung et al., 2005, EC Ib; Pavo et al., 2003, EC Ib; Schernthaner et al., 2004, EC Ib; Tan et al., 2005, EC Ib; Charbonnel et al., 2004, EC Ib; Tan et al., 2004a, EC Ib; Tan et al., 2004b, EC Ib; Natali et al., 2004, EC Ib; St. John-Sutton, 2002, EC Ib).; Deutsches Ärzteblatt 2006; Mitt. TAKEDA Pharma GmbH, March 2007; Mitt. GlaxoSmithKline GmbH acc. to data ADOPT study February, 2007; Schwartz 1998, EC Ib; Rosenstock 2002, EC Ib, Raskin 2001, EC Ib.

\subsection{Contraindications (Technical information on Avandia ${ }^{\circledR}$ March 2008, Technical information on Actos $^{\circledR}$, January 2007, EC IV, press release EMEA 24.01.08 - Doc.Ref.EMEA/42232/2008)}

Rosiglitazone and pioglitazone are contraindicated for patients with

- Liver function disorders

- Congestive heart failure or previous congestive heart failure (NYHA I-IV)

- Pregnant or nursing

- Hypersensitivity to any of the active agents

- Diabetic ketoacidosis or diabetic precoma

Rosiglitazone is contraindicated for patients with acute coronary syndrome such as angina pectoris, non-ST-elevation myocardial infarction and ST-elevation myocardial infarction. The use of rosiglitazone is not recommended for patients with ischaemic heart disease and/ or peripheral arterial occlusive disease.

\subsection{Glitazones: Advantages and disadvantages}

(Matthaei et al., 2000, EC IV; Parulkar et al., 2001, EC IV, Gastadelli et al., 2006, EC IIb).

\section{Advantages}

- pathophysiologically orientated therapy (lowering of visceral lipid accumulation, reduction of gluconeogenesis)

\section{Disadvantages}

- weight gain 


\section{Advantages}

no hypoglycaemia in monotherapy

- fewer hypoglycaemia in combination therapy with metformin than sulphonylureas in overweight patients (Hamann et. al., 2008, EC Ib)

- risk reduction of (secondary) cardiovascular endpoint in the ProActive study (pioglitazone)

- favourable influence on new cardiovascular surrogate parameters (adiponectin, hsCRP, MMP-9, PAI-1) [Haffner et al., 2002, EC Ib; Pfützner et al., 2006, EC Ib; Yang et al., 2002, EC Ib; Chu et al., 2003 EC IIb; Esposito et al., 2006, EC Ib; Marx et al., 2003, EC Ib; Kim et. al. 2006, EC Ib].

- other risk factors are influenced favourably (lipid parameters, blood pressure $\boldsymbol{\nabla}$ )

- improvement of microalbuminuria [Bakris et al., 2003; Pistrosch et al., 2005; both EC Ib].

\subsubsection{Combination therapy with non- $\beta$-cytotropic medications}

The next section describes the combination therapies of biguanides with $\alpha$-glucosidase inhibitors and biguanides with PPAR- $\gamma$ ligands (rosiglitazone and pioglitazone). The third, theoretically possible combination therapy ( $\alpha$-glucosidase inhibitors with PPAR- $\gamma$ ligands) is not approved; moreover, no data relating to this possible combination has yet been published.

\subsection{Biguanides and $\alpha$-glucosidase inhibitors}

\subsection{Indication}

For patients with type 2 diabetes who have not reached their HbA1c target value with either of the two substances in mono- therapy (Rosenstock et al., 1998, EC Ib; Chiasson et al., 1994, EC Ib) (recommendation grade A).

\subsection{Antihyperglycaemic efficacy}

The results of the acarbose arm of the UKPDS study showed that patients who received acarbose in addition to various prior therapies (including metformin) experienced an average HbA1c reduction of $0.5 \%$ (in the group of patients who took acarbose for a period of 3 years (39\% of the acarbose arm); in the full cohort of the acarbose arm, HbA1c was lowered by $0.2 \%$ ) (Holman et al., 1999, EC Ib) (recommendation grade B).

\subsubsection{Biguanides and PPAR-y ligands \\ 1.1.1.4.2.1 Indication}

Patients with type 2 diabetes who have not reached their HbA1c target value with metformin in monotherapy (Fonseca et al., 2000, EC Ib; Einhorn et al., 2000, EC Ib) (recommendation grade A).

\subsection{Antihyperglycaemic efficacy}

Table 2 lists the previously published studies on the effect of supplementary therapy with rosiglitazone or pioglitazone for type 2 diabetics who have been unable to achieve adequate control with prior metformin therapy.

\subsection{2 $\beta$-cytotropic oral antidiabetics: potassium channel blockers}

Sulphonylureas, repaglinide and nateglinide stimulate insulin secretion by blocking the ATP-sensitive potassium channels in the plasma membrane of $\beta$-cells. (Panten et al., 1996, EC IV). This $\beta$-cytotropic effect occurs in hyper-, normo- and hypoglycaemia depending on dosage. Direct effects of the sulphonylureas glibenclamide and glimepiride on non- $\beta$ cells have also been described, though their role in the clinical effect thereof is still unclear and disputed. In chemical terms, repaglinide and nateglinide are not sulphonylureas, but their molecular structures are closely related to sulphonylureas (Panten et al., 1996, EC IV). Repaglinide and nateglinide differ from the sulphonylureas that are available in Germany mainly in their short duration of action and rapid elimination. Taken directly before main meals, they are designed to serve the pathophysiologically defined objective, particularly of lowering rises in prandial blood glucose levels and reducing the incidence of postprandial hypoglycaemia.

\subsubsection{Sulphonylureas \\ 1.1.2.1.1 Indication}

For patients with diabetes mellitus type 2 in conjunction with non-pharmacological measures (education, nutrition therapy, increase in physical activity) for whom intolerance/

Table 2 Studies of the effect of supplementary therapy with rosiglitazone or pioglitazone after prior treatment with metformin.

\begin{tabular}{|c|c|c|c|c|c|c|}
\hline & Author & EC & $\mathbf{N}$ & initial HbA1c (\%) & $\Delta \mathrm{A} 1 \mathrm{c}(\%)$ & $\mathbf{P}$ \\
\hline Rosi + Metf(2g) vs. $\operatorname{Metf}(3 g)$ & Bailey 2005 & $\mathrm{lb}$ & 551 & 7.4 vs. 7.5 & 0.33 vs. 0.1 & $<0.001$ \\
\hline Rosi $4 \mathrm{mg} / 8 \mathrm{mg}+$ Metf vs. Metf & Fonseca 2000 & $\mathrm{lb}$ & 348 & $8.9 / 8.9$ vs. 8.6 & $0.56 / 0.78$ vs. +0.45 & $<0.001$ \\
\hline Rosi + Metf vs.Glimep + Metf & Derosa 2005a & $\mathrm{lb}$ & 95 & 8.0 vs. 7.9 & 0.6 vs. 0.7 & ns \\
\hline Rosi + Metf vs. Glibencl + Metf & Garber 2006 & $\mathrm{lb}$ & 318 & 8.4 vs. 8.5 & 1.1 vs. 1.5 & $<0.001$ \\
\hline Pio + Metf vs.Glicl+ Metf & Matthews 2005 & $\mathrm{lb}$ & 637 & 8.71 vs. 8.53 & 0.99 vs. 1.01 & ns \\
\hline Pio + Metf vs. Glibenclamide + Metf & Hanefeld 2006 & Ilb & 500 & 8.5 vs. 8.6 & 1.0 vs 0.6 & $<0.005$ \\
\hline Pio + Met vs. Glimepiride + Met & Umpierrez 2006 & $\mathrm{lb}$ & 203 & 8.31 vs. 8.4 & 1.23 vs. 1.3 & ns \\
\hline
\end{tabular}

Rosi $=$ Rosiglitazone, $\mathrm{Pio}=$ Pioglitazone, Metf= Metformin, Plac= Placebo, EC=Evidence class, N= Number of study participants, Therapy duration in weeks, $\mathrm{HbA1c}$ in \%, $\mathrm{p}=$ Significance level, $\mathrm{ns}=$ not significant $(\mathrm{p}>0.05)$ 
contraindication for metformin exists. The best documented is monotherapy with glibenclamide, particularly with reference to the results of the UKPDS (UKPDS 33, 1998, EC Ib) (recommendation grade A). However, there is no clear proof that therapy with any other of the sulphonylureas available in Germany would yield inferior results, although there are no endpoint studies on this question. Besides monotherapy, combination therapy with a $\alpha$-glucosidase inhibitor (Chiasson et al., 1994, EC Ib; Holman et al., 1999, EC Ib) (recommendation grade B) or a PPAR- $\gamma$ ligand (for patients with intolerance or contraindications for metformin) may also be considered (Kipnes et al., 2001; EC Ib) (recommendation grade $A$ ). The benefit-risk ratio of combination therapy of a sulphonylurea with metformin has not been established (see 1.1.2.3.1).

\subsection{Dosage}

According to the manufacturer's instructions, therapy with any of the sulphonylureas available in Germany should be started gradually at the following daily doses: $1.75-3.5 \mathrm{mg}$ glibenclamide, $12.5 \mathrm{mg}$ glibornuride, $40 \mathrm{mg}$ gliclazid, $1 \mathrm{mg}$ glimepiride, $15 \mathrm{mg}$ gliquidone, $0.5-1 \mathrm{~g}$ tolbutamide. The manufacturer also provides instructions for increasing the dosage incrementally if metabolism is not controlled satisfactorily (up to maximum daily doses of $10.5 \mathrm{mg}$ glibenclamide, $75 \mathrm{mg}$ glibornuride, $240 \mathrm{mg}$ gliclazide, $6 \mathrm{mg}$ glimepiride, $120 \mathrm{mg}$ gliquidone, or $2 \mathrm{~g}$ tolbutamide) and recommendations to take the entire daily dose at breakfast for low and medium dosages, and to take half each of high doses in the morning and evening. In the case of glimepiride, it is emphasised that the preparation only needs to be taken once a day (in the morning). But glibenclamide should also be taken only once a day (up to $7 \mathrm{mg}$ in the morning), because there are no clinical studies that confirm any advantage in taking the dosage of glibenclamide several times in the day, and because taking another $3.5 \mathrm{mg}$ of glibenclamide in the evening increases the risk of hypoglycaemia, possibly due to the higher level of $\beta$ cytotropic glibenclamide metabolites in the circulation (Jönsson et al., 1994, EC IV; Jönsson et al., 2001, EC IV; Wan Mohamad et al., 2000, EC III).

\subsection{Antihyperglycaemic efficacy}

Glibenclamide is the only sulphonylurea available in Germany for which long-term use has been demonstrated to result in a significant reduction in microvascular complications among patients with type 2 diabetes (UKPDS 33, 1998, EC Ib). On the other hand, macrovascular complications and diabetes-related death were only lowered with metformin, not with sulphonylureas. In intensified antihyperglycaemic therapy with glibenclamide, the HbA1c value (average over a 10 -year period) was $7.2 \%$, with conventional therapy and diet control this value was $7.9 \%$ (UKPDS 33, 1998, EC Ib). According to a comparative study for monotherapy with glibenclamide and glimepiride, the baseline HbA1c ( $8.5 \%$ ) was lowered by $0.83 \%$ and $085 \%$ respectively (Dills et Schneider, 1996, EC Ib). Compared with metformin, sulphonylureas have a very similar effect on HbA1c, fasting blood glucose and postprandial blood glucose (Hermann et al., 1994, EC Ia; Campbell und Howlett, 1995, EC Ia). However, the effect of glibenclamide diminishes more rapidly than that of metformin and rosiglitazone: after 5 years, the rate of secondary failures was $34 \%$ compared with $21 \%$ for metformin and $15 \%$ for rosiglitazone (Kahn et al., 2006, EC Ib). Accordingly, it would seem that sulphonylureas are the least effective in slowing the natural progression of the disease.

\subsection{Side effects}

In keeping with their $\beta$-cytotropic effect, all sulphonylureas can cause weight gain and hypoglycaemia. During treatment with glibenclamide (in addition to diet treatment) $1.4 \%$ of patients per year experienced severe hypoglycaemia (defined as the requirement of third party assistance), compared to $0.7 \%$ with diet treatment alone (UKPDS 33, 1998, EC Ib). It has not been confirmed that other sulphonylureas in comparable antidiabetic therapies would cause hypoglycaemia significantly less often than glibenclamide (Schneider, 1996, EC IV; Draeger et al., 1996, EC Ib). Only in one study were hypoglycaemia observed less often with glimepiride therapy than with glibenclamide therapy (Holstein et al., 2001, EC III). At the same time, it should be noted that the patient cohorts involved in this comparison were very different. In rare cases, sulphonylureas can cause gastrointestinal disorders (e.g., feeling of having overeaten, nausea), and very rarely haematopoietic dysfunctions and allergic reactions. The assumption that sulphonylureas increase the risk of cardiovascular incidents was not confirmed in controlled intervention studies with previously unaffected patients (Glibenclamide; UKPDS 33, 1998, EC Ib; Kahn et al., 2006, EC Ib); a retrospective analysis of patients who had suffered myocardial infarction also revealed no contributory effects by the sulphonylureas (Klamann et al., 2000, EC III; Dauchin et al., 2005, EC III). A number of other studies yielded indications of unfavourable effects by glibenclamide on the heart (e.g., on ischaemic preconditioning, changes in ECG (Klepzig et al., 1999, EC Ib, Övünç, 2000, EC III, Huizar et al., 2003, EC III, Lee und Chou, 2003, EC III) and on cardiac mortality (Garratt et al., 1999, EC III), partly among patients with previously compromised cardiac conditions, and when sulphonylureas were combined with metformin (Olsson et al., 2000, EC III; Fisman et al., 2001, EC III). However, the retrospective design of all of these studies makes it impossible to rule out the possibility that the groups treated with sulphonylurea and particularly sulphonylurea and metformin in combination included an unusually high proportion of patients with more advanced diabetes and greater cardiovascular risk.

\subsection{Contraindications}

Sulphonylureas are contraindicated in

- Type 1 diabetes

- Complete secondary failure of a therapy that includes sulphonylureas or analogues thereof, particularly in the case of compensation for metabolic acidosis, precoma or coma

- Pancreatectomy

- Impaired renal function (treatment with gliquidone possible under strict supervision)

- Severe liver function disorders

- Hypersensitivity to sulphonylureas and (because of crossallergies) sulphonamide antimicrobial agents, sulphonamide diuretics and probenecid

- Relatively major surgical procedures, accidents and infections that may possibly entail post aggression syndrome

- Planned or current pregnancy and while nursing

Tolbutamide and gliquidone are also contraindicated in acute porphyria.

Gliclazide is also contraindicated if the patient is using miconazol. 


\subsection{Advantages and disadvantages of sulphonylureas}

\begin{abstract}
Advantages
- positive endpoint data for microvascular complications with glibenclamide - extensive experience in long-term use
\end{abstract}

\author{
Disadvantages \\ - risk of hypoglycaemia \\ - weight gain \\ - secondary failure occurs \\ faster than that of metformin \\ or rosiglitazone
}

\subsubsection{Sulphonylurea analogues (repaglinide, nateglinide) \\ 1.1.2.2.1 Indication}

Monotherapy with repaglinide may be considered for patients with type 2 diabetes whose metabolism is not satisfactorily controlled despite nutrition and exercise therapy (Moses et al., 2001, EC Ib; Marbury et al., 1999, EC Ib; Jovanovic et al. 2000, EC Ib; Goldberg et al., 1998, EC Ib) (recommendation grade A]. Repaglinide is also approved for use in combination therapy with metformin. However, the benefit-risk ratio associated with long-term use of this combination therapy has not been defined precisely because there is little documented information. The same is true for nateglinide, which is only approved for combination therapy with metformin, and then only if the patient's metabolism cannot be controlled satisfactorily with the maximum tolerable dose of metformin (Moses et al., 1999, EC Ib; Horton et al., 2000, EC Ib) (recommendation grade B).

\subsection{Dosage}

Maximum concentration of repalinide and nateglinide in plasma is reached within 1 and $1.5 \mathrm{~h}$ respectively after administration, and then falls with a half-life period of 1 and $1.4 \mathrm{~h}$ respectively (Lebovitz, 1999, EC IV). This profile results in a rapid rise in the insulin level in plasma, which has almost returned to original values after $\sim 4$ and $\sim 2 \mathrm{~h}$ respectively (Dunning, 1997, EC IV). In this way particularly prandial rises in blood sugar are attenuated. Therefore, repaglinide and nateglinide should be taken directly before main meals. Treatment with repaglinide should be started at a daily dose of $0.5 \mathrm{mg}$ with main meals, treatment with nateglinide should be started at a dose of $60 \mathrm{mg}$ three times a day. If metabolism is not controlled satisfactorily, the daily dosage of repaglinide can be increased incrementally to no more than $16 \mathrm{mg}$, whereby each individual dose must not exceed $4 \mathrm{mg}$. If metabolism is not controlled satisfactorily, the daily dosage of nateglinide can be increased to a maximum of $3 \times 180 \mathrm{mg}$.

\subsection{Antihyperglycaemic efficacy}

Studies of the effect of repaglinide on HbA1c in therapy-naive type 2 diabetics show an average reduction in HbA1c value of 1.7\% (HbA1c 9.1\% >> 7.4\%) (Moses et al., 2001, EC Ib; Marbury et al., 1999, EC Ib; Jovanovic et al., 2000, EC Ib; Goldberg et al., 1998, EC Ib) (Recommendation grade A). One comparative study of monotherapies with repaglinide and glibenclamide reported reductions of $1.8 \%$ and $1.6 \%$ respectively with respect to the HbA1c baseline values (9.4\% and 9.6\%) after 3 months in type 2 diabetic patients who had never before received antidiabetic medication (Marbury et al., 1999, EC Ib). As expected, HbA1c values were lowered less by repaglinide when the baseline HbA1c values were lower, but in this study too, these results were not significantly different from the glibenclamide effect (Landgraf, 2000, EC IV). Regarding monotherapy with nateglinide $(3 \times 120 \mathrm{mg} / \mathrm{die}), \mathrm{HbA} 1 \mathrm{c}$ reductions of $0.6-1 \%$ compared with a placebo were reported (Dunn und Faulds, 2000, EC IV). A direct comparison of repaglinide and nateglinide concluded that repaglinide lowered fasting blood sugar and HbA1c significantly more, but also caused greater weight gain (Rosenstock et al., 2004, EC I b). However, it is possible that increasing the dosage of nateglinide above $120 \mathrm{mg} / \mathrm{meal}$ might also have a more marked effect. The question of whether repaglinide and nateglinide have an additional therapeutic effect besides the blood glucose reduction included in the HbA1c reduction by the preferred lowering of prandial blood glucose must be investigated in studies with endpoints.

\subsection{Side effects}

In keeping with their $\beta$-cytotropic effect, repaglinide and nateglinide can cause weight gain and hypoglycaemia. During treatment with repaglinide, weight gain was observed in one study (Marbury et al., 1999, EC Ib) and not in another (Moses et al., 2001, EC Ib). Previously published investigations do not prove unequivocally that the risk of hypoglycaemia is significantly lower in long-term treatment with repaglinide and nateglinide than in treatment with sulphonylureas (Landgraf et al., 1999, EC Ib; Marbury et al., 1999, EC Ib; Hanefeld et al., 2000b, EC Ib). It is not known whether sulphonylurea analogues increase the risk of cardiovascular incidents. Unlike sulphonylureas and D-phenylalanine derivatives (to which nateglinide belongs), in preclinical studies benzoic acid derivatives (to which repaglinide belongs) displayed no selectivity for SUR1 the sulphonylurea receptor subtype of the $\beta$-cell - as opposed to SUR2A and SUR2B - the cardiovascular sulphonylurea receptor subtypes. (Meyer et al., 1999, EC IV; Dabrowski et al., 2001, EC IV). Repaglinide is deactivated by CYP2C8, so that administering a second CYP2C8 substrate (e.g., gemfibrozil) at the same time can prolong (elimination half-life period prolonged to $3.7 \mathrm{~h}$ ) and reinforce the effect. In rare cases, repaglinide can cause gastrointestinal disorders (e.g., nausea, feeling of having overeaten) and allergic reactions. Also in rare cases, nateglinide can cause elevated liver enzyme values and trigger allergic reactions.

\subsection{Contraindications}

Repaglinide is contraindicated

- In combination with gemfibrozil or any other active agent that is metabolised by CYP2C8

- Repaglinide and nateglinide are contraindicated in

- Type 1 diabetes

- Complete secondary failure of a therapy that includes sulphonylureas or analogues thereof, particularly in the case of compensation for metabolic acidosis, precoma or coma

- Pancreatectomy

- Severe liver disorders

- Hypersensitivity to repaglinide or nateglinide

- Relatively major surgical procedures, accidents and infections that may possibly entail post aggression syndrome

- Planned or current pregnancy and during nursing

\subsection{Advantages and disadvantages of sulphonylurea analogues}

\section{Advantages Disadvantages}

- pronounced effect - pronounced effect on postprandial on postprandial blood glucoseRisk of hypoglycaemia blood glucose - weight gain

- lack of endpoint data

- no extensive experience in longterm application

- safety in combination with metformin or glitazone not established 


\subsubsection{Combination therapy with non- $\beta$-cytotropic oral antidiabetics}

1.1.2.3.1 $\beta$-cytotropic substances and metformin

In patients with type 2 diabetes whose metabolism was not controlled satisfactorily with sulphonylurea in monotherapy, metabolic control was improved by a supplementary therapy with metformin (UKPDS 34, 1998, EC Ib). However, the combination with glibenclamide or chlorpropamide led to a rise in diabetesrelated deaths (compared to a sulphonylurea monotherapy; UKPDS 34, 1998, EC Ib; Nathan, 1998, EC IV). This unfavourable result was explained by the authors by the subsequent change to the study medication. A number of retrospective studies, some with very large patient cohorts, gave no indication that the combination was associated with greater cardiovascular risk (Gulliford and Latinovic, 2004, EC III; Danchin et al., 2005, EC III). However, there are also other studies that report negative endpoint data of the combination therapy (Olsson et al., 2000, EC III; Fisman et al., 2001, EC III; Johnson et al., 2001, EC III; Evans et al., 2006, EC III; Simpson et al., 2006, EC III). Given their retrospective design, it is not possible to confirm for any of these studies that they did not include an unusually high proportion of higher risk patients in the group treated with this combination. Even so, the benefit-risk ratio of the combination therapy of a sulphonylurea with metformin is still not established with regard to cardiovascular endpoints. Therapy with a metformin-repaglinide or metformin-nateglinide combination led to a greater HbA1c reduction than a metformin monotherapy (Moses et al., 1999, EC Ib; Horton et al., 2000, EC Ib). Increased risk of mortality cannot be ruled out even for therapy with the metformin plus sulphonylurea analogue combination, because no long-term studies have been published on this subject and the $\beta$-cytotropic action of sulphonylurea analogues is based on the same mechanism of action as that of sulphonylureas themselves. Long-term studies regarding the safety of metformin-repaglinide combination therapy are also needed because repaglinide does not distinguish between the various sulphonylurea receptor subtypes (see 1.1.2.2.4).

\subsubsection{2 $\beta$-cytotropic substances and $\alpha$-glucosidase inhibitors}

In patients with type 2 diabetes whose metabolism has not been controlled satisfactorily with sulphonylurea in monotherapy, additional therapy with an $\alpha$-glucosidase inhibitor may be considered. In an additional therapy with acarbose or miglitol, HbA1c has been lowered by a further 0.5-1\% (Holman et al., 1999, EC Ib; Willms und Ruge, 1999, EC Ib; Johnston et al., 1994, EC Ib) (Recommendation grade B). As yet, there is no endpoint data available for the combination therapy of a $\beta$-cytotropic substance with an $\alpha$-glucosidase inhibitor.

\subsubsection{3 $\beta$-cytotropic substances and PPAR-y ligands}

For patients with type 2 diabetes not tolerating metformin or with contraindications and who are unable to reach their HbA1c goal with a sulphonylurea or glinide monotherapy, a supplementary therapy with a PPAR- $\gamma$ ligand may be considered (see Table 3).

Dailey et al. compared a triple therapy consisting of metformin/ glibenclamide/rosiglitazone with a combination therapy of metformin/glibenclamide. After 24 weeks, a significantly greater reduction in fasting blood sugar and the HbA1c value was observed for the triple therapy than for the double therapy (Dailey et al., 2004, EC Ib).

Rosenstock et al. compared the effect of $10 \mathrm{U} /$ day insulinglargine with $4 \mathrm{mg} /$ day rosiglitazone in patients whose HbA1c was between 7.5 and $11 \%$ on a combination therapy of metformin and sulphonylureas. After 24 weeks, there was no significant difference between the effects on the HbA1c value in the two groups. Fasting blood sugar was lowered significantly more with the insulin-glargine combination (Rosenstock et al., 2006, EC Ib).

\subsubsection{DPP- 4 inhibitors}

DPP-4 inhibitors are a new class of oral antidiabetics, which inhibit the enzyme dipeptidyl-peptidase IV (DPP-4). DPP-4 is a key enzyme that determines the rate of degradation of the incretin hormones glucagon-like peptide-1 (GLP-1) and glucosedependent insulinotropic polypeptide (GIP) as well as other regulatory peptides (Mentlein R 1999, EC IV). Inhibiting DPP-4 has the effect of increasing the endogenous concentrations of these peptides and thus also strengthening their effect, particularly that of endogenous GLP-1. GLP-1 stimulates insulin secretion based on the presence of glucose and only under conditions of hyperglycaemia, and inhibits glucagon secretion by the pancreatic alpha cell. These actions are primarily responsible for the antihyperglycaemic properties of DPP-4 inhibitors, and they disappear when blood sugar values fall below the normal range. Accordingly, DPP-4 inhibitors do not present any intrinsic risk of hypoglycaemia. They are also body weight neztral. In animal models, DPP-4 inhibitors manifest favourable influences on islet function and morphology but whether these influences are also reflected in humans has yet to be determined (Gallwitz B 2007, EC IV).

The DPP-4 inhibitors described in the literature, sitagliptin, vildagliptin and others, are chemically different and do not form a unified substance class. Consequently, the individual substances

Table 3 Glitazone + Sulphonylurea/Glinide combination therapy.

\begin{tabular}{|c|c|c|c|c|c|c|}
\hline & Author & & $\mathbf{N}$ & Initial HbA1c [\%] & $\Delta \mathrm{A} 1 \mathrm{c}[\%]$ & $\mathbf{P}$ \\
\hline Rosi + Glip vs.Plac+ Glip & Rosenstock 2005 & $\mathrm{EC} \mathrm{Ib}$ & 227 & 7.72 vs. 7.65 & $0.65 /-0.13$ & $<0.0001$ \\
\hline Rosi8/4mg + SU vs. Plac + SU & Zhu 2003 & $\mathrm{EC} \mathrm{Ib}$ & 530 & $9.9 / 9.8$ vs. 9.8 & $1.9 / 1.4$ vs. 0.4 & $<0.001$ \\
\hline Rosi + Glibencl.vs.Glibencl. & Kerenyi 2004 & $\mathrm{EC} \mathrm{Ib}$ & 340 & 7.9 vs. 8.1 & 0.91 vs. 0.14 & $=0.053$ \\
\hline Glim + Plac vs.Glim + rosi 4 mg $/ 8 \mathrm{mg}$ & Pfützner 2006 & $\mathrm{EC} \mathrm{Ib}$ & 102 & $7.7 / 8.3 / 8.0$ & 0 vs. $1.1 / 1.3$ & $<0.001$ \\
\hline Rosi + Nate vs. Rosi & Fonseca 2003 & $\mathrm{EC} \mathrm{Ib}$ & 402 & 8.4 vs. 8.3 & 0.8 & $<0.0001$ \\
\hline Rosi + Repa vs.Rosi vs.Repa & Raskin 2004 & $\mathrm{EC} \mathrm{Ib}$ & 252 & $9.1 / 9.0 / 9.3$ & $1.43 / 0.56 / 0.17$ & $<0.001$ \\
\hline Rosi + Glim vs. Met + Glim & Jung 2005 & EC Ib & 30 & 9.3 vs. 9.0 & 1.5 vs. 1 & nd \\
\hline Pio + SU vs. Met + SU & Nagasaka 2004 & $\mathrm{EC} \mathrm{Ib}$ & 78 & 8.3 vs. 8.3 & $1.2 / 1.3$ & ns \\
\hline SU + Pio vs. SU + Met & Hanefeld 2004 & EC Ib & 320 & 8.82 vs. 8.80 & 1.21 vs. 1.36 & ns \\
\hline
\end{tabular}

Rosi = Rosiglitazone, Glip=Glipizide, SU =Sulphonylurea, Glibencl = Glibenclamide, Glim=Glimepiride, Nate= Nateglinide, Repa = Repaglinide, Met = Metformin, EC = Evidence class, $\mathrm{N}=$ Number of patients, $\Delta \mathrm{A} 1 \mathrm{c}(\%)=$ Percentage of negative change in HbA1c value during the study, $\mathrm{p}=$ Signifikance level, $\mathrm{ns}=$ not significant $(\mathrm{p}>0.05)$, nd $=$ no data 
cannot be compared directly with each other in terms of pharmacodynamics and pharmacokinetics (Barnett A 2006, EC IV). At the moment, only sitagliptin and vildagliptin have been approved for market release in Germany. Therefore, only these two substances will be described in the following section, particularly with reference to indications, dosage, and contraindications.

\subsubsection{Indication}

Sitagliptin and vildagliptin have been approved for oral combination therapy. For patients with type 2 diabetes whose metabolism is unsatisfactorily controlled despite a change in lifestyle and oral medication with metformin, additional therapy with these DPP-4 inhibitors may be considered, particularly if hypoglycaemia prevention (e.g. professional activity factors, concomitant diseases, patient safety) or control of bodyweight is also a primary therapeutic objective. There are also fixed combination preparations for sitagliptin and vildagliptin with met- formin. A therapy with sitagliptin or vildagliptin may also be an option for patients with type 2 diabetes who cannot reach their metabolic therapy objectives on monotherapy with a PPAR- $\gamma$ agonist, particularly if they are intolerant of metformin and/or it is contraindicated for them.

Approval also exists for the combination of DPP-4 inhibitors with a sulphonylurea, which is also an option if a combination of the sulphonylurea with metformin is not possible for the reasons given above or PPAR- $\gamma$ agonists or alpha-glucosidase inhibitors are not suitable. Both DPP-4 inhibitors can also be administered in addition to an existing combination of metformin with sulphonylurea if the therapeutic objectives are not reached with this double combination alone.

The benefit-risk ratio of these forms of combination therapy with DPP-4 inhibitors has not yet been defined because of insufficient experience with their long-term use.

Table 4 Antihyperglycaemic efficacy of DPP-4 inhibitors compared to other therapy forms with reference to HbA1c as Outcome Parameter.

\begin{tabular}{|c|c|c|c|c|c|c|}
\hline \multirow[t]{2}{*}{ Studies } & \multirow{2}{*}{$\begin{array}{l}\text { No. of } \\
\text { studies } \\
\text { [n] }\end{array}$} & \multirow{2}{*}{$\begin{array}{l}\text { Probability of event } \\
\text { Achievement of } \\
\text { HbA1c objec- } \\
\text { tive }<7 \% \text { [ } 95 \% \mathrm{Cl} \\
\text { DPP-4 vs. control] }\end{array}$} & \multicolumn{2}{|c|}{ DPP-4 inhibitors } & \multicolumn{2}{|c|}{ Control } \\
\hline & & & $\begin{array}{l}\text { Average [\% ( } 95 \% \\
\mathrm{CI}) \text { ] of achievement } \\
\text { of objective] }\end{array}$ & $\begin{array}{l}\text { No. of } \\
\text { patients [n] }\end{array}$ & $\begin{array}{l}\text { Control Average [\% } \\
(95 \% \mathrm{CI}) \text { ] of achieve- } \\
\text { ment of objective] }\end{array}$ & $\begin{array}{l}\text { No. of } \\
\text { patients [n] }\end{array}$ \\
\hline $\begin{array}{l}\text { all DPP-4 inhibitors vs. placebo } \\
\text { [Nauck MA et al. 2007a] } \\
\text { [Raz I et al. 2006] } \\
\text { [Aschner P et al. 2006] } \\
\text { [Charbonnel B et al. 2006] } \\
\text { [Rosenstock J et al. 2006] } \\
\text { [Nonaka K et al. 2006] } \\
\text { [Ahrén B et al. 2004] } \\
\text { [Ristic S et al. 2005] } \\
\text { [Pi-Sunyer FX et al. 2007] } \\
\text { [Dejager S et al. 2007] } \\
\text { [all listed studies EC Ib, recom- } \\
\text { mendation grade A] }\end{array}$ & 9 & $2.47(2.14-2.84)$ & $43(39-47)$ & 1442 & $17(15-20)$ & 1146 \\
\hline $\begin{array}{l}\text { sitagliptin vs. placebo } \\
+/[\text { Nauck MA et al. 2007a] } \\
\text { [Raz I et al. 2006] } \\
\text { [Aschner P et al. 2006] } \\
\text { [Charbonnel B et al. 2006] } \\
\text { [Rosenstock J et al. 2006] } \\
\text { [Nonaka K et al. 2006] } \\
\text { [all listed studies EC Ib, recom- } \\
\text { mendation grade A] }\end{array}$ & 5 & $2.43(2.03-2.92)$ & $44(39-51)$ & 1113 & $18(16-21)$ & 821 \\
\hline $\begin{array}{l}\text { vildagliptin vs. placebo } \\
\text { [Ahrén B et al. 2004] } \\
\text { [Ristic S et al. 2005] } \\
\text { [Pi-Sunyer FX et al. 2007] } \\
\text { [Dejager S et al. 2007] } \\
\text { [all listed studies EC Ib, recom- } \\
\text { mendation grade A] }\end{array}$ & 4 & $2.40(1.78-3.24)$ & $38(31-45)$ & 317 & $15(11-20)$ & 325 \\
\hline $\begin{array}{l}\text { all DPP-4 inhibitors vs. glipizide, } \\
\text { metformin, pioglitazone or } \\
\text { rosiglitazone } \\
\text { [Nauck MA et al. 2007b] } \\
\text { [Rosenstock J et al. 2007a] } \\
\text { [Rosenstock J et al. 2007b] } \\
\text { Schweizer A et al. 2007] } \\
\text { [all listed studies EC Ib, recom- } \\
\text { mendation grade A] }\end{array}$ & 3 & $0.93(0.77-1.11)$ & $43(32-55)$ & 1237 & $47(42-52)$ & 965 \\
\hline
\end{tabular}




\subsubsection{Dosage}

The dosage for sitagliptin is $100 \mathrm{mg}$ once a day. Its half-life period $(\mathrm{t} 1 / 2)$ is $11.8-14.4 \mathrm{~h}$, a steady state is achieved after 3 days. It is eliminated mainly renally, $70 \%$ of the unmetabolised sitagliptin is eliminated via the kidneys, $16 \%$ of the applied dose of sitagliptin is metabolised by CYP 3A4 and CYP 2C8. With dosages $50 \mathrm{mg} /$ day, the rate of inhibition of DPP- 4 is $80 \%$ for 24 h (Bergman AJ et al. 2006, EC Ib, recommendation grade A).

Vildagliptin is administered in a dosage of $2 \times 50 \mathrm{mg}$ daily. Its half-life period $\left(t^{1 / 2}\right)$ is about $3 \mathrm{~h}$. It is eliminated by hydrolysis in the liver, the intestine, the kidneys and other organs, approx. $20-25 \%$ is eliminated unmetabolised via the kidneys. The primary metabolite is pharmacologically inert. Maximum inhibition of DPP-4 is reached about $0.5-1 \mathrm{~h}$ after a single dose of vildagliptin, and inhibition remains at this level for at least $3 \mathrm{~h}$, falling to a level of $67 \%$ after $24 \mathrm{~h} .1 .6 \%$ of the applied dose of vildagliptin is metabolised by CYP 3A4. (Ristic S \& Bates PC 2006, EC Ia, recommendation grade A).

Interaction between both DPP-4 inhibitors and other drugs is low (Bergman et al., 2006, EC Ib, recommendation grade A; Ristic \& Bates, 2006, EC Ia, recommendation grade A). Both can be taken independently of food ingestion. Patients with mild renal insufficiency (creatinine clearance $50 \mathrm{ml} / \mathrm{min}$ ) do not need to adjust the dosage, DPP-4 inhibitors are not recommended for patients with moderate or severe renal insufficiency because lit- tle information is available yet on this issue. If they are used, the dose should then be reduced based on pharmacokinetic data, i.e., $50 \mathrm{mg}$ /day sitagliptin for a GFR $<50 \mathrm{ml} / \mathrm{min}$ and only $25 \mathrm{mg} /$ die for a GFR $<30 \mathrm{ml} / \mathrm{min}$. Patients with mildly or moderately impaired liver function (Child-Pugh Score 9) also do not need to adjust the dosage of sitagliptin, but vildagliptin should not be given to any patients with impaired liver function or transaminase levels more than three times above the normal range.

\subsubsection{Antihyperglycaemic efficacy}

The antihyperglycaemic efficacy of DPP-4 inhibitors was investigated in monotherapy and in various combinations with other oral antidiabetics. In a systematic meta-analysis of the clinical studies that were available at the time, administration of DPP-4 inhibitors lowered HbA1c by $-0.74 \%$ compared to placebo $(95 \%$ confidence interval $[\mathrm{CI}]-0.85 \%$ to $-0.62 \%)$. Overall, the DPP-4 inhibitors were not inferior to other antihyperglycaemic substances Amori et al. 2007, EC Ia, recommendation grade A). Table 4 shows the results of the meta-analysis with reference to the HbA1c outcomes, Table 5 with reference to fasting glucose. The meta-analysis by Amori (Amori et al. 2007, EC Ia, recommendation grade A) does not reveal a clear superiority of any one DPP-4 inhibitor over other DPP-4 inhibitors, since the diverse patient populations mean that the studies included in the metaanalysis cannot be compared with each other directly, and this is

Table 5 Antihyperglycaemic efficacy of DPP-4 inhibitors compared to other therapies with reference to fasting glucose as outcome parameter.

\begin{tabular}{|c|c|c|c|}
\hline Studies & $\begin{array}{l}\text { No. of } \\
\text { studies [n] }\end{array}$ & $\begin{array}{l}\text { Reduction of fasting glucose [mg/dl] Weighted average } \\
\text { difference from initial value [ } 95 \% \mathrm{CI} \text { DPP-4 vs. control] }\end{array}$ & $\begin{array}{l}I^{2} \text { Heterogeneity } \\
\text { [\%] }\end{array}$ \\
\hline $\begin{array}{l}\text { all DPP-4 inhibitors vs. placebo } \\
\text { [Scott R et al. 2007] } \\
\text { [Raz I et al. 2006] } \\
\text { [Aschner P et al. 2006] } \\
\text { [Charbonnel B et al. 2006] } \\
\text { [Rosenstock J et al. 2006] } \\
\text { [Nonaka K et al. 2006] } \\
\text { [Pi-Sunyer FX et al. 2007] } \\
\text { [Garber A] et al. 2007] } \\
\text { [Bosi E et al. 2007] } \\
\text { [Fonseca V et al. 2007] } \\
\text { [all listed studies EC Ib, recommendation grade A] }\end{array}$ & 15 & $-18(-22$ to -14$)$ & 63 \\
\hline $\begin{array}{l}\text { Sitagliptin vs. placebo } \\
\text { [Scott R et al. 2007] } \\
\text { [Raz I et al. 2006] } \\
\text { [Aschner P et al. 2006] } \\
\text { [Charbonnel B et al. 2006] } \\
\text { [Rosenstock J et al. 2006] } \\
\text { [Nonaka K et al. 2006] } \\
\text { [all listed studies EC Ib, recommendation grade A] }\end{array}$ & 7 & $-22(-26$ to -18$)$ & 50 \\
\hline $\begin{array}{l}\text { Vildagliptin vs. placebo } \\
\text { [Ahrén B et al. 2004] } \\
\text { [Ristic S et al. 2005] } \\
\text { [Pratley RE et al. 2006] } \\
\text { [Pi-Sunyer FX et al. 2007] } \\
\text { [Garber A] et al. 2007] } \\
\text { [Bosi E et al. 2007] } \\
\text { [Fonseca V et al. 2007] } \\
\text { [all listed studies EC Ib, recommendation grade A] }\end{array}$ & 8 & $-12(-16$ to -7$)$ & 3 \\
\hline $\begin{array}{l}\text { all DPP-4 inhibitors vs. glipizide, metformin, piogli- } \\
\text { tazone or rosiglitazone } \\
\text { [Nauck MA et al. 2007b] } \\
\text { [Rosenstock J et al. 2007a] } \\
\text { [Rosenstock J et al. 2007b] } \\
\text { [Schweizer A et al. 2007] } \\
\text { [all listed studies EC Ib, recommendation grade A] }\end{array}$ & 4 & $11(-1$ to 123$)$ & 91 \\
\hline
\end{tabular}


also reflected in the differing confidence intervals and heterogeneities.

Besides the studies listed in Tables $\mathbf{4}$ and $\mathbf{5}$ and in the meta-analysis (Amori et al. 2007, EC Ia, recommendation grade A), additional clinical data was collected in randomised controlled studies for sitagliptin (Hermansen et al., EC Ib, recommendation grade A; Nonaka et al., 2008, EC Ib, recommendation grade A; Raz et al., 2008, EC Ib, recommendation grade A) and vildagliptin (Bolli et al., 2008, EC Ib, recommendation grade A, Fonseca et al., EC Ib, recommendation grade A, Pan et al., EC Ib, 2008, ) to confirm and supplement the data for monotherapy or combination therapy shown in the tables.

\subsubsection{Effect on body weight}

In a systematic meta-analysis of the clinical studies that existed at the time, a total of 13 studies reporting on weight evolution were identified for evaluation. These studies revealed only a slight weight increase during treatment with DPP-4 inhibitors compared to placebo (average difference $0.5 \mathrm{~kg}$; $95 \% \mathrm{CI} 0.3-$ $0.7 \mathrm{~kg}$ ) (Amori et al. 2007, EC Ia, recommendation grade A). In non-inferiority trials, sitagliptin had a favourable effect on body weight compared with glipizide $(-2.5 \mathrm{~kg}$ for sitagliptin vs. $1.0 \mathrm{~kg}$ for glipizide) (Nauck et al, 2007b, EC Ib, recommendation grade A). Vildagliptin had a similarly favourable effect on bodyweight compared with thiazolidinediones (average difference $-1.7 \mathrm{~kg}$; $95 \% \mathrm{CI}-2.2$ to $-1.2 \mathrm{~kg}$ ) (Rosenstock et al., 2007a and 2007b, both EC Ib, recommendation grade A), but not compared with metformin (2.2 kg more weight loss with metformin) (Schweizer et al., 2007, EC Ib, recommendation grade A).

\subsubsection{Hypoglycaemia}

Because of their mechanism of action, DPP-4 inhibitors do not pose an intrinsic risk of hypoglycaemia. In a meta-analysis of 29 clinical studies, severe hypoglycaemia (defined as hypoglycaemia requiring external assistance) were reported for a total of just 2 patients receiving treatment with DPP-4 inhibitors (Amori et al., 2007, EC Ia, recommendation grade A). There were no differences in the incidences of self-reported, mild hypoglycaemia when DPP-4 inhibitors were compared with other forms of therapy (placebo, all other forms of oral antihyperglycaemic therapy insulin therapy) (1.6\% for DPP-4 inhibitors vs $1.4 \%$ for other therapies; risk ratio $1.0 ; 95 \% \mathrm{Cl} 0.5-1.9)$. The risk of hypoglycaemia is elevated when DPP-4 inhibitors are used in combination with sulphonylureas, and this is attributable to the effect of the sulphonylurea. In this case, it may be necessary to reduce the sulphonylurea dosage, and instruct patients in how to recognise and treat hypoglycaemia (Amori et al., 2007, EC Ia, Recommendation grade A). In a study of the combination therapy of vildagliptin with insulin for patients who received vildagliptin additionally because their metabolism was inadequately controlled with insulin alone, the incidence $(p<0.001)$ and severity $(p<0.05)$ of hypoglycaemia in the vildagliptin group was significantly lower than in the placebo group (Fonseca et al., EC Ib, Recommendation grade $\mathrm{A}$ ).

\subsubsection{Side effects}

Overall, the DPP-4 inhibitors are well tolerated, low rates of side effects were reported in the clinical studies. In a comparison with placebo, gastrointestinal side effects (nausea, vomiting, diarrhoea, abdominal pain) were not observed any more frequently than for placebo. In a summary evaluation of all studies that could be evaluated, the therapy with DPP-4 inhibitors presented a slightly greater incidence of nasopharyngitis (6.4\% for DPP-4 inhibitors vs. $6.1 \%$ for other therapy forms; risk ratio 1.2 ; $95 \%$ CI 1.0-1.4), which was somewhat more pronounced with sitagliptin (Amori et al., 2007, EC Ia, recommendation grade A). The incidence of urinary tract infections was also slightly elevated (3.2\% for DPP-4 inhibitors vs. $2.4 \%$ for other therapy forms; risk ratio $1.5 ; 95 \% \mathrm{CI} 1.0-2.2$ ), and this occurred equally often with both DPP-4 inhibitors. Headaches were also reported more frequently by patients taking the DPP-4 inhibitors, and particularly by patients using vildagliptin ( $5.1 \%$ for DPP- 4 inhibitors vs. $3.9 \%$ for other therapy forms; risk ratio $1.4 ; 95 \% \mathrm{CI} 1.1-1.7$ ) (Amori et al., 2007, EC Ia, recommendation grade A). There is not yet sufficient data available to allow any statements to be made regarding long-term tolerability and safety.

When vildagliptin was taken in single doses greater than $50 \mathrm{mg}$ twice a day and more, very rare cases (incidence no more than $0.3 \%$ ) of impaired liver function were observed, the symptoms of which were mostly subclinical. In these cases, liver values returned to normal when administration was discontinued, and there were no after-effects. The elevated transaminase levels were not progressive and were not associated with cholestasis or jaundice. Transaminase levels should be determined before beginning treatment with vildagliptin (as it should before beginning treatment with glitazones or statins as well) and then every three months for the first year of the treatment.

\subsubsection{Contraindications}

Sitagliptin and vildagliptin are contraindicated for patients with type 1 diabetes, patients younger than 18 years, and in pregnancy. Moreover, these DPP-4 inhibitors should not be administered to patients with moderate or severe renal insufficiency (creatinine clearance $<50 \mathrm{ml} / \mathrm{min}$ ).

\subsubsection{Summary: Advantages and disadvantages of DPP-4 inhibitors}

DPP-4 inhibitors are drugs that function as "incretin enhancers" to inhibit the degeneration of endogenous incretin hormones (GLP-1, GIP). In hyperglycaemic conditions, insulin secretion is stimulated depending on the presence of glucose, and at the same time the excessive glucagon secretion that takes place in type 2 diabetes is inhibited. Because their mechanism of action is pharmacologically different from that of other compounds, DPP-4 inhibitors can be used in combination with such medications, and in this case they have an additive antiglycaemic effect. The combination with metformin is especially favourable, particularly with regard to weight control and the risk of hypoglycaemia, which is comparable with placebo. There are currently no endpoint studies available for DPP-4 inhibitors. Severe side effects are rare, but there is currently no information regarding long-term effects. DPP-4 inhibitors are agents that can be used as an addition to therapy with metformin, thiazolidinediones or sulphonylureas, if the therapy objective could be reached with these, and if it is important to avoid weight gain or hypoglycaemia. 


\section{Advantages}

- theoretically, can be used as addition to

\section{Disadvantages}

all therapy principles, with additive effect

(but currently only approved for use in combination with metformin, thiazolidinediones and sulphonylureas)

- weight-neutral

- risk of hypoglycaemia in combination

with sulphonylureas

- favourable side effects profile

- in preclinical studies: positive effects on

all beta-cell functions and parameters

\subsection{Injectable therapies \\ 1.2.1 Incretin mimetics (exenatide) \\ 1.2.1.1 Indication}

Incretin mimetics are peptides that are capable of activating the receptor for Glucagon-Like-Peptide-1. The only incretin mimetic that has been approved so far is exenatide. It is indicated in combination with metformin and/or sulphonylurea preparations for treating diabetes mellitus type 2 patients whose blood glucose has not been controlled satisfactorily with the maximum tolerable dose of these oral therapies. In general, the effect of lowering blood glucose in monotherapy has also been documented (Poon et al., 2005, EC Ib; Nelson et al., 2007, EC Ib). It has also been shown to lower blood glucose in patients who have been treated previously with thiazolidindiones ( \pm metformin) (Zinman et al., 2007, EC Ib). A limited amount of experience has been gathered regarding the use of exenatide instead of insulin (Davis et al., 2007, EC III) or in combination with insulin (Viswanathan et al., 2007, EC IIb) for patients who have previously received insulin for type 2 diabetes. No approval has been granted for these additional indications. Exenatide has been investigated in randomised studies lasting up to 52 weeks with respect to glucose control (HbA1c), body weight, blood pressure, as well as safety and tolerability. There have been no studies regarding its long-term safety or hard clinical endpoints. Exenatide is a therapy option for patients who are unable to control their metabolism adequately with the maximum tolerable dosage of metformin and/or sulphonylureas and who would otherwise have to begin a regimen of insulin therapy. At the moment, the benefit-risk ratio compared with insulin therapy can only be evaluated on the basis of surrogate parameters and so remains undetermined.

\subsubsection{Dosages}

Exenatide is available as a pre-filled pen device with a delivery volume of $5 \mu \mathrm{g}$ or $10 \mu \mathrm{g}$ per dose. According to the manufactur- er's information, and in keeping with relevant study results (Finman et al., 2004, EC Ib) treatment should initially be administered subcutaneously at a level of $5 \mu \mathrm{g}$ per dose, twice daily, once before breakfast and once before the evening meal. After 4 weeks, if the patient tolerates the dosage well and the required effect has not been achieved, the $5 \mu$ g dose may be increased to $10 \mu \mathrm{g}$ per dose. This higher dose can be expected to lower HbA1c more effectively, but also to have a more pronounced benefit in terms of reducing body weight (Buse et al., 2004, EC Ib; DeFronzo et al., 2005, EC Ib; Kendall et al., 2005, EC Ib). If adverse drug effects are experienced (particularly gastrointestinal side effects such as nausea, retching, vomiting, diarrhoea), the therapy can be continued at the better tolerated $5 \mu$ g dose. Pharmacokinetic studies have revealed that the one-time injection of 5 or $10 \mu \mathrm{g}$ exenatide results in effective plasma levels for a period of about $6 \mathrm{~h}$ (Kolterman et al., 2006, EC IIb). Therefore, injections of exenatide that are administered twice a day cannot ensure that concentrations of active agents will remain adequate for a full $24 \mathrm{~h}$. However, clinical studies have shown that more frequent injections during the day were no more effective (Finman et al., 2003, EC Ib). Exenatide should be injected less than $60 \mathrm{~min}$ before the meal (breakfast, dinner). The effect of the therapy is not more reliable or pronounced if the time between injecting and starting to eat is established more precisely (Linnebjerg et al., 2006, EC Ib).

\subsubsection{Antihyperglycaemic efficacy}

Injecting exenatide twice a day lowers HbA1c values by 0.8 to 1.1\% (Table 6) (Buse et al., 2004, EC Ib; DeFronzo et al., 2005, EC Ib; Kendall et al., 2005, EC Ib; Heine et al., 2005, EC Ib; Nauck et al., 2007, EC Ib; Zinman et al., 2007, EC Ib). Fasting blood glucose is lowered relatively little, but significantly. Almost no postprandial spike in blood glucose is observed after meals that have been preceded by an injection of exenatide (Koltermann et al., 2003, EC Ib). However, blood glucose is elevated after lunch. One meta-analysis has been conducted on the antihyperglycaemic effect of exenatide (Amori et al., 2007, EC Ia).

\subsubsection{Effect on body weight}

Weight loss is usually experienced after several weeks of treatment with exenatide (table), and this weight loss is more pronounced than for placebo injections. The differences compared with insulin treatment were particularly notable, since this usually results in a weight gain (Heine et al., 2005, EC Ib; Nauck et al., 2007, EC Ib). In informal observations over periods of up to 2 years, outside of randomised, controlled studies, this ongoing weight loss continued, with some patients losing as much as $5 \mathrm{~kg}$ (Blonde et al., 2006, EC IIb; Ratner et al., 2006, EC IIb; Buse et al., 2007, EC Iib). However, the patients who took part in the final

Table 6 Studies on the effect of exenatide vs. placebo or vs. insulin in subjects pretreated with oral antidiabetics.

\begin{tabular}{|c|c|c|c|c|c|c|c|c|c|c|}
\hline Author/Year & EC & $\mathbf{N}$ & $\begin{array}{l}\text { Initial } \\
\text { HbA1c [\%] }\end{array}$ & Comparison & Duration & $\Delta \mathrm{HbA1c}[\%]$ & $\mathbf{p}$ & $\begin{array}{l}\text { Prior } \\
\text { medication }\end{array}$ & $\begin{array}{l}\Delta \text { bodyweight } \\
{[\mathrm{kg}]}\end{array}$ & $\mathbf{p}$ \\
\hline DeFronzo 2005 & $\mathrm{lb}$ & 336 & 8.2 vs. 8.2 & Placebo & 30 & -0.8 vs. +0.1 & $<0.002$ & Metf. & -2.8 vs. -0.3 & $<0.001$ \\
\hline Buse 2004 & $\mathrm{lb}$ & 377 & 8.6 vs. 8.7 & Placebo & 30 & -0.9 vs. +0.1 & $<0.001$ & Sulph. & -1.6 vs. -0.6 & $<0.05$ \\
\hline Kendall 2005 & $\mathrm{lb}$ & 733 & 8.5 vs. 8.5 & Placebo & 30 & -0.8 vs. +0.2 & $<0.0001$ & Metf. + Sulph. & -1.6 vs. -0.9 & $<0.01$ \\
\hline Zinman 2007 & $\mathrm{lb}$ & 233 & 7.9 vs. 7.9 & Placebo & 16 & -0.9 vs. +0.1 & $<0.001$ & TZD \pm Metf. & 1.8 vs. -0.2 & - \\
\hline Heine 2005 & $\mathrm{lb}$ & 551 & 8.2 vs. 8.3 & Ins. glargin & 26 & -1.1 vs. -1.1 & $\mathrm{NS} / \mathrm{NI}$ & Metf. + SU & -2.3 vs. +1.8 & $<0.05$ \\
\hline Nauck 2007 & $\mathrm{lb}$ & 501 & 8.6 vs. 8.6 & Biph. Aspart & 52 & -1.0 vs. -0.9 & $\mathrm{NS} / \mathrm{NI}$ & Metf. + SU & -2.5 vs. +2.9 & $<0.001$ \\
\hline
\end{tabular}

$\mathrm{EC}=$ Evidence class; $\mathrm{N}=$ No. of study participants; $\mathrm{NS}=$ not significant; $\mathrm{NI}=$ not inferior; In studies that examined several exenatide dosages, only the results with the highest

dosage $(10 \mu \mathrm{g} 2 \times$ per day) are presented 
examination represented only a small fraction of the original cohort (possibly indicating a selection bias). In one study, a significant drop in blood pressure (systolic minus 5, diastolic minus $2 \mathrm{~mm} / \mathrm{Hg}$, significant) was observed (Nauck et al., 2007, EC Ib). Studies of the influence of treatment with exenatide on hard clinical endpoints are not yet available

\subsubsection{Hypoglycaemia}

Exenatide does not present an intrinsic risk of hypoglycaemia. In principle, however, hypoglycaemia can occur with exenatide. This happens almost exclusively when exenatide is administered in combination with sulphonylureas (Buse et al., 2004, EC Ib; Kendall et al., 2005, EC Ib; Heine et al., 2005, EC Ib; Nauck et al., 2007, EC Ib). Patients who have been previously treated with metformin do not experience hypoglycaemia more often after an injection of exenatide (DeFronzo et al., 2005, EC Ib). This is also true for patients receiving exenatide as monotherapy. If sulphonylureas are used, the improved blood glucose control exenatide provides does cause more frequent episodes of hypoglycaemia. When exenatide is combined with sulphonylureas, the advantages (improved efficacy) must be weighed up carefully against the special risks (risk of hypoglycaemia).

\subsubsection{Side effects}

When treatment with exenatide is started, up to $50 \%$ of patients may experience adverse gastrointestinal effects such as nausea, wretching, vomiting and diarrhoea caused by the medication. These side effects are usually assessed as mild to moderate. In 3.0 to $6.6 \%$ of cases, nausea is evaluated as severe (studies listed in Table 6), and in 1.8 to $14.0 \%$ of cases, treatment was discontinued because of adverse gastrointestinal effects of the medication. $9.6 \%$ of patients ( 7.1 to $15.7 \%$ ) discontinued the treatment in the studies because of adverse effects of the medication, $5.7 \%$ because of gastrointestinal side effects. Gradually increasing the dosage (initially $5 \mu \mathrm{g}$ twice a day, $10 \mu \mathrm{g}$ per dose after 4 weeks) helps to prevent gastrointestinal side effects (Finman et al., 2004, EC Ib). Gastrointestinal side effects are often experienced shortly after the start of treatment or after the dose is increased and they often diminish as the treatment time progresses.

As a foreign protein, exenatide provokes antibody production in about $45 \%$ of the patients treated (studies listed in Table 6). These antibodies are described as low-affinity and low-titre. Antibody formation is not associated with side effects. It is not clear whether the clinical treatment with exenatide is obstructed in some cases by higher-titre antibodies.

A few cases of acute pancreatitis have been observed with exenatide. In most cases, typical risk constellations (gallstones, alcohol, etc.) for pancreatitis were implicated. The frequency of the cases of acute pancreatitis reported in association with exenatide does not exceed the expected frequency of such events in a population of patients suffering from type 2 diabetes. A causal relationship between exenatide therapy and the onset of an acute pancreatitis episode cannot be asserted definitively.

\section{Advantages and disadvantages of exenatide.}

\section{Advantages}

- glucose control without risk of hypoglycaemia (provided it is not combined with sulphonylureas)

- weight loss

- lowered blood pressure

- in preclinical studies, positive effects on betacell function and mass

\section{Disadvantages}

\subsubsection{Contraindications}

Contraindication exists in the case of hypersensitivity to the active agent or any one of the other components. Exenatide should not be used to treat patients with type 1 diabetes or diabetic ketoacidosis. Exenatide should not be given to type 2 diabetics for whom insulin therapy is necessary as a result of beta-cell failure. Care must be taken in the case of patients with gastrointestinal diseases, particularly if these are accompanied by delayed motility of the gastrointestinal tract (e.g., gastroparesis). Administration of exenatide together with insulin, fast-acting sulphonylurea analogues and $\alpha$-glucosidase inibitors has not been studied adequately and cannot be recommended. Clinical experience is very limited for patients aged over 75 . For patients with moderately impaired renal function (creatinine clearance $30-50 \mathrm{ml} / \mathrm{min}$ ), the dose escalation from $5 \mu \mathrm{g}$ to $10 \mu \mathrm{g}$ should be undertaken with extreme caution. Therapy with exenatide cannot be recommended for patients with terminal renal insufficiency or severe renal function disorders (creatinine clearance $<30 \mathrm{ml} / \mathrm{min}$ ). No prior experience is available for adolescents under the age of 18 years.

\subsubsection{Insulin therapy}

Insulin is administered to correct insulin deficiency, promote the uptake of glucose by peripheral tissues after meals, and reduce glucose toxicity. Insulin also suppresses hepatic glucose production, which is the fundamental cause of basal hyperglycaemia in type 2 diabetics. Insulin also corrects other metabolic disorders, such as excessive lypolysis, and has a beneficial effect on blood lipids (Emanuele et al., 1998, EC Ib) (recommendation grade A) and the clotting system (Jain et al., 1993, EC Ib) (recommendation grade A). Finally, the UKPD study (UKPDS 33, 1998, EC Ib) (recommendation grade A) demonstrated that insulin is instrumental in lowering microvascular endpoints, whereas a reduction in macrovascular endpoints did not reach a level of significance. Insulin has the most powerful effect of all pharmacological products that are designed to lower blood sugar.

\subsubsection{Indication}

Insulin therapy for type 2 diabetics is indicated whenever the individual therapeutic objective is not achieved with dietary measures and oral antidiabetics, or if contraindications exist for oral antidiabetics (recommendation grade A). There are no evidence-based endpoint studies indicating that a given form of insulin therapy is superior to any other. The respective form of insulin therapy must therefore be selected individually for each patient. Short-term insulin therapy may become necessary in 
the case of surgical procedures or more severe illnesses. Finally, insulin therapy is indicated for pregnant type 2 diabetics and female patients with gestational diabetes if metabolism cannot be controlled optimally with dietary measures alone (recommendation grade $\mathrm{A}$ ).

\subsubsection{Blood glucose self monitoring}

Every insulin therapy should be accompanied by a self-check of blood glucose (European Diabetes Policy Group, 1999, EC IV) [recommendation grade A)). This enables hypoglycaemia to be detected early, diabetic control to be better monitored, and the insulin dose to be adjusted to the respective blood glucose level and the planned carbohydrate uptake in insulin regimens. The time and frequency of such blood glucose self-checks must be defined individually and depends largely on the type of insulin therapy in question. Insulin therapy and blood glucose selfchecks must be supported by intensive education, which enables the patient to respond appropriately to the blood glucose values obtained. The blood sugar measurements should be taken often enough to achieve the individual's treatment goal. For patients undergoing intensified insulin therapy, as a rule at least 3-4 measurements should be taken per day (Goldstein et al., 2004, EC IV). For patients undergoing conventional insulin therapy, one or two measurements per day are usually sufficient when metabolic control is stable and nutrition is constant, the number of readings can also be reduced further. In combination therapy with a bedtime insulin and oral antidiabetics, one fasting blood sugar reading is usually sufficient for titrating the subsequent insulin dose (Yki-Järvinen et al., 2007, EC IV). There is no reliable data regarding the optimum frequency of blood sugar self-measurements for patients who are not on insulin therapy. Some research indicates that in theory these patients might also benefit from checking their own blood sugar level (Jansen, 2006, EC Ib; Welschen et al., 2005, EC Ib; Sarol, 2005, EC Ib; Martin et al., 2006, EC IIb).

\subsubsection{Application}

The large number of treatment regimens serves as the basis for a wide variety of insulin therapy options for treating type 2 diabetes. In general, a distinction is made between conventional insulin therapy (CT), intensified conventional insulin therapy (ICT), and combination therapy (insulin plus oral antidiabetics). The choice regarding which of these therapies to implement must be guided by consideration for the patient's individual needs, quality of life and degree of metabolic control. Even today, there are no evidence-based studies of the advantages and disadvantages of the various therapy regimens in terms of clinically relevant endpoints. In the UKPD study, both conventional and intensified insulin therapy were used, but no evaluation of the various regimens was carried out (UKPDS 33, 1998). The Kumamoto study (Ohkubo et al.,1995, EC Ib; Shichiri et al., 2000, EC Ib) was a randomised controlled study of 110 normal-weight patients of Asian descent with type 2 diabetes. It was conducted over a period of 8 years and, like the DCCT study (The Diabetes Control and Complications Trial Research Group, 1993, EC Ib) its results indicated an advantage of intensified insulin therapy with several insulin injections per day over the conventional therapy with 1-2 insulin injections per day in terms of reducing the risk of microvascular complications. In a randomised, controlled multicentre study (Abraira et al., 1998, EC Ib) that was conducted with 153 obese (BMI $30.7 \mathrm{~kg} / \mathrm{m} 2$ ) type 2 diabetics and lasted an average of 27 months, HbA1c was lowered more effectively with intensified insulin therapy than with conventional or combination therapies. However, no conclusions regarding clinically relevant endpoints could be drawn within the framework of this study. Yki-Järvinen and associates (YkiJärvinen et al., 1992, EC Ib) compared combination therapy with conventional and intensified therapy with 153 type 2 diabetics in a 3-month, randomised, controlled study, and were unable to find any advantages in any of the various insulin regimens with regard to optimising glucose metabolism, although the HbA1c was significantly lower in all groups that received insulin than in the control group that only received oral antidiabetics. Weight gain with insulin therapy was lowest in the group with combination therapy and highest in the group with intensified insulin therapy, which is why combination therapy was preferred.

\subsubsection{Insulin administration}

Nowadays, insulin is usually administered with insulin pens. These pens are simple to use, provide an exact dose, and cause considerably fewer administration errors than disposable insulin syringes. Disposable insulin syringes are also suitable for administering insulin. However, the user must be particularly careful to note whether they are calibrated for U-100 or U-40 insulin. Patients must be educated accordingly. Injection sites should be easy to reach and readily visible. The most frequently used site is the stomach, the upper thigh is recommended for NPH insulin, but this site can also be used for other insulins if necessary. If possible, no other sites should be used for autoinjection. A fold should be made in the skin before injecting (recommendation grade $\mathrm{C}$ ).

\subsubsection{Conventional therapy}

In conventional therapy, insulin is usually injected twice a day, in the morning and evening, before meals on both occasions. In less common cases, insulin only needs to be taken once a day (usually in the morning). Normally, a mixed insulin is used, consisting of 25 to $30 \%$ regular insulin and $70-75 \% \mathrm{NPH}$ insulin. In the case of mixed insulin, it is advisable to leave a period of about 15-30 min between injecting and eating, depending on the preprandial blood sugar level (the higher the blood sugar value, the longer the period between injecting and eating). Insulins with a different mix proportions may also be appropriate depending on the behaviour of the blood glucose. For this purpose mixed insulins with varied mix proportions are available $(15 / 85,25 / 75,30 / 70,50 / 50)$. Combination insulin analogues with a fixed mix proportion of a short-acting insulin analogue and a delayed insulin in protamine crystal suspension are also available for conventional therapy. The average daily dose of insulin is between 0.5 and $1.0 \mathrm{U} / \mathrm{kg}$ bodyweight, and the insulin units are allocated roughly in proportions of $2 / 3$ in the morning and $1 / 3$ in the evening. In many cases, however, this allocation must be adjusted to individual circumstances, and substantially higher insulin doses are often necessary because of strong insulin resistance.

Insulin therapy is generally begun with a small number of units, e. g., 8-10 units in the morning and 4-6 units in the evening. The dose is then increased incrementally until the glucose target values are reached.

In order to pursue a conventional therapy successfully, it is necessary to follow an ordered daily routine with fixed times for injections and eating. The quantity of insulin and eating and portioning of carbohydrates must be adapted to the individual. After a mix insulin has been injected, the pharmodynamics of 
this insulin make it often necessary that about $4-5 \mathrm{~h}$ after injection another carbohydrate-containing meal must be eaten in order to avoid hypoglycaemia. Many patients must also eat snacks between meals to avoid hypoglycaemia, which is unfavourable in view of the weight problems that often accompany the condition. Moreover, hypoglycaemia may also be triggered by unanticipated physical exertion. The conventional therapy thus demands a certain amount of rigidity in the way many patients lead their lives. Blood glucose self-checks and any necessary adjustments to the insulin dose in accordance with an insulin dosage adjustment schedule should also be carried out regularly.

\subsubsection{Intensified conventional insulin therapy}

The questions of when, how and for whom an intensified insulin therapy (ICT) may be suitable must be determined for each patient individually. In intensified insulin therapy, the patient has greater flexibility in terms of his or her daily routine and nutrition, which in turn may result in improved quality of life. In the Kumamoto study, the intensified insulin therapy brought about an improvement in the HbA1c value, which in turn resulted in reduced microvascular endpoints (Ohkubo et al., 1995, EC Ib). Intensified insulin therapy is indicated whenever adequate metabolic control cannot be achieved with a conventional insulin therapy or a combination therapy (oral antidiabetics (OAD), OAD+basal insulin) (recommendation grade $A$ ). In order to initiate intensified insulin therapy, it is recommended to administer short-acting insulin before meals, adjusted to the current blood glucose level and the planned size of the meal, at first without subsequent administration of an intermediate acting insulin (Kalfhaus et al., 2000, EC III). The practice of taking short-acting insulin on its own before meals only works in the long term for a small number of patients. For example, $41 \%$ of patients in a study including 77 type 2 diabetics (Kalfhaus et al., 2000, EC III) needed a dose of NPH insulin in the evening in order to control their fasting blood glucose adequately. Otherwise, for type 2 diabetics with normal bodyweight, an ICT is administered in the same way as for type 1 diabetics, though individual factors for carbohydrate consumption and correction must be defined. Obese, insulin-resistant type 2 diabetics often need very high doses of short-acting insulin, and calculating carbohydrates is of little help in most cases (recommendation grade B).

Prandial insulin therapy or ICT can be administered to type 2 diabetics with normal insulin or insulin analogues (Insulin lispro $\left(\right.$ Humalog $\left.^{\circledR}\right)$ or Insulin aspart (Novorapid $\left.{ }^{\circledR}\right)$ ) or insulin glulisin $\left(\right.$ Apidra $\left.^{\circledR}\right)$. The potential advantage of insulin analogues is that they can be injected immediately before meals, patients most often do not have to eat snacks between meals to avoid hypoglycaemia, postprandial blood glucose spikes can be controlled more effectively, and according to some studies the tendency to hypoglycaemia is less pronounced than with normal insulin. For example, one 6-month randomised crossover multicentre study with 722 type 2 diabetics (Anderson et al., 1997, EC Iia) showed that postprandial blood glucose spikes were lower and hypoglycaemia occurred less frequently with Insulin lispro than with human insulin. Insulin aspart and insulin glulisin were also observed to regulate postprandial blood glucose values better than normal insulin (Rosenfalck et al., 2000, EC IIa, Rave et al., 2006, EC Ia). At present, there are no endpoint studies relating to short-acting insulin analogues.

For administration of an intermediate acting insulin in the late evening, NPH insulin and long-acting insulin analogues (insulin glargine, insulin detemir) can be used. A comparative study between the long-acting insulin glargine and NPH was conducted in an ICT-regimen with 518 patients (Rosenstock et al., 2001, EC Ib). No difference with regard to lowering HbA1c was determined between NPH insulin and insulin glargine, but the rate of nocturnal hypoglycaemia was lower with insulin glargine. Because of its constant, 24-hour effect, it may also be considered an advantage of insulin glargine that it can be injected at any time of the day (though always at the same time) (Fritsche et al., 2003, EC Ib).

A comparative study between the long-acting insulin analogue detemir and NPH was also conducted in an ICTregimen with 505 type 2 diabetics (Haak et al., 2005, EC Ib). In this case, no significant difference was observed in terms of glucose control and the occurrence of hypoglycaemia. However, the detemir treatment was accompanied by significantly less weight gain $(1.0 \mathrm{~kg}$ versus $1.8 \mathrm{~kg}$ with NPH). Another study (Raslova et al., 2004, EC IIb) revealed a $38 \%$ relative reduction in risk for nocturnal hypoglycaemia. In this study too, weight gain with detemir was about $1 \mathrm{~kg}$ less than with NPH insulin.

A recently published Cochrane meta-analysis showed that, while the HbA1c values were the same, type 2 diabetics using longacting insulin analogues experienced nocturnal hypoglycaemia $34 \%$ (insulin glargine) and 37\% (insulin detemir) less frequently than those using NPH (Horvath K et al., 2007, EC Ia).

At present, there are no endpoint studies relating to long-acting insulin analogues.

\subsubsection{Combination therapy with insulin and oral antidiabetics}

Combination therapy with insulin and suphonylureas has been recommended for more than 20 years (Hamelbeck et al., 1982, EC IV) and its efficacy in terms of lowering $\mathrm{HbA} 1 \mathrm{c}$ has been confirmed in a number of studies (Osei et al., 1984, EC IIa; Quatraro et al., 1986, EC IIb; Stenman et al.,1988, EC IIa; Del Prato et al., 1990, EC IIb; Pontroli et al., 1990, EC III; Riddle et al., 1992, EC IIb; Fritsche et al., 2003, EC Ib). In most such cases, sulphonylureas were administered together with a long-acting insulin at night. It was also demonstrated that in combination therapy with sulphonylureas considerably less insulin was required to achieve the same metabolism control than when insulin was administered alone (Riddle et al., 1992, EC IIb; Lotz et al., 1988, EC IIa; Bachmann et al., 1988, EC IIa; Chow et al., 1995, EC IIa; Goudswaard et al., 2004, EC Ia). In a meta-analysis that summarised 16 randomised, placebo-controlled studies (Johnson et al., 1996, EC Ia), combination therapy of sulphonylureas with insulin lowered fasting blood glucose and the $\mathrm{HbA} 1 \mathrm{c}$ value, and insulin was also used more economically (recommendation grade A). This combination therapy is also easy to administer. Normally, long-acting sulphonylureas (glibenclamide or glimepiride) are taken once or twice a day and long-acting insulin is taken as a bedtime dose (Yki-Järvinen et al., 1999, EC Ib; Seigler et al., 1992, EC IIa, Fritsche et al., 2003, EC 1b). Positive effects on blood glucose control were also described when repaglinide was taken three times a day in combination with a bedtime injection of HPH insulin (De Luis et al., 2001, EC Ib). No data on endpoint efficacy is available.

Combinations of insulin with metformin have been reported as having particularly favourable effects on metabolism control in various studies (Yki-Järvinen et al., 1992, EC Ib; Yki-Järvinen et al., 1999, EC Ib; Yki-Järvinen, 2001, EC IV; Aviles-Santa et. al., 1999, EC Ib; Mäkimattila et al., 1999, EC Ib) (recommendation 
grade A). This combination is particularly suitable for obese patients with pronounced insulin resistance. Taking metformin additively allows the quantity of insulin to be reduced and weight to be controlled to good effect (Yki-Järvinen, 2001, EC IV; Ponssen et al., 2000, EC Ib; Fritsche et al., 2000, EC Ila; Goudswaard et al., 2004, EC Ia). Adding supplementary metformin (provided it is not contraindicated) to an existing insulin therapy can be helpful for all patients who are overweight and obese (Ponssen et al., 2000, EC Ib; Fritsche et al., 2000, EC Ila, Goudswaard et al., 2004, EC Ia) (Recommendation grade A). No data on endpoint efficacy is available.

Combination therapy of insulin with the thiazolidindione pioglitazone has now been approved for use in Germany as well. This combination has been in use in other countries (e.g. USA) for a long time. Its side effects are essentially the same as those associated with glitazone monotherapy (Berlie et al.,2007, EC Ia; Rosenstock et al., 2002, EC Ib) (see also section 1.1.1.3). In this case, significant weight gain and increased susceptibility to oedema should be noted in particular. Administering a supplementary $30 \mathrm{mg}$ pioglitazone per day to an existing insulin therapy lowered HbA1c by an average of $1.3 \%$, lowered fasting glucose significantly, by $48 \mathrm{mg} / \mathrm{dl}$, and improved dyslipidaemia, (Rosenstock et al., 2002, EC Ib). A combination of insulin and glitazones helps to improve the type 2 diabetic's insulin sensitivity. This can also reduce his or her insulin requirement and lead to more frequent episodes of hypoglycaemia (Rosenstock et al., 2002, EC Ib).

Relatively large, randomised controlled studies and meta-analyses have found that when long-acting analogue insulins are given as bedtime doses in combination with oral antidiabetics, significantly fewer hypoglycaemia occur than with NPH, while glucose control is equally good (Yki-Järvinen et al., 2000, EC Ib; Riddle et al., 2003, EC Ib; Rosenstock et al., 2005, EC Ia; Hermansen et al., 2006, EC IIa, Fritsche et al., 2003, EC Ib, Tschritter et al., 2005, EC Ia, Mullins et al., EC Ia) (recommendation grade A). One meta-analysis (Tschritter et al., 2005, EC Ia) found that overall, nocturnal and severe hypoglycaemia were significantly reduced with insulin glargine, and overall and nocturnal hypoglycaemia were significantly reduced with insulin detemir. A number of different randomised, controlled multicentre studies and meta-analyses (Rosenstock et al., 2001, EC Ib, Fritsche et al., 2003, EC Ib; Rosenstock et al., 2005, EC Ib; Tschritter et al., 2005, EC Ia, Mullins et al., 2007, EC Ia) found no difference between NPH insulin and insulin glargine in terms of HbA1clevel, but overall hypoglycaemia occurred significantly less often with insulin glargine than with NPH insulin. In one study, hypoglycaemia only occurred less frequently with insulin glargine for the first 12 weeks, though blood sugar levels before the evening meal were significantly lower with insulin glargine than with NPH insulin (Yki-Järvinen et al., 2006, EC Ib). In an evaluation of practice-related phase IV studies, one new summary meta-analysis found that confirmed symptomatic hypoglycaemia were reduced by $40.8 \% \quad(\mathrm{p}<0.01)$ and severe hypoglycaemia by $46.8 \%$ ( $<<0.05$ ) with insulin glargine relative to NPH insulin for both type 1 and type 2 diabetics (Mullins et al., 2007, EC Ia).

A direct comparison of both long-acting analogue insulins in a 52-week Treat-to-Target study found that HbA1c was lowered equally with insulin glargine and insulin detemir, and that hypoglycaemia rates were comparable. $55 \%$ of the patients using insulin detemir received an injection twice daily and the average insulin dose required to achieve the therapeutic objective was higher for insulin detemir $(0.78 \mathrm{IU} / \mathrm{kg})$ than for insulin glargine (0.44 IU $/ \mathrm{kg})$. Insulin detemir was associated with less weight gain than insulin glargine $(2.7 \mathrm{~kg}$ vs. $3.5 \mathrm{~kg}$ ) (Rosenstock et al, 2008, EC Ib). Weight gain with insulin detemir was also lower than with NPH insulin (1.2 kg vs. $2.8 \mathrm{~kg}$ ) (Hermansen et al., 2006, EC Ib).

The use of long-acting insulin analogues is advisable particularly for patients who experience hypoglycaemia with NPH insulin and need a simple method for administering insulin (no mixing as with NPH insulins).

Two recently published studies compared various insulin therapy strategies for patients with type 2 diabetes. The results of the "Treating to Target in Type 2 Diabetes (4-T)" study (basal insulin vs. prandial insulin vs. mixed insulin in the context of an established OAD therapy) showed that HbA1c was lowered significantly more with prandial insulin and mixed insulin therapies than with the basal insulin therapy. However, this effect was associated with an elevated risk of hypoglycaemia and pronounced weight gain (Holman et al., 2007, EC Ib).

In the Apollo study, an insulin/OAD combination therapy with one-time administration of insulin glargine was compared with a therapy consisting of three doses per day of insulin lispro in the context of an established OAD therapy (Bretzel et al., 2008, EC Ib). In this case, HbA1c was lowered comparably with both therapies, but the once daily administration of insulin glargine was associated with fewer hypoglycaemia episodes (5.2 vs. 24 events per patient per year) and better patient satisfaction than the therapy with three daily doses of insulin lispro (Bretzel et al., 2008, EC Ib).

\subsubsection{Side effects of insulin therapy}

Hypoglycaemia: These occur considerably more frequently with insulin therapy than with treatments using oral antidiabetics. For example, the incidence of severe hypoglycaemia in the UKPD study was 2.3 episodes per 100 patient years (UKPDS 33, 1998, EC Ib).

Weight gain: In the UKPD study, the group receiving insulin treatment recorded an average weight gain of $4 \mathrm{~kg}$ within 10 years compared with the group receiving conventional treatment (UKPDS 33, 1998, EC Ib).

Retinopathy progression: A 5-year study with 1017 patients receiving insulin treatment that was presented at ADA 2008 demonstrated that insulin glargine was not associated with a higher risk of retinopathy than NPH insulin (Rosenstock et al., 2008, EC Ib).

Allergies: Allergies may be triggered by insulin itself or by additives therein. True insulin allergies are extremely rare when human insulins and insulin analogues are used. 


\section{Flowchart: Antihyperglycaemic therapy of type 2 diabetes}
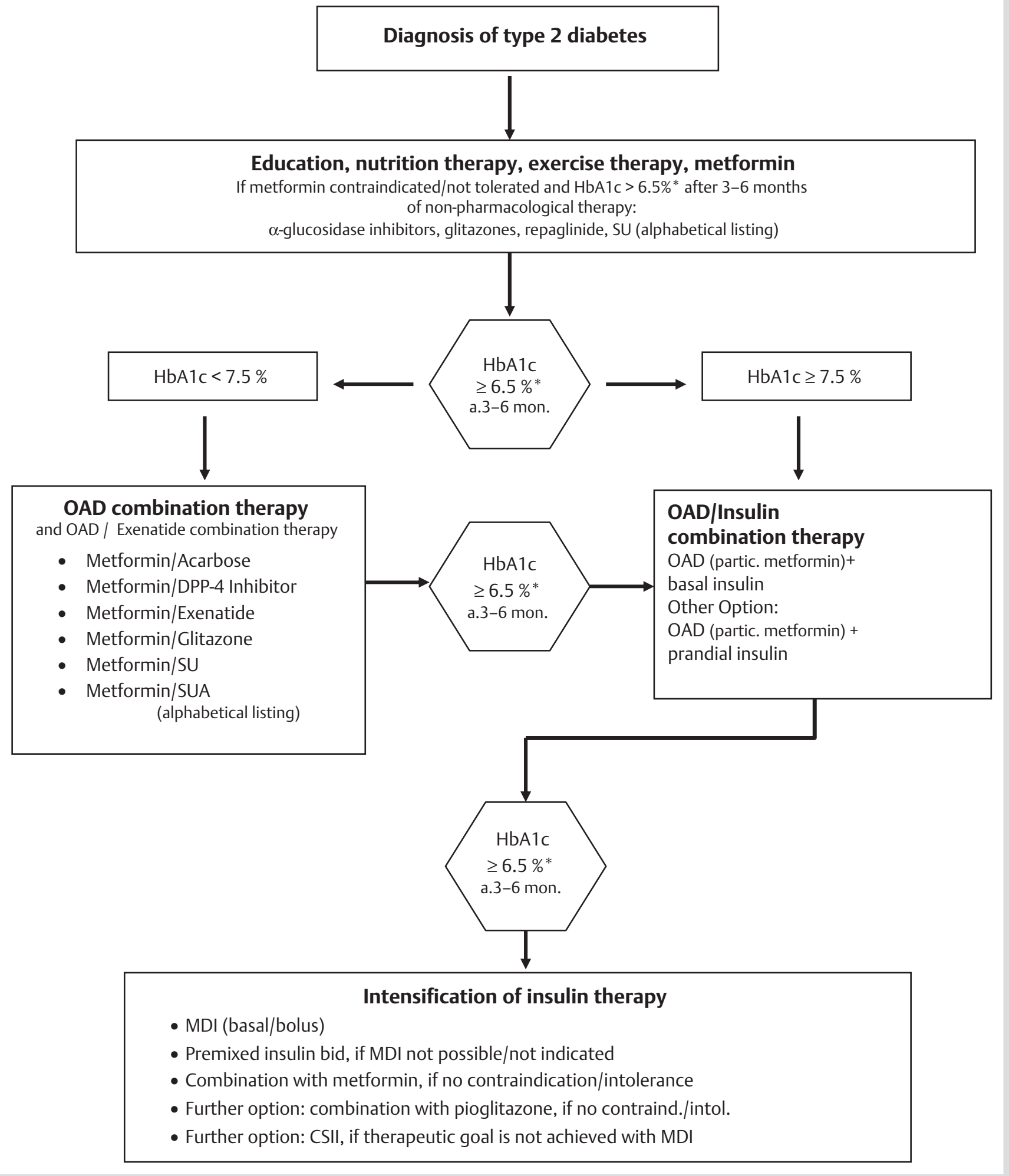


\section{Legend to flowchart}

$\nabla$

\section{General notes}

* Note on HbA1c target value

Based on the data from the UKPDS, the UKPDS 10-year follow-up as well as the ADVANCE study and in accordance with the recommendations of the European Association for the Study of Diabetes and global IDF guidelines, these guidelines recommend a target range of $<6.5 \%$ for HbA1c. The authors of this guideline point out that these target values are the result of a decision that was necessarily discretionary, and that in individual, substantiated cases, deviations are permissible.

In the light of the results of the ACCORD and ADVANCE studies (The Action to Control Cardiovascular Risk in Diabetes Study Group, 2008, EC Ib; The ADVANCE Collaborative Group, 2008, EC Ib), it should also be borne in mind that lowering HbA1c to $6.5 \%$ as opposed to a target value of $7.0 \%$ can be beneficial to the patient, but should only be attempted if

- hypoglycaemia (particularly severe hypoglycaemia) are largely prevented,

- the therapeutic effect is not accompanied by excessive weight gain,

- multiple combinations of oral antidiabetics (i.e. usually more than two) on which little research has been done, and particularly continuation of such multiple combinations when supplementing with insulin are avoided. (see also section 4 (appendix 1))

The HbA1c value should be determined every 3 months. If the therapeutic objective for the HbA1c is not achieved, the therapy is intensified. Once the HbA1c value is stabilised in the target range, another option consists in attempting a treatment pause (e.g. for insulin), whereby patient can be treated experimentally (and as a rule temporarily) at the earlier therapy stage.

\section{Education, nutrition and exercise therapy, metformin}

Patients who have recently been diagnosed with diabetes mellitus type 2 should attend a formal diabetes education programme. Among the value of information provided at such sessions, they will learn the principles of nutritional and exercise therapy. The effectiveness of non-pharmacological therapy is reflected in the fact that it is capable of lowering the HbA1c by about $2 \%$ (UKPDS 34,1998 , EC Ib) (recommendation grade A).

A metformin therapy should be started as soon as possible (Nathan et al., 2006, EC IV) (recommendation grade A), provided no contraindications exist (see 1.1.1.1.8). For information about metformin titration, see page 43 . If a contraindication or intolerance for metformin does exist, therapy is recommended with a substance that is approved for monotherapy (acarbose, PPAR- $\gamma$ ligands, repaglinide, sulphonylurea (alphabetical list)), if the HbA1c is still > 6.5\% after 3-6 months of non-pharmacological treatment. Selection of the antihyperglycaemic substance should be made with consideration for differential therapeutic considerations and the pertinent spectrum of side effects.

If the $\mathrm{HbA} 1 \mathrm{c}$ value is $6.5 \%$ and $<7.5 \%$ after $3-6$ months, an OAD/ exenatide combination therapy is recommended (see below, 2.). If the HbA1c value is $7.5 \%$ after 3-6 months, an insulin/OAD (particularly metformin) combination therapy is recommended (see below 3.), since a combination therapy listed under 2. (generally causing a further reduction of $\mathrm{HbA} 1 \mathrm{c}$ of $<1 \%$, ) is unlikely to achieve the HbA1c target of $<6.5 \%$ in patients who have received prior non-pharmacological treatment and metformin.

\section{OAD combination therapy, OAD/exenatide combination therapy \\ $\nabla$}

At this level of therapy, the combinations shown in the flowchart can be used. They are listed in alphabetical order. There is no scientifically based order of preference. The choice of combination partners must be made on a case by case basis in accordance with the patient's current metabolic situation and taking into account the advantages and disadvantages as well as side effects/contraindications of the respective substance. Combination therapies with two OADs or OADs with exenatide are not advisable unless the HbA1c target appears to be achievable in view of the degree by which the selected substances can be expected to lower HbA1c. With regard to the combination therapy metformin/glibenclamide, according to the published data currently available, it cannot be guaranteed that this combination will not increase cardiovascular risk. Therefore, this combination should only be administered if alternatives of equivalent efficacy cannot be used and after the patient has been informed in detail about the possible risk and alternative therapies. Due to the lack of pertinent data, it is not known whether other SU or SUA/metformin combination therapies are associated with a similar possibility of increased risk. In this situation, the authors do not believe that it is necessary to change the medications for all diabetics who are being treated with these combinations, but they suggest a more rigorous indication system is called for, particularly for new patients and patients with coronary heart disease. A combination of three OADs should not be used except in special circumstances (e.g. need to avoid insulin therapy for reasons related to the patient's profession).

If the $\mathrm{HbA} 1 \mathrm{c}$ therapeutic target of $<6.5 \%$ is not achieved after 3-6 months, treatment is intensified with a combination therapy consisting of insulin and OAD (see below, 3.).

\section{Combination therapy OAD (particularly metformin) plus insulin $\nabla$}

In this phase of the disease, the patient's metabolism is characterised primarily by fasting glucose values that are above the target value of $100 \mathrm{mg} / \mathrm{dl}$, since endogenous glucose production is no longer adequately suppressed by endogenous insulin. Thus, the objective of insulin therapy is to compensate for this deficiency. For this, basal insulins are recommended. They are injected at bedtime in the evening and thus block endogenous glucose production (also called basal insulin supported oral therapy, BOT). The dose of these basal insulins is titrated so as to achieve a fasting blood glucose level of $100 \mathrm{mg} / \mathrm{dl}$ while avoiding nocturnal hypoglycaemia (Yki-Järvinen, 1999, EC Ib) (recommendation grade A). If plasma glucose levels during the day remain near to normal with this therapy, there is currently no need for escalating insulin therapy using also injections during daytime.

In the (much rarer) event that with this regimen the fasting blood sugar level is in the normal range but the preprandial blood sugar levels during the day are not in the target range, prandial insulin therapy should be implemented (also called supplementary insulin therapy, SIT). 
In the absence of contraindications, the respective combination therapy with metformin is recommended (Ponssen et al., 2000, EC Ib; Cusi \& DeFronzo, 1998, EC IV) (recommendation grade A). Another option is the combination therapy with SU or repaglinide. Provided there are no contraindications, another option is the combination therapy with pioglitazone (Technical information on Actos $^{\circledR}$; Berlie et al., 2007, EC Ia; Rosenstock et al., 2002, $\mathrm{EC} \mathrm{Ib})$.

If the HbA1c goal of $<6.5 \%$ is not achieved after 3-6 months, the insulin therapy is intensified (see below, 4.).

\section{Intensifying insulin therapy (MDI, premixed bid, (SII)}

$\nabla$

MDI (multiple daily injection of basal/bolus insulin) and premixed bid (injection of premixed insulins twice daily) are essentially insulin therapy procedures that assist in achieving the individual therapeutic goal. The advantages and disadvantages of both therapy forms should be discussed with the patient before any decision regarding therapy is made (see also 1.2.5, 1.2.6).

MDI: Besides taking basal insulin at night, patients inject themselves with bolus insulin at mealtimes. The decision as to whether the patient must also take basal insulin during the day is determined by the result of the basal rate test (skipping lunch, plasma glucose measurement every hour until dinner, determination of the need for basal insulin based on plasma glucose development). Insulin glargine can also be administered at times other than at night, and metabolism is equally well controlled (Fritsche et al. 2003, EC Ib). Provided it is not contraindicated, the combination therapy with metformin is recommended (Ponssen et al., 2000, EC Ib; Cusi \& DeFronzo, 1998, EC IV) (recommendation grade $\mathrm{A}$ ).

Premixed bid: If MDI is not indicated for individual, social or organisational reasons, a so called conventional form of insulin therapy, usually injecting premixed insulin twice a day, is applied. Provided it is not contraindicated, the combination therapy with metformin is recommended (Ponssen et al., 2000, EC Ib; Cusi \& DeFronzo, 1998, EC IV) (recommendation grade A). Provided it is not contraindicated, another option is the combination therapy of insulin with pioglitazone (Technical information on Actos $^{\circledR}$; Berlie et al., 2007, EC Ia; Rosenstock et al., 2002, EC Ib). CSII (Continuous Subcutaneous Insulin Infusion, insulin pump therapy): If the therapeutic HbA1c goal is not achieved with MDI despite repetitive structured education of the patient, CSII represents a therapeutic option. Provided it is not contraindicated, the combination therapy with metformin is recommended (Ponssen et al., 2000, EC Ib; Cusi \& DeFronzo, 1998, EC IV) (recommendation grade $\mathrm{A}$ ).

\section{Metformin titration}

Start with $1 \times 500 \mathrm{mg}$ with the evening meal (0-0-1).

If tolerated, increase after 1 week to $2 \times 500 \mathrm{mg}$ with breakfast and evening meal (1-0-1).

If tolerated, increase after 1 week to $2 \times 1 \mathrm{~g}$ with breakfast and evening meal (1-0-1).

If the patient develops an intolerance in response to the dosage increase, the dose should be reduced to the level at which it is tolerated. If possible, a further attempt should be made to increase the dosage later

\section{Abbreviations}

HbA1c, glycosylated haeoglobin; OAD, oral antidiabetics; SU, sulphonylureas; SUA, sulphonylurea analogues (repaglinide, nateglinide); $\alpha$-GI, $\alpha$-glucidase inhibitor; glitazone, PPAR- $\gamma$ ligand (rosiglitazone, pioglitazone); MDI, multiple daily injection of basal/bolus insulins; CSII, continuous subcutaneous insulin infusion, (insulin pump therapy); Premixed bid, injection of premixed insulin preparations twice daily; partic., particularly; a, after.

\section{References}

1 Abraira C, Henderson WG, Colwell JA et al. Response to intensive therapy steps and to glipizide dose in combination with insulin in type 2 diabetes. VA feasibility study on glycemic control and complications (VA CSDM). Diabetes Care 1998; 21: 574-579 Evidence class Ib

2 Ahrén B, Gomis R, Standl E et al. Twelve- and 52-week efficacy of the dipeptidyl peptidase IV inhibitor LAF237 in metformin-treated patients with type 2 diabetes. Diabetes Care 2004; 27: 2874-2880 Evidence class Ib

3 Amori RE, Lau J, Pittas AG. Efficacy and safety of incretin therapy in type 2 diabetes: Systematic review and meta-analysis. JAMA 2007; 298: 194-206 Evidence class Ia

4 Anderson JH, Brunelle RL, Keohane P et al. Mealtime treatment with an insulin analog improves postprandial hyperglycemia and hypoglycemia in patients with non-insulin-dependent diabetes mellitus. Multicenter Insulin Lispro Study Group. Arch Intern Med 1997; 157: 1249-1255 Evidence class IIa

5 Anfosso F, Chromiki N, Alessi M et al. Plasminogen activator inhibitor1 synthesis in the human hepatoma cell line Hep G2: Metformin inhibits the stimulating effect of insulin. J Clin Invest 1993; 91: 2185-2193 Evidence class Ila

6 Aschner P, Kipnes MS, Lunceford JK et al. Sitagliptin Study 021 Group. Effect of the dipeptidyl peptidase-4 inhibitor sitagliptin as monotherapy on glycemic control in patients with type 2 diabetes. Diabetes Care 2006; 29: 2632-2637 Evidence class Ib

7 Aviles-Santa L, Sinding J, Raskin P. Effects of metformin in patients with poorly controlled, insulin-treated type 2 diabetes mellitus. A randomized double-blind, placebo-controlled trial. Ann Intern Med 1999; 131: 182-188 Evidence class Ib

8 Bachmann W, Lotz N, Mehnert $H$ et al. Effectiveness of combined treatment with glibenclamide and insulin in secondary sulfonylurea failure. A controlled multicenter double-blind clinical trial. Dtsch Med Wochenschr 1988; 113: 631-636 Evidence class Ila

9 Bailey CJ, Bagdonas A, Rubes J et al. Rosiglitazone/Metformin fixeddose combination compared with uptitrated metformin alone in type 2 diabetes mellitus: A 24-week, multicenter, randomized, double-blind, parallel-group study. Clin Ther 2005; 27: 1548-1561 Evidence class Ib

10 Bailey CJ, Turner RC. Metformin. N Engl J Med 1996; 334: 574-579 Evidence class IV

11 Bakris G, Viberti G, Weston WM et al. Rosglitazone reduces urinary albumin excretion in type II diabetes. Journal of Human Hypertension 2003; 17: 7-12 Evidence class Ib

12 Balfour JA, Plosker GL. Rosiglitazone. Drugs 1999; 57: 921-930 Evidence class IV

13 Barnett A. DPP-4 inhibitors and their potential role in the management of type 2 diabetes. Int J Clin Pract 2006; 60: 1454-1470 Evidence class IV

14 Baron $A D$, Eckel RH, Kolterman OG. The effect of short-term alphaglucosidase inhibition on carbohydrate and lipid metabolism in type2-diabetics. Metabolism 1987; 36: 409-415 Evidence class II b

15 Baron AD, Neumann C. PROTECT Interim Results: A large multicenter study of patients with type-2 diabetes. Clinical Therapeutics 1997; 19: 282-295 Evidence class II a

16 Bergman AJ, Stevens C, Zhou Y et al. Pharmacokinetic and pharmacodynamic properties of multiple oral doses of sitagliptin, a dipeptidyl peptidase-IV inhibitor: A double-blind, randomized, placebo-controlled study in healthy male volunteers. Clin Ther 2006; 28: 55-72 Evidence class Ib

17 Berlie HD, Kalus JS, Jaber LA. Thiazolidinediones and the risk of edema: a meta-analysis. Diabetes Res Clin Pract 2007; 76: 279-289 Evidence class Ia 
18 Blonde L, Klein EJ, Han J et al. Interim analysis of the effects of exenatide treatment on A1C, weight and cardiovascular risk factors over 82 weeks in 314 overweight patients with type 2 diabetes. Diabetes Obes Metab 2006; 8: 436-447 Evidence class IIb

19 Bolli G, Dotta F, Rochotte E et al. Efficacy and tolerability of vildagliptin vs. pioglitazone when added to metformin: A 24-week randomized double blind study. Diabetes Obes Metab 2008; 10: 82-90 Evidence class Ib

20 Bosi E, Camisasca RP, Collober C et al. Effects of vildagliptin on glucose control over 24 weeks in patients with type 2 diabetes inadequately controlled with metformin. Diabetes Care 2007; 30: 890-895 Evidence class Ib

21 Braun D, Schönher U, Mitzkat HJ. Efficacy of acarbose monotherapy in patients with type 2 diabetes: a double-blind study conducted in general practice. Endocrinology and Metabolism 1996; 3: 275-280 Evidence class Ib

22 Bretzel RG, Nuber $U$, Landgraf $W$ et al. Once-daily basal insulin glargine versus thrice-daily prandial insulin lispro in people with type 2 diabetes on oral hypoglycemic agents (APOLLO): an open randomised controlled trial. Lancet 2008; 371: 1073-1084 Evidence class Ib

23 Buse JB, Henry RR, Han J et al. Effects of exenatide (exendin-4) on glycemic control over 30 weeks in sulfonylurea-treated patients with type 2 diabetes. Diabetes Care 2004; 27: 2628-2635 Evidence class $\mathrm{Ib}$

24 Buse JB, Klonoff DC, Nielsen LL et al. Metabolic effects of two years of exenatide treatment on diabetes, obesity, and hepatic biomarkers in patients with type 2 diabetes: An interim analysis of data from the open-label, uncontrolled extension of three double-blind, placebocontrolled trials. Clin Ther 2007; 29: 139-153 Evidence class IIb

25 Calle-Pascual A, Garcia-Honduvilla J, Martin-Alvarez PJ. Influence of 16 week monotherapy with acarbose on cardiovascular risk factors in obese subjects with non-insulin-dependent diabetes mellitus: a controlled double blind study with placebo. Diab Metab 1996; 22: 201-202 Evidence class II a

26 Campbell IW, Howlett HCS. Worldwide experience of metformin as an effective glucose-lowering agent: a metaanalysis. Diabetes Metab Rev 1995; 11: 557-562 Evidence class Ia

27 Carey DG, Cowin GJ, Galloway GJ et al. Sensitivity effect of rosiglitazone on insulin and body composition in type 2 diabetic patients. Obes Res 2002; 10: 1008-1015 Evidence class Ib

28 Ceriello A, Johns D, Widel M et al. Comparison of effect of pioglitazone with metformin or sulfonylurea (monotherapy and combination therapy) on postload glycemia and composite insulin sensitivity index during an oral glucose tolerance test in patients with type 2 diabetes. Diabetes Care 2005; 28: 266-272 Evidence class Ib

29 Ceriello A, Taboga C, Tonutti L et al. Post-meal coagulation activation in diabetes mellitus: the effect of acarbose. Diabetologia 1996; 39 : 469-473 Evidence class I b

30 Chan NN, Brain HP, Feher MD. Metformin-associated lactic acidosis: a rare or very rare clinical entity? Diabetes Care 1998; 21: 16591663 Evidence class Ila

31 Charbonnel B, Karasik A, Liu J et al., Sitagliptin Study 020 Group. Efficacy and safety of the dipeptidyl peptidase- 4 inhibitor sitagliptin added to ongoing metformin therapy in patients with type 2 diabetes inadequately controlled with metformin alone. Diabetes Care 2006; 29: 2638-2634 Evidence class Ib

32 Charbonnel BH, Matthews DR, Schernthaner G et al. A long-term comparison of pioglitazone and gliclazide in patients with type 2 diabetes mellitus: a randomized, double-blind, parallel-group comparison trial. Diabet Med 2004; 22: 399-405 Evidence class Ib

33 Chiasson JL, Josse RG, Hunt JA et al. The efficacy of acarbose in the treatment of patients with non-insulin-dependent diabetes mellitus A multicenter controlled clinical trial. Ann Intern Med 1994; 121: 928-935 Evidence class Ib

34 Chiasson JL, Nathan DM, Josse RG et al. The effect of acarbose on insulin sensitivity in subjects with impaired glucose tolerance. Diabetes Care 1996; 19: 1190 Evidence class Ib

35 Chiasson JL, Gomis R, Hanefeld M et al. Acarbose can prevent the progression of impaired glucose tolerance to type 2 diabetes mellitus: The STOPNIDDM Trial. The Lancet 2002; 359: 2072-2077 Evidence class Ib

36 Chilcott J, Tappendenden P, Jones ML et al. A systematic review of the clinical effectiveness of pioglitazone in the treatment of type 2 diabetes mellitus. Clin Ther 2001; 23: 1792-1823 Evidence class IV

37 Chow CC, Tsang LW, Sorensen JP et al. Comparison of insulin with or without continuation of oral hypoglycemic agents in the treatmentt of secondary failure in NIDDM patients. Diabetes Care 1995; 18 : 307-314 Evidence class IIa
$38 \mathrm{Chu}$ J, Abbasi F, Lamendola $\mathrm{C}$ et al. Improvements in vascular and inflammatory markers in rosiglitazone-treated insulin-resistant subjects are independent of changes in insulin sensitivity or glycemic control. Diabetes 2003; 52: 325-30R Evidence class IIb

39 Cusi K, DeFronzo RA. Metformin: a review of its metabolic effects. Diabetes Reviews 1998; 6: 89-131 Evidence class IV

40 Dabrowski M, Wahl P, Holmes WE et al. Effect of repaglinide on cloned beta cell, cardiac and smooth muscle types of ATP-sensitive potassium channels. Diabetologia 2001; 44: 747-756 Evidence class IV

41 Dailey GE, Noor MA, Park JS et al. Glycemic control with glyburide/ metformin tablets in combination with rosiglitazone in patients with type 2 diabetes: a randomized, double-blind trial. Am J Med 2004; 116: 223-229 Evidence class Ib

42 Danchin N, Charpentier G, Ledru F et al. Role of previous treatment with sulfonylureas in diabetic patients with acute myocardial infarction: results from a nationwide French registry. Diabetes Metab Res Rev 2005; 21: 143-149 Evidence class III

43 Davis SN, Johns D, Maggs D et al. Exploring the substitution of exenatide for insulin in patients with type 2 diabetes treated with insulin in combination with oral antidiabetes agents. Diabetes Care 2007; 30: 2767-2772 Evidence class III

44 DeFronzo RA, Ratner RE, Han J et al. Effects of exenatide (exendin-4) on glycemic control and weight over 30 weeks in metformin-treated patients with type 2 diabetes. Diabetes Care 2005; 28: 1092-1100 Evidence class Ib

45 DeFronzo R, Goodman AM. Efficacy of Metformin in NIDDM patients poorly controlled on diet alone or diet plus sulfonlyurea. N Engl J Med 1995; 333: 541-549 Evidence class Ib

46 Dejager S, Razac S, Foley JE et al. Vildagliptin in drug-naïve patients with type 2 diabetes: a 24-week, double-blind, randomized, placebocontrolled, multiple-dose study. Horm Metab Res 2007; 39: 218-223 Evidence class Ib

47 Del Prato S, Vigili de Kreutzenberg S, Riccio A et al. Partial recovery of insulin secretion and action after combined insulin-sulfonylurea treatment in type 2 (non-insulin-dependent) diabetic patients with secondary failure to oral agents. Diabetologia 1990; 33: 688-695 Evidence class IIb

48 De Luis DA, Aller R, Terroba C et al. Effect of repaglinide addition to NPH insulin monotherapy on glycemic control in patients with type 2 diabetes. Diabetes Care 2001; 24: 1844-1845 Evidence class Ib

49 Derosa G, Cicero AFG, d'Angelo A et al. Thiazolidinedione effects on blood pressure in diabetic patients with metabolic syndrome treated with glimepiride. Hypertens Res 2005; 28: 917-924 Evidence class Ib

50 Derosa G, Gaddi AV, Ciccarelli L et al. Long-term effect of glimepiride and rosiglitazone on non-conventional cardiovascular risk factors in metformin-treated patients affected by metabolic syndrome: a randomized, double-blind clinical trial. J Int Med Res 2005; 33: 284-294 Evidence class Ib

51 Derosa G, Gaddi AV, Piccinni MN et al. Antithrombotic effects of rosiglitazone-metformin versus glimepiride-metformin combination therapy in patients with type 2 diabetes mellitus and metabolic syndrome. Pharmacotherapy 2005; 25: 637-645 Evidence class Ib

52 Derosa G, Gaddi AV, Piccinni MN et al. Differential effect of glimepirid and rosiglitazone on metabolic control of type 2 diabetic patients treated with metformin: a randomized, double-blind, clinical trial. Diab Obes Metab 2006; 8: 197-205 Evidence class Ib

53 Diamond GA, Bax L, Kaul S. Uncertain effects of rosiglitazone on the risk for myocardial infarction and cardiovascular death. Annals of Internal Medicine 2007; 147: 578-581 Evidence class Ia

54 Dills DG, Schneider J. Clinical evaluation of glimepiride versus glyburide in NIDDM in a double-blind comparative study. Horm Metab Res 1996; 28: 426-429 Evidence class Ib

55 Dormandy JA, Charbonnel B, Eckland DJ et al. Secondary prevention of macrovascular events in patients with type 2 diabetes in the PROactive Study (PROspective pioglitAzone Clinical Trial In macroVascular Events): a randomised controlled trial. Lancet 2005; 366: 1279-1289 Evidence class Ib

56 Draeger KE, Wernicke-Panten K, Lomp H-J et al. Long-term treatment of type 2 diabetic patients with the new oral antidiabetic agent glimepiride (Amaryl ${ }^{\circledR}$ ): a double-blind comparison with glibenclamide. Horm Metab Res 1996; 28: 419-425 Evidence class Ib

57 Dunn CJ, Faulds D. Nateglinide. Drugs 2000; 60: 607-615 Evidence class IV

58 Dunning BE. New non-sulfonylurea insulin secretagogues. Exp Opin Invest Drugs 1997; 6: 1041-1048 Evidence class IV

59 Ebeling P, Teppo AM, Koistinen HA et al. Concentration of the complement activation product, acylation-stimulating protein, is related to C-reactive protein in patients with type 2 diabetes. Metabolism 2001; 50: 283-287, Evidence class Ib 
60 Einhorn D, Rendell M, Rosenzweig J et al. Pioglitazone hydrochloride in combination with metformin in the treatment of type 2 diabetes mellitus: a randomized, placebo-controlled study The Pioglitazone 027 Study Group. Clin Ther 2000; 22: 1395-1409 Evidence class Ib

61 Emanuele N, Azad N, Abraira C et al. Effect of intensive glycemic control on fibrinogen, lipids, and lipoproteins: Veterans affairs cooperative study in type II diabetes mellitus. Arch Intern Med 1998; 158 : 2485-2490 Evidence class Ib

62 Esposito $K$, Ciotola $M$, Carleo $D$ et al. Effect of rosiglitazone on endothelial function and inflammatory markers in patients with the metabolic syndrome. Diabetes Care 2006; 29: 1071-1076 Evidence class Ib

63 Eurich DT, McAlister FA, Blackburn DF et al. Benefits and harms of antidiabetic agents in patients with diabetes and heart failure: systematic review. British Medical Journal 2007; 335: 497-507 Evidence class Ia

64 European Diabetes Policy Group. A desktop guide to type 2 diabetes mellitus. European Diabetes Policy Group 1999. Diabet Med 1999; 16: 716-730 Evidence class IV

65 Evans JM, Donnelly LA, Emslie-Smith AM et al. Metformin and reduced risk of cancer in diabetic patients. Brit Med J 2005; 330: 1304-1305 Evidence class IV

66 Evans JM, Ogston SA, Emslie-Smith A et al. Risk of mortality and adverse cardiovascular outcomes in type 2 diabetes: a comparison of patients treated with sulfonylureas and metformin. Diabetologia 2006; 49: 930-936 Evidence class III

67 FachInfo Actos ${ }^{\circledR}$. Bundesverband der Pharmazeutischen Industrie: Zusammenfassung der Merkmale des Arzneimittels Actos ${ }^{\circledR}$. Oktober 2000 2000; 1-3 Evidence class IV

68 Fineman MS, Shen LZ, Taylor K et al. Effectiveness of progressive doseescalation of exenatide (exendin-4) in reducing dose-limiting side effects in subjects with type 2 diabetes. Diabetes Metab Res Rev 2004; 20: 411-417 Evidence class Ib

69 Fineman MS, Bicsak TA, Shen LZ et al. Effect on glycemic control of exenatide (synthetic exendin-4) additive to existing metformin and/ or sulfonylurea treatment in patients with type 2 diabetes. Diabetes Care 2003; 26: 2370-2377 Evidence class Ib

70 Fischer $S$, Hanefeld $M$, Spengler $M$ et al. European study on doseresponse relationship of acarbose as a first-line drug in non-insulindependent diabetes mellitus: efficacy and safety of low and high doses. Acta Diabetol 1998; 35: 34-40 Evidence class I b

71 Fisman EZ, Tenenbaum A, Boyko $\mathrm{V}$ et al. Oral antidiabetic treatment in patients with coronary disease: Time-related increased mortality on combined glyburide/metformin therapy over a 7.7-year followup. Clin Cardiol 2001; 24: 151-158 Evidence class III

72 Fonseca V, Grunberger G, Gupta S et al. Addition of nateglinide to rosiglitazone monotherapy suppresses mealtime hyperglycemia and improves overall glycemic control. Diab Care 2003; 26: 1685-1690 Evidence class Ib

73 Fonseca V, Rosenstock J, Patwardhan $R$ et al. Effect of metformin and rosiglitazone combination therapy in patients with type 2 diabetes mellitus: a randomized controlled trial. JAMA 2000; 283: 1695-1702 Evidence class Ib

74 Fonseca V, Schweizer A, Albrecht D et al. Addition of vildagliptin to insulin improves glycaemic control in type 2 diabetes. Diabetologia 2007; 50: 1148-1155 Evidence class Ib

75 Freed MI, Ratner R, Marcovina SM et al. Effects of rosiglitazone alone and in combination with atorvastatin on the metabolic abnormalities in type 2 diabetes mellitus. Am J Cardiol 2002; 90: 947-952 Evidence class Ib

76 Fritsche A, Schmülling RM, Häring HU et al. Intensive insulin therapy combined with metformin in obese type 2 diabetic patients. Acta Diabetol 2000; 37: 13-18 Evidence class IIa

77 Fritsche A, Schweitzer MA, Häring HU et al., 4001 Study Group. Glimepiride combined with morning insulin glargine bedtime neutral protamine hagedorn insulin, or bedtime insulin glargine in patients with type 2 diabetes. A randomized, controlled trial: Ann Intern Med 2003; 138: 952-959 Evidence class Ib

78 Gaede $P$, Vedel $P$, Larsen $N$ et al. Multifactorial intervention and cardiovascular disease in patients with type 2 diabetes. $\mathrm{N}$ Engl J Med 2003; 348: 383-393 Evidence class Ib

79 Gaede $P$, Andersen HL, Parving $H H$ et al. Effect of a Multifactorial intervention on Mortality in Type Diabetes. N Engl J Med 2008; 358: 580-591 Evidence class Ib

80 Gallwitz B. Sitagliptin: Profile of a novel DPP-4 inhibitor for the treatment of type 2 diabetes. Drugs Today (Barc) 2007; 43: 13-25 Evidence class IV
81 Garber A, Duncan T, Goodman A et al. Efficacy of metformin in typeII diabetes: results of a double-blind, placebo-controlled, doseresponse trial. Am J Med 1997; 102: 491-497 Evidence class IIa

82 Garber A, Klein E, Bruce S et al. Metformin-glibenclamide versus metformin plus rosiglitazone in patients with type 2 diabetes inadequately controlled on metformin monotherapy. Diab Obes Metab 2006; 8: 156-163 Evidence class Ib

83 Garber AJ, Schweizer A, Baron MA et al. Vildagliptin in combination with pioglitazone improves glycaemic control in patients with type 2 diabetes failing thiazolidinedione monotherapy: a randomized, placebo-controlled study. Diabetes Obes Metab 2007; 9: 166-174 Evidence class Ib

84 Garratt KN, Brady PA, Hassinger NL et al. Sulfonylurea drugs increase early mortality in patients with diabetes mellitus after direct angioplasty for acute myocardial infarction. J Am Coll Cardiol 1999; 33: 119-124 Evidence class III

85 Gin H, Freyburger C, Boisseau M et al. Effect of metformin on platelet hyperaggregation in the insulin-dependent diabetic. Diabete Metab 1988; 14: 596-600 Evidence class IIa

86 Goldberg $R B$, Einhorn D, Lucas $C P$ et al. A randomized placebocontrolled trial of repaglinide in the treatment of type 2 diabetes. Diabetes Care 1998; 21: 1897-1903 Evidence class Ib

87 Goldberg RB, Kendall DM, Deeg MA et al. A comparison of lipid and glycemic effects of pioglitazone and rosiglitazone in patients with type 2 diabetes and dyslipidemia. Diabetes Care 2005; 28: 1547-1554 Evidence class Ib

88 Goldstein DE, Little RR, Lorenz RA et al. Tests of glycemia in diabetes. Diabetes Care 2004; 27: 1761-1773 Evidence class IV

89 Goudswaard AN, Furlong NJ, Rutten GE et al. Insulin monotherapy versus combinations of insulin with oral hypoglycaemic agents in patients with type 2 diabetes mellitus. Cochrane Database Syst Rev 2004; 18: SD003418 Evidence class Ia

90 Gulliford $M$, Latinovic $R$. Mortality in type 2 diabetic subjects prescribed metformin and sulfonylurea drugs in combination: cohort study. Diabetes Metab Res Rev 2004; 20: 239-245 Evidence class III

91 Haak T, Tiengo A, Draeger E et al. Lower within-subject variability of fasting blood glucose and reduced weight gain with insulin detemir compared to NPH insulin in patients with type 2 diabetes. Diabetes Obes Metab 2005; 7: 56-64 Evidence class Ib

92 Haffner S, Temprosa M, Crandall J et al. Intensive lifestyle intervention or metformin on inflammation and coagulation in participants with impaired glucose tolerance. Diabetes 2005; 54: 1566-1572 Evidence class Ib

93 Hamann A, Garcia-Puig J, Paul G et al. Comparison of fixed-dose rosiglitazone/metformin combination therapy with sulphonylurea plus metformin in overweight individuals with type 2 diabetes inadequately controlled on metformin alone. Exp Clin Endocrinol Diabetes 2008; 116: 6-13 Evidence class Ib

94 Hamelbeck $H$, Klein W, Zoltobrocki $M$ et al. Glibenclamide-insulin combination in management of secondary failure of sulfonyl-urea medication. Dtsch Med Wochenschr 1982; 107: 1581-1583 Evidence class IV

95 Hanefeld $M$, Brunetti P, Schernthaner GH et al. One-year glycemic control with a sulfonylurea plus pioglitazone versus a sulfonylurea plus metformin in patients with type 2 diabetes. Diab Care 2004; 27: 141-147 Evidence class Ib

96 Hanefeld M, Pfützner A, Forst T et al. Glycemic control and treatment failure with pioglitazone versus glibenclamide in type 2 diabetes mellitus: a 42-month, open-label, observational, primary care study. Curr Med Res Op 2006; 22: 1211-1215 Evidence class IIa

97 Hanefeld M, Göke B. Combining pioglitazone with sulphonylurea or metformin in the management of type 2 diabetes. Exp Clin Endocrinol Diabetes 2000a; 108 (Suppl 2): 256-266 Evidence class IV

98 Hanefeld M, Bouter KP, Dickinson S et al. Rapid and short-acting mealtime insulin secretion with nateglinide controls both prandial and mean glycemia. Diabetes Care 2000b; 23: 202-207 Evidence class $\mathrm{Ib}$

99 Hasche $H$, Mertes $G$, Bruns $C$ et al. Effects of acarbose treatment in type-2 diabetic patients under dietary training. A multicentre, double blind, place-controlled 2-year study. Diab Nutr Metab 1999; 12 : 277-285 Evidence class Ib

100 Heine RJ, Van Gaal LF, Johns D et al. Exenatide versus insulin glargine in patients with suboptimally controlled type 2 diabetes: a randomized trial. Ann Intern Med 2005; 143: 559-569 Evidence class Ib 
101 Hermann BL, Schatz H, Pfeiffer A. Kontinuierliche Blutglucosemessung. Der AkuteffECt von Acarbose auf die Blutglucoseschwankungen. Med Klin 1998; 93: 651-655 Evidence class IIb

102 Hermann LS, Schersten B, Bitzen PO et al. Therapeutic comparison of metformin and sulfonylurea, alone and in various combinations $\mathrm{A}$ double-blind controlled study. Diabetes Care 1994; 17: 1100-1109 Evidence class Ia

103 Hermansen K, Davies M, Derezinski T et al. A 26-week, randomized, parallel, treat-to-target trial comparing insulin detemir with NPH insulin as add-on therapy to oral glucose-lowering drugs in insulinnaïve people with type 2 diabetes. Diabetes Care 2006; 29: 12691274 Evidence class Ib

104 Hermansen K, Kipnes M, Luo E et al., Sitagliptin Study 035 Group. Efficacy and safety of the dipeptidyl peptidase- 4 inhibitor, sitagliptin, in patients with type 2 diabetes mellitus inadequately controlled on glimepiride alone or on glimepiride and metformin. Diabetes Obes Metab 2007; 9: 733-745 Evidence class Ib

105 Hoffmann J, Spengler M. Efficacy of 24-week monotherapy with acarbose, glibenclamide or placebo in NIDDM patients. Diabetes Care 1994; 17: 561-566 Evidence class Ib

106 Holman RR, Cull CA, Turner RC. A randomised double-blind trial of Acarbose in type-2 diabetes shows improved glycemic control over 3 years (UKPD Study 44). Diabetes Care 1999; 22: 960-964 Evidence class Ib

107 Holman RR, Thorne KI, Farmer AJ et al. Addition of biphasic, prandial, or basal insulin to oral therapy in type 2 diabetes. N Engl J Med 2007; 357: 1716-1730 Evidence class Ib

108 Holman RR, Paul SK, Bethel MA et al. 10-year follow-up of intensive glucose control in type 2 diabetes. N Engl J Med 2008; 359: 1 10.1056/NEJMoa0806470. Evidence class Ib

109 Holstein A, Plaschke A, Egberts E-H. Lower incidence of severe hypoglycaemia in patients with type 2 diabetes treated with glimepiride versus glibenclamide. Diabetes Metab Res Rev 2001; 17: 467-473 Evidence class III

110 Home PD, Pocock SJ, Beck-Nielsen $\mathrm{H}$ et al. Rosiglitazone evaluated for cardiovascular outcomes - an interim analysis. N Engl J Med 2007; 357: 1 doi 10.1056/NEJMoa073394. Evidence class Ib

111 Horton ES, Clinkingbeard C, Gatlin M et al. Nateglinide alone and in combination with metformin improves glycemic control by reducing mealtime glucose levels in type 2 diabetes. Diabetes Care 2000; 23 : 1660-1665 Evidence class Ib

112 Horvath $K$, Jeitler $K$, Berghold A et al. Long-acting insulin analogues versus NPH insulin (human isophane insulin) for type 2 diabetes mellitus (Review). Cochrane Database of systematic Review 2007, Issue 2, Art. No. CD005613. D01:10, 1002/14651858, CD005613. pub3

113 Huizar JF, Gonzalez LA, Alderman J et al. Sulfonylureas attenuate electrocardiographic ST-segment elevation during acute myocardial infarction in diabetics. J Am Coll Cardiol 2003; 42: 1017-1021

114 Jain SK, Nagi DK, Slavin BM et al. Insulin therapy in type 2 diabetic subjects suppresses plasminogen activator inhibitor (PAI-1) activity and proinsulin-like molecules independently of glycemic control. Diabet Med 1993; 10: 27-32 Evidence class Ib

115 Jansen JP. Self-moitoring of glucose in type 2 diabetes mellitus: a Bayesian meta-analysis of direct and indirect comparisons. Curr Med Res Opin 2006; 22: 671-681 Evidence class Ia

116 Jönsson A, Rydberg T, ECberg $G$ et al. Slow elimination of glyburide in NIDDM subjects. Diabetes Care 1994; 17: 142-145 Evidence class IV

117 Jönsson A, Hallengren B, Rydberg $T$ et al. Effects of glibenclamide and its active metabolites in patients with type 2 diabetes. Diabetes Obes Metab 2001; 3: 403-409 Evidence class IV

118 Johnson JA, Majumdar SR, Simpson SH et al. Decreased mortality associated with the use of metformin compared with sulfonylurea monotherapy in type 2 diabetes. Diabetes Care 2002; 25: 2244-2248 Evidence class III

119 Johnson JA, Simpson SH, Toth EL et al. Reduced cardiovascular morbidity and mortality associated with metformin use in subjects with Type 2 diabetes. Diabet Med 2005; 22: 497-502 Evidence class III

120 Johnston $P$, Sheu WH, Hollenbeck CB et al. Effect of metformin on carbohydrate and lipoprotein metabolism in NIDDM patients. Diabetes Care 1990; 13: 1-8 Evidence class Ila

121 Johnston PS, Coniff RF, Hoogwerf BJ et al. Effects of the carbohydrase inhibitor miglitol in sulfonylurea-treated NIDDM patients. Diabetes Care 1994; 17: 20-29 Evidence class Ib

122 Jovanovic L, Dailey G, Huang WC et al. Repaglinide in type 2 diabetes: a 24-week fixed dose efficacy and safety study. J Clin Pharmacol 2000; 40: 49-57 Evidence class Ib
123 Johnson JL, Wolf SL, Kabadi UM. Efficacy of insulin and sulfonylurea combination therapy in type II diabetes. A meta-analysis of the randomized placebo-controlled trials. Arch Intern Med 1996; 156: 259-264 Evidence class Ia

124 Jung HS, Youn BS, Cho YM et al. The effects of rosiglitazone an metformin on the plasma concentrations of resistin in patients with type 2 diabetes mellitus. Metabolism 2005; 54: 314-320 Evidence class Ib

125 Kado S, Murakami T, Aoki A et al. Effect of acarbose on postprandial lipid metabolism in type 2 diabetes mellitus. Diab Res and Clin Pract 1998; 41: 49-55 Evidence class IIb

126 Kahn SE, Haffner SM, Heise MA et al. Glycemic durability of rosiglitazone, metformin, or glyburide monotherapy. N Engl J Med 2006; 355: 2427-2443 Evidence class Ib

127 Kalfhaus J, Berger M. Insulin treatment with preprandial injections of regular insulin in middle-aged type 2 diabetic patients A two years observational study. Diabetes Metab 2000; 26: 197-201 Evidence class III

128 Kendall DM, Riddle MC, Rosenstock J et al. Effects of exenatide (exendin-4) on glycemic control over 30 weeks in patients with type 2 diabetes treated with metformin and a sulfonylurea. Diabetes Care 2005; 28: 1083-1091 Evidence class Ib

129 Kerenyi Z, Samer H, James $R$ et al. Combination therapy with rosiglitazone and glibenclamide compared with upward titration of glibenclamide alone in patients with type 2 diabetes mellitus. Diabet Res Clin Pract 2004; 63: 213-223 Evidence class Ib

$130 \mathrm{Kim}$ SG, Ryu OH, Kim HY et al. Effect of rosiglitazone on plasma adiponectin levels and arterial stiffness in subjects with prediabetes or non-diabetic metabolic syndrome. Europ J Endocrin 2006; 154: 433-440 Evidence class Ib

131 King AB, Armstrong DU. Lipid response to pioglitazone in diabetic patients: clinical observations from a retrospective chart review. Diabetes Technol Ther 2002; 4: 145-151 Evidence class III

132 Kipnes MS, Krosnick A, Rendell MS et al. Pioglitazone hydrochloride in combination with sulfonylurea therapy improves glycaemic control in patients with type 2 diabetes mellitus: a randomized, placebo-controlled study. Am J Med 2001; 111: 10-17 Evidence class Ib

133 Klamann A, Sarfert P, Launhardt V et al. Myocardial infarction in diabetic vs non-diabetic subjects. Survival and infarct size following therapy with sulfonylureas (glibenclamide). Eur Heart J 2000; 21: 220-229 Evidence class III

134 Klepzig H, Kober G, Matter C et al. Sulfonylureas and ischaemic preconditioning: a double-blind, placebo-controlled evaluation of glimepiride and glibenclamide. Eur Heart J 1999; 20: 439-446 Evidence class Ib

135 Koivisto VA, Tuominen JA, Ebeling P. Lispro mix25 insulin as premeal therapy in type 2 diabetic patients. Diabetes Care 1999; 22: 459-462 Evidence class IIa

136 Kolterman OG, Kim DD, Shen L et al. Pharmacokinetics, pharmacodynamics, and safety of exenatide in patients with type 2 diabetes melllitus. Am Health Syst Pharm 2005; 62: 173-181 Evidence class III

137 Kolterman OG, Buse JB, Fineman MS et al. Synthetic exendin-4 (exenatide) significantly reduces postprandial and fasting plasma glucose in subjects with type 2 diabetes. J Clin Endocrinol Metab 2003; 88: 3082-3089 Evidence class Ib

138 Lago RM, Singh PP, Nesto RW. Congestive heart failure and cardiovascular death in patients with prediabetes and type 2 diabetes giben thiazolidinediones: a metaanalysis of randomised clinical trials. Lancet 2007; 370: 1129-1136 Evidence class Ia

139 Langenfeld MR, Forst T, Hohberg C et al. Pioglitazone decreases carotid intima-media thickness independently of glycemic control in patients with type 2 diabetes mellitus. Circulation 2005; 111: 25252531 Evidence class Ib

140 Landgraf $R$. Meglitinide analogues in the treatment of type 2 diabetes mellitus. Drugs and Aging 2000; 17: 411-452 Evidence class IV

141 Landgraf R, Bilo HJ, Müller PG. A comparison of repaglinide and glibenclamide in the treatment of type 2 diabetic patients previously treated with sulphonylureas. Eur J Clin Pharmacol 1999; 55: 165171 Evidence class Ib

142 Laube H, Linn Th, Heyen P. The effect of acarbose on insulin sensitivity and proinsulin in overweight subjects with impaired glucose tolerance. Exp Clin Endocrinol Diabetes 1998; 106: 231-233 Evidence class IIa

143 Lawrence JM, Reid J, Taylor GJ et al. Favorable effects of pioglitazone and metformin compared with gliclazide on lipoprotein subfractions in overweight patients with early type 2 diabetes. Diab Care 2004; 27: 41-46 Evidence class Ib 
144 Lebovitz H, Kreider M, Freed MI. Evaluation of liver function in type 2 diabetic patients during clinical trials. Diabet Care 2002; 25: 815821 Evidence class III

145 Lebowitz HE. Alpha-glucosidase inhibitors as agents in the treatment of diabetes. Diab Res 1998; 6: 132-145 Evidence class Ia

146 Lebowitz HE. Insulin secretagogues: old and new. Diabetes Reviews 1999; 7: 139-153 Evidence class IV

147 Lee TM, Chou TM. Impairment of myocardial protection in type 2 diabetic patients. J Clin Endocrinol Metab 2003; 88: 531-537 Evidence class Ib

148 Lindsay JR, Duffy NA, McKillop AM et al. Inhibition of dipeptidyl peptidase IV activity by oral metformin in Type 2 diabetes. Diabet Med 2005; 22: 654-657

149 Linnebjerg H, Kothare PA, Skrivan ECZ et al. Exenatide: effect of injection time on postprandial glucose in patients with Type 2 diabetes. Diabet Med 2006; 23: 240-245 Evidence class Ib

150 Lotz N, Bachmann W, Ladik T et al. Combination therapy with insulin/sulfonylurea in the long-term therapy of type II diabetes following "secondary failure". Klin Wochenschr 1988; 66: 1079-1084 Evidence class IIa

151 Mäkimattila S, Nikkila K, Yki-Järvinen H. Causes of weight gain during insulin therapy with and without metformin in patients with typ II diabetes mellitus. Diabetologia 1999; 42: 406-412 Evidence class Ib

152 Malmberg K. Prospective randomised study of intensive insulin treatment on long term survival after acute myocardial infarction in patients with diabetes mellitus DIGAMI (Diabetes Mellitus Insulin Glucose Infusion in Acute Myocardial Infarction) Study Group. BM] 1997; 314: 1512-1515 Evidence class Ib

153 Malone JK, Woodworth JR, Arora $V$ et al. Improved postprandial glycemic control with Humalog Mix 75/25 after a standard test meal in patients with Type 2 diabetes mellitus. Clin Ther 2000; 22 : 222-230 Evidence class Ib

154 Marbury T, Huang W-C, Strange P et al. Repaglinide versus glyburide: a one year comparison trial. Diab Res Clin Pract 1999; 43: 155-166 Evidence class Ib

155 Mather KJ, Verma S, Anderson TJ. Improved endothelial function with metformin in type 2 diabetes mellitus. J Am Coll Cardiol 2001; 37: 1344-1350 Evidence class IIa

156 Martin S, Schneider B, Heinemann L et al. Self-monitoring of blood glucose in type 2 diabetes and long-term outcome: an epidemiological cohort study. Diabetologia 2006; 49: 271-278 Evidence class IIb

157 Marx N, Froehlich J, Siam L et al. Antidiabetic PPARgamma-Activator rosiglitazone reduces MMP-9 serum levels in type 2 diabetic patients with coronary artery disease. Aterioscler Thromb Vasc Biol 2003; 23: 283-288 Evidence class IIa

158 Matthaei S, Stumvoll M, Kellerer M et al. Pathophysiology and pharmacological treatment of insulin resistance. Endocrine Reviews 2000; 21: 585-618 Evidence class IV

159 Matthaei S, Stumvoll M, Häring HU. Neue AspECte in der Therapie des Diabetes mellitus Typ 2: Thiazolidindione (Insulinsensitizer). Deutsches Ärzteblatt 2001; 98: A912-A918 Evidence class IV

160 Matthews DR, Charbonnel BH, Hanefeld $M$ et al. Long-term therapy with addition of pioglitazone to metformin compared with the addition of gliclazide to metformin in patients with type 2 diabetes: a randomized, comparative study. Diab Metab Res Rev 2005; 21: 167-174 Evidence class Ib

161 May C. Wirksamkeit und Verträglichkeit von einschleichend dosierter Acarbose bei Patienten mit nicht-insulinpflichtigem Diabetes mellitus (Typ-2 diabetes) unter Sulfonylharnstoffen. Diab Stoffw 1995; 4: 3-8 Evidence class IIa

162 Mazzone T, Meyer PM, Feinstein SB et al. Effect of pioglitazone compared with glimepiride on carotid intima-media thickness in type 2 diabetes. JAMA 2006; 296: 2572-2581 Evidence class Ib

163 Meneilly GS, Rabasa-Lhoret R, Ryan EA et al. Effect of acarbose on insulin sensitivity in elderly patients with diabetes. Diabetes Care 2000; 23: 1162-1167 Evidence class Ib

164 Mentlein R. Dipeptidyl-peptidase IV (CD26) - role in the inactivation of regulatory peptides. Regul Pept 1999; 30: 9-24 Evidence class IV

165 Meyer M, Chudziak F, Schwanstecher C et al. Structural requirements of sulphonylureas and analogues for interaction with sulphonylurea receptor subtypes. Br J Pharmacol 1999; 128: 27-34 Evidence class IV

166 Monami M, Luzzi C, Lamanna C et al. Three-year mortality in diabetic patients treated with different combinations of insulin secretagogues and metformin. Diabetes Metab Res Rev 2006; 22: 477-482 Evidence class III
167 Moses $R$, Slobudniuk $R$, Boyages $S$ et al. Effect of repaglinide addition to metformin monotherapy on glycaemic control in patients with type 2 diabetes. Diabetes Care 1999; 22: 119-124 Evidence class $\mathrm{Ib}$

168 Moses RG, Gomis R, Brown Frandsen $K$ et al. Flexible meal-related dosing with repaglinide facilitates glycemic control in therapy-naive type 2 diabetes. Diabetes Care 2001; 24: 11-15 Evidence class Ib

169 Mullins $P$, Sharplin P, Yki-Jarvinen $H$ et al. Negative binomial metaregression analysis of combined glycosylated hemoglobin and hypoglycemia outcomes across eleven Phase III and IV studies of insulin glargine compared with neutral protamine Hagedorn insulin in type 1 and type 2 diabetes mellitus. Clin Ther 2007; 29: 16071619 Evidence class Ia

170 Nagasaka S, Aiso Y, Yoshizawa K et al. Comparison of pioglitazone and metformin efficacy using homoeostasis model assessment. Diabet Med 2004; 21: 136-141 Evidence class Ib

171 Nagi D, Yudkin J. Effects of metformin on insulin resistance, risk factors for cardiovascular disease, and plasminogen activator inhibitor in NIDDM subjects: a study of two ethnic groups. Diabetes Care 1993; 16: 621-629 Evidence class IIa

172 Natali A, Baldeweg S, Toschi E et al. Vascular effects of improving metabolic control with metformin or rosiglitazone in type 2 diabetes. Diab Care 2004; 27: 1349-1357 Evidence class Ib

173 Natali A, Ferrannini E. Effects of metformin and thiazolidinediones on suppression of hepatic glucose production and stimulation of glucose uptake in type 2 diabetes: a systematic review. Diabetologia 2006; 49: 434-441 Evidence class Ib

174 Nathan DM. Some answers, more controversy, from UKPDS. Lancet 1998; 352: 832-833 Evidence class IV

175 Nathan DM, Buse JB, Davidson MB et al. Management of hyperglycemia in Type 2 Diabetes: A consensus algorithm for the initiation and adjustment of therapy. A consensus statement from the American Diabetes Association and the European Association for the Study of Diabetes. Diabetes Care 2006; 29: 1963-1972 Evidence class IV

176 Nauck MA, Duran S, Kim D et al. A comparison of twice-daily exenatide and biphasic insulin aspart in patients with type 2 diabetes who were suboptimally controlled with sulfonylurea and metformin: a non-inferiority study. Diabetologia 2007a; 50: 259-267 Evidence class Ib

177 Nauck MA, Meininger G, Sheng D et al., Sitagliptin Study 024 Group. Efficacy and safety of the dipeptidyl peptidase-4 inhibitor, sitagliptin, compared with the sulfonylurea, glipizide, in patients with type 2 diabetes inadequately controlled on metformin alone: a randomized, double-blind, non-inferiority trial. Diabetes Obes Metab 2007b; 9: 194-205 Evidence class Ib

178 Nelson P, Poon T, Guan X et al. The incretin mimetic exenatide as a monotherapy in patients with type 2 diabetes. Diabetes Technol Ther 2007; 9: 317-326 Evidence class Ib

179 Nissen SE, Wolski K. Effect of rosiglitazone on the risk of myocardial infarction and death from cardiovascular causes. N Engl J Med 2007; 356: 2457-2471 Evidence class Ia

180 Nonaka K, Kakikawa T, Sato A et al. Twelve-week efficacy and tolerability of sitaglipitin, a dipeptidyl peptidase-IV inhibitor, in Japanese patients with T2DM. Diabetes 2006; 55: A129 Evidence class Ib

181 Nonaka K, Kakikawa T, Sato A et al. Efficacy and safety of sitagliptin monotherapy in Japanese patients with type 2 diabetes. Diabetes Res Clin Pract. 2008; 79: 291-298 Evidence class Ib

182 Ohkubo Y, Kishikawa H, Araki E et al. Intensive insulin therapy prevents the progression of diabetic microvascular complications in Japanese patients with non-insulin-dependent diabetes mellitus: A randomized prospective 6-year study. Diabetes Res Clin Pract 1995; 28: 103-117 Evidence class Ib

183 Ong CR, Molyneaux LM, Constantino MI et al. Long-term efficacy of metformin therapy in nonobese individuals with type 2 diabetes. Diabetes Care 2006; 29: 2361-2364 Evidence class III

184 Övünç K. Effects of glibenclamide, a KATP channel blocker, on warmup phenomenon in type II diabetic patients with chronic stable angina pectoris. Clin Cardiol 2000; 23: 535-539 Evidence class III

185 Olsson J, Lindberg G, Gottsater $M$ et al. Increased mortality in Type II diabetic patients using sulphonylurea and metformin in combination: A population-based observational study. Diabetologia 2000; 43: 558-560 Evidence class III

186 Orbay E, Sargin $M$, Sargin $H$ et al. Addition of rosiglitazone to glimepirid and metformin combination therapy in type 2 diabetes. Endocr J 2004; 51: 521-527 Evidence class IIa

187 Osei K, O'Dorisio TM, Falko JM. Concomitant insulin and sulfonylurea therapy in patients type II diabetes. Effects on glucoregulation and lipid metabolism. Amer J Med 1984; 77: 1002-1009 Evidence class Iia 
188 Pan C, Yang W, Barona JP et al. Comparison of vildagliptin and acarbose monotherapy in patients with Type 2 diabetes: A 24-week, double-blind, randomized trial. Diabet Med 2008; 25: 435-441 Evidence class Ib

189 Panten U, Schwanstecher M, Schwanstecher C. Sulfonylurea receptors and mechanism of sulfonylurea action. Exp Clin Endocrinol Diabetes 1996; 104: 1-9 Evidence class IV

190 Parulkar AA, Pendergrass ML, Granda-Ayala R et al. Nonhypoglycemic effects of thiazolidindiones. Ann Inter Med 2001; 134: 61-71 Evidence class IV

191 Pavo I, Jermendy G, Varkonyi TT et al. Effect of pioglitazone compared with metformin on glycemic control and indicators of insulin sensitivity in recently diagnosed patients with type 2 diabetes. J Clin Endocrinol Metab 2003; 88: 1637-1645 Evidence class Ib

192 Perriello G, Misericordia P, Volpi E et al. Acute antihyperglycemic mechanisms of metformin in NIDDM. Evidence for suppression of lipid oxidation and hepatic glucose production. Diabetes 1994; 43: 920-928 Evidence class IIa

193 Pfützner A, Schöndorf T, Seidel D et al. Impact of rosiglitazone on beta-cell function, insulin resistance, and adiponectin concentrations: results from a double-blind oral combination study with glimepiride. Metab Clin Exp 2006; 55: 20-25 Evidence class Ib

194 Pfützner A, Forst T. Pioglitazone: An antidiabetic drug with the potency to reduce cardiovascular mortality. Expert Opin Pharmacother 2006; 7: 463-476 Evidence class IV

195 Pistrosch F, Herbrig K, Kindel B et al. Rosiglitazone improves glomerular hyperfiltration, renal endothelial dysfunction, and microalbuminuria of incipient diabetic nephropathy in patients. Diabetes 2005; 54: 2206-2211 Evidence class Ib

196 Pi-Sunyer FX, Schweizer A, Mills D et al. Efficacy and tolerability of vildagliptin monotherapy in drug-naïve patients with type 2 diabetes. Diabetes Res Clin Pract 2007; 76: 132-138 Evidence class Ib

197 Ponssen HH, Elte JW, Lehert P et al. Combined metformin and insulin therapy for patients with type 2 diabetes mellitus. Clin Ther 2000; 22: 709-713 Evidence class Ib

198 Pontroli AE, Dino G, Capra F et al. Combined therapy with glibenclamide and ultralente insulin in lean patients with NIDDM with secondary failure of sulfonyureas Follow up at two years. Diabete Metab 1990; 16: 323-327 Evidence class III

199 Poon T, Nelson P, Shen $L$ et al. Exenatide improves glycemic control and reduces body weight in subjects with type 2 diabetes: A doseranging study. Diabetes Technol Ther 2005; 7: 67-477 Evidence class Ib

200 Prager R, Schernthaner G. Insulin receptor binding to monocytes, insulin secretion, and glucose tolerance following metformin treatment. Diabetes 1983; 32: 1083-1086 Evidence class Ib

201 Prager $R$, Schernthaner G, Graf $H$. Effect of metformin on peripheral insulin sensitivity in non insulin dependent diabetes mellitus. Diabete Metab 1986; 12: 346-350 Evidence class Iia

202 Pratley RE, Jauffret-Kamel S, Galbreath $E$ et al. Twelve-week monotherapy with the DPP-4 inhibitor vildagliptin improves glycemic control in subjects with type 2 diabetes. Horm Metab Res 2006; 38: 423-428 Evidence class Ib

203 Psaty BM, Furberg CD. Rosiglitazone and cardiovascular risk. N Engl J Med 2007; 356: 2522-2524 Evidence class IV

204 Quatraro A, Consoli G, Ceriello A et al. Combined insulin and sulfonylurea therapy in non-insulin-dependent diabetics with secondary failure to oral drugs: a one year follow-up. Diabete Metab 1986; 12: 315-318 Evidence class IIb

205 Ramachandran A, Snehalatha C, Salini J et al. Use of glimepiride and insulin sensitizers in the treatment of type 2 diabetes - a study in Indians. J Assoc Physicians India 2004; 52: 459-463 Evidence class Ib

206 Raskin P, Rendell M, Ridde MC et al. A randomized trial of rosiglitazone therapy in patients with inadequately controlled insulintreated type 2 diabetes. Diabetes Care 2001; 24: 1226-1232 Evidence class Ib

207 Raskin P, McGill J, Saad MF et al. Combination therapy for type 2 diabetes: Repaglinide plus rosiglitazone. Diab Med 2004; 21: 329335 Evidence class Ib

208 Raslova K, Bogoev M, Raz I et al. Insulin detemir and insulin aspart: A promising basal-bolus regimen for type 2 diabetes. Diabetes Res Clin Pract 2004; 66: 193-201 Evidence class Ib

209 Ratner RE, Maggs D, Nielsen LL et al. Long-term effects of exenatide therapy over 82 weeks on glycaemic control and weight in overweight metformin-treated patients with type 2 diabetes mellitus. Diabetes Obes Metab 2006; 8: 419-428 Evidence class IIb
210 Rave K, Klein O, Frick AD. Advantage of premeal-injected insulin glulisine compared with regular human insulin in subjects with type 1 diabetes. Diabetes Care 2006; 29: 1812-1817 Evidence class Ib

211 Raz I, Hanefeld M, Xu L et al., Sitagliptin Study 023 Group. Efficacy and safety of the dipeptidyl peptidase- 4 inhibitor sitagliptin as monotherapy in patients with type 2 diabetes mellitus. Diabetologia 2006; 49: 2564-2571 Evidence class Ib

212 Raz I, Chen Y, Wu M et al. Efficacy and safety of sitagliptin added to ongoing metformin therapy in patients with type 2 diabetes. Curr Med Res Opin 2008; 24: 537-550 Evidence class Ib

213 Riddle M, Hart J, Bingham P et al. Combined therapy for obese type 2 diabetes: suppertime mixed insulin with daytime sulfonylurea. Am J Med Sci 1992; 303: 151-156 Evidence class IIb

214 Riddle MC, Rosenstock J, Gerich J et al., Insulin Glargine 4002 Study Investigators. The treat-to-target trial: trandomized addition of glargine or human NPH insulin to oral therapy of type 2 diabetic patients. Diabetes Care 2003; 26: 3080-3086 Evidence class Ib

215 Ristic S, Byiers S, Foley J et al. Improved glycaemic control with dipeptidyl peptidase-4 inhibition in patients with type 2 diabetes: Vildagliptin (LAF237) dose response. Diabetes Obes Metab 2005; 7: 692-698 Evidence class Ib

216 Ristic S, Bates BC. Vildagliptin: A novel DPP-4 inhibitor with pancreatic islet enhancement activity for treatment of patients with type 2 diabetes. Drugs Today (Barc) 2006; 42: 519-531 Evidence class Ia

217 Roach $P$, Trautmann M, Anderson J. Lower incidence of nocturnal hypoglycemia with a novel protamine based formulation of insulin lispro. Diabetes 1998; 47: A92

218 Rosenfalck AM, Thorsby P, Kjems L et al. Improved postprandial glycaemic control with insulin Aspart in type 2 diabetic patients treated with insulin. Acta Diabetol 2000; 37: 41-46 Evidence class Ib

219 Rosenstock J, Brown A, Fischer J et al. Efficacy and safety of acarbose in metformin-treated patients with type 2 diabetes. Diabetes Care 1998; 21: 2050-2055 Evidence class Ib

220 Rosenstock J, Schwartz SL, Clarc Jr CM et al. Basal insulin therapy in type 2 diabetes: 28-week comparison of insulin glargine (HOE 901) and NPH insulin. Diabetes Care 2001; 24: 631-636 Evidence class Ila

221 Rosenstock J, Einhorn D, Hershon $K$ et al. Efficacy and safety of pioglitazone in type 2 diabetes: A randomised, placebo-controlled study in patients receiving stable insulin therapy. Int J Clin Pract 2002; 56: 51-257 Evidence class Ib

222 Rosenstock J, Hassman DR, Madder RD et al., Repaglinide Versus Nateglinide Comparison Study Group. Repaglinide versus nateglinide monotherapy: A randomized, multicenter study. Diabetes Care 2004; 27: 1265-1270 Evidence class Ib.

223 Rosenstock J, Dailey G, Massi-Benedetti M et al. Reduced hypoglycemia risk with insulin glargine: A meta-analysis comparing insulin glargine with human NPH insulin in type 2 diabetes. Diabetes Care 2005; 28: 950-955 Evidence class Ia

224 Rosenstock J, Goldstein BJ, Vinik AI et al. Effect of early addition of rosiglitazone to sulphonylurea therapy in older type 2 diabetes patients ( $>$ 60 years): the Rosiglitazone Early vs. SULphonylurea Titration (RESULT) study. Diab Obes Metab 2005; 7: 1-9 Evidence class Ib.

225 Rosenstock J, Sugimoto D, Strange $P$ et al. Triple therapy in type 2 diabetes. Diabetes Care 2006; 29: 554-559 Evidence class Ib

226 Rosenstock J, Brazg R, Andryuk PJ et al. Sitagliptin Study 019 Group. Efficacy and safety of the dipeptidyl peptidase- 4 inhibitor sitagliptin added to ongoing pioglitazone therapy in patients with type 2 diabetes: A 24-week, multicenter, randomized, double-blind, placebocontrolled, parallel-group study. Clin Ther 2006; 28: 1556-1568 Evidence class Ib

227 Rosenstock J, Baron MA, Dejager S et al. Comparison of vildagliptin and rosiglitazone monotherapy in patients with type 2 diabetes: A 24-week, double-blind, randomized trial. Diabetes Care 2007a; 30: 217-223 Evidence class Ib

228 Rosenstock J, Baron MA, Camisasca RP et al. Efficacy and tolerability of initial combination therapy with vildagliptin and pioglitazone compared with component monotherapy in patients with type 2 diabetes. Diabetes Obes Metab 2007b; 9: 175-185 Evidence class Ib

229 Rosenstock J, Davies M, Home PD et al. A randomised, 52-week, treatto-target trial comparing insulin detemir with insulin glargine when administered as add-on to glucose-lowering drugs in insulin-naive people with type 2 diabetes. Diabetologia 2008; 51: 408-416 Evidence class Ib

230 Rosenstock R, Fonseca V, McGill J et al. Similar Progression of Diabetic Retinopathy with Glargine or NPH Insulin in Type 2 Diabetes. Diabetes 2008; 57 (Suppl 1): A86 301 OR. Evidence class Ib 
231 Saenz A, Fernandez-Esteban I, Mataix A et al. Metformin monotherapy for type 2 diabetes mellitus. Cochrane Database Syst Rev. 2005; 20: CD002966 Review. Evidence class Ia

232 Salpeter S, Greyber E, Pasternak G et al. Risk of fatal and nonfatal lactic acidosis with metformin use in type 2 diabetes mellitus. Cochrane Database Syst Rev 2006; 25: CD002967 Evidence class Ia

233 Sarol JN, Nicodemus NA, Tan KM et al. Self-monitoring of blood glucose as part of a multicomponent therapy among non-insulin requiring type 2 diabetes patients: Ameta-analysis (1966-2004). Curr Med Res Pin 2005; 21: 173-184 Evidence class Ia

234 Schatz H, Massi-Benedetti M. Pioglitazone: From Discovery to Clinical Practice. Exp Clin Endocrinol Diabetes 2000; 108 (Suppl 2): 221-274 Evidence class IV

235 Schernthaner G, Matthews DR, Charvonnel B et al. Efficacy and safety of pioglitazone versus metformin in patients with type 2 diabetes mellitus: A double-blind, randomized trial. J Clin Endocrinol Metab 2004; 89: 6068-6076 Evidence class Ib

236 Schernthaner $G$. Is dyslipidaemia important if we control glycaemia? Atherosclerosis Supplementum 6; 2005: 3-10 Evidence class IV

237 Schernthaner G, Schernthaner GH. Metformin - from Devil to Angel In: Pharmacotherapy of Diabetes Mellitus Ed. Mogensen CEM, Spinger New York; 2007, (in press). Evidence class IV

238 Schneider J. An overview of the safety and tolerance of glimepiride. Horm Metab Res 1996; 28: 413-418 Evidence class IV

239 Schwartz S, Raskin P, Fonseca V et al. Effect of troglitazone in insulintreated patients with type II diabetes mellitus. Troglitazone and exogenous insulin study group. N Engl J Med 1998; 338: 861-866 Evidence class Ib

240 Schweizer A, Couturier A, Foley JE et al. Comparison between vildagliptin and metformin to sustain reductions in HbA1c over 1 year in drug-naïve patients with Type 2 diabetes. Diabet Med 2007; 24 : 955-961 Evidence class Ib

241 Scott $R, W u$ M, Sanchez $M$ et al. Efficacy and tolerability of the dipeptidyl peptidase- 4 inhibitor sitagliptin as monotherapy over 12 weeks in patients with type 2 diabetes. Int J Clin Pract 2007; 61: 171-180 Evidence class Ib

242 Seigler DF, Olsson GM, Skyler JS. Morning versus bedtime isophane insulin in type 2 (non-insulin-dependent) diabetes mellitus. Diabet Med 1992; 9: 826-833 Evidence class IIa

243 Shichiri M, Kishikawa H, Ohkubo $Y$ et al. Long-term results of the Kumamoto Study on optimal diabetes control in type 2 diabetic patients. Diabetes Care 2000; 23 (Suppl 2): B21-B29 Evidence class Ib

244 Simpson SH, Majumdar SR, Tsuyuki RT et al. Dose-response relation between sulfonylurea drugs and mortality in type 2 diabetes mellitus: A population-based cohort study. CMAJ. 2000; 174: 169-174 Evidence class III

245 Singh S, Loke YK, Furberg CD. Long-term risk of cardiovascular events with rosiglitazone: A metaanalysis. JAMA 2007; 298: 1189-1195 Evidence class Ia

246 Smith SA et al. Rosiglitazone, but not glyburide, reduces circulating proinsulin and the proinsulin: Insulin ration in type 2 diabetes. J Clin Endocrinol Metab 2004; 89: 6048-6053 Evidence class Ib.

247 Stenman S, Groop PH, Saloranta C et al. Effects of the combination of insulin and glibencamide in type 2 (non-insulin-dependent) diabetic patients with secondary failure to oral hypoglycaemic agents. Diabetologia 1988; 31: 206-213 Evidence class Iia

248 Stettler C, Allemann S, Jüni P et al. Glycemic control and macrovascular disease in types 1 and 2 diabetes mellitus: Meta-analysis of randomized trials. Am Heart J 2006; 152: 27-38 Evidence class Ia.

249 Stocker DJ, Taylor AJ, Langley RW et al. A randomized trial of the effects of rosiglitazone and metformin on inflammation and subclinical atherosclerosis in patients with type 2 diabetes. Am Heart J 2007; 153: 445 e1-6 Evidence class Ib

250 St. John-Sutton $M$, Rendell $M$, Dandona $P$ et al. A comparison of the effects of rosiglitazone and glyburide on cardiovascular function and glycemic control in patients with type 2 diabetes. Diabetes Care 2002; 25: 2058-2064 Evidence class Ib

251 Tan M, Johns D, Gonzalez Galvez G et al. Effects of pioglitazone and glimepiride on glycemic control and insulin sensitivity in Mexican patients with type 2 diabetes mellitus: a multicenter, randomized, double-blind, parallel group trial. Clin Ther 2004; 26: 680-693 Evidence class Ib

252 Tan MH, Johns D, Strand J et al. Sustained effects of pioglitazone vs glibenclamide on insulin sensitivity, glycaemic control, and lipid profiles in patients with type 2 diabetes. Diabet Med 2004; 21 : 859-866 Evidence class Ib
253 Tan MH, Baksi A, Krahulec B et al. Comparison of pioglitazone and gliclazide in sustaining glycemic control over 2 years in patients with type 2 diabetes. Diab Care 2005; 28: 544-550 Evidence class Ib

254 Tanaka $Y$, Uchino H, Shimuzu T et al. Effect of metformin on advanced glycation endproduct formation and peripheral nerve function in streptozotocin-induced diabetic rats. Eur J Pharmacol 1999; 376: 17-22

255 The Action to Control Cardiovascular Risk in Diabetes Study Group Effect of Intensive Glucose Lowering in Type 2 Diabetes. N Eng J Med 2008; 358: 2545-2559 Evidence class Ib

256 The ADVANCE Collaborative Group. Intensive Blood Glucose Control and Vascular Outcomes in Patients with Type 2 Diabetes. N Eng J Med 2008; 358: 2560-2572 Evidence class 1b

257 The Diabetes Control and Complications Trial Research Group. The effects of intensive treatment of diabetes on the development and progression of long-term complications in insulin-dependent diabetes mellitus. N Engl J Med 1993; 329: 977-986 Evidence class Ib

258 Tiikainen M, Häkkinen AM, Korsheninnikova E et al. Effects of rosiglitazone and metformin on liver fat content, hepatic insulin resistance, insulin clearance, and gene expression in adipose tissue in patients with type 2 diabetes. Diabetes 2004; 53: 2169-2176 Evidence class Ib

259 Tschritter O, Fritsche A, Gallwitz B et al. Langwirkende Insulinanaloga in der Therapie des Diabetes mellitus. Typ 1 und Typ 2 Diabetes und Stoffwechsel 2005; 6: 375-382 Evidence class Ia

260 UK Prospective Diabetes Study (UKPDS) Group. Intensive blood-glucose control with sulfonylureas or insulin compared with conventional treatment and risk of complications in patients with type-2 diabetes. (UKPDS 33). Lancet 1998; 352: 837-853 Evidence class Ib

261 UKPDS Group. Effect of intensive blood-glucose control with metformin on complications in overweight patients with type 2 diabetes (UKPDS 34). Lancet 1998; 352: 854-865 Evidence class Ib

262 Umpierrez G, Issa M, Vlajnic A. Glimepiride versus pioglitazone combination therapy in subjects with type 2 diabetes inadequately controlled on metformin monotherapy: results of a randomized clinical trial. Curr Med Res Opin 2006; 22: 751-759 Evidence class Ib

263 Vague PH, Juhan-Vague I, Alessi MC et al. Metformin decreases the high plasminogen activator inhibition capacity, plasma insulin, and triglyceride levels in non-diabetic obese subjects. Thromb Haemost 1987; 57: 326-328 Evidence class IIa

264 Van Wijk JPH, de Koning EJP, Castro Carbezas $M$ et al. Rosiglitazone improves postprandial triglyzeride and free fatty acid metabolism in type 2 diabetes. Diabetes Care 2005; 28: 844-849 Evidence class Ib

265 Viswanathan $P$, Chaudhuri A, Bhatia $R$ et al. Exenatide therapy in obese patients with type 2 diabetes mellitus treated with insulin. Endocr Pract 2007; 13: 444-450 Evidence class IIb

266 Wagstaff AJ, Goa KL. Rosiglitazone - a review of its use in the management of type 2 diabetes mellitus. Drugs 2002; 62: 1805-1837 Evidence class IV

267 Wan Mohamad WB, Tun Fizi A, Ismail RB et al. Efficacy and safety of single versus multiple daily doses of glibenclamide in type 2 diabetes mellitus. Diabetes Res Clin Pract 2000; 49: 93-99 Evidence class III

268 Watanabe I, Tani S, Anazawa T et al. Effect of pioglitazone on arterosclerosis in comparison with that of glibenclamide. Diabetes Res Clin Pract 2005; 68: 104-110 Evidence class Ib

269 Welschen LM, Bloemendal E, Nijpels G et al. Self-monitoring of blood glucose in patients with type 2 diabetes who are not using insulin: A Systematic review. Diabetes Care 2005; 28: 1510-1517 Evidence class Ia

270 Widen E, Erikson J, Groop L. Metformin normalizes nonoxidative glucose metabolism in insulin-resistant normoglycemic first degree relatives of patients with NIDDM. Diabetes 1992; 41: 354-358 Evidence class IIa

271 Willms B, Ruge D. Comparison of acarbose and metformin in patients with type-2 diabetes mellitus insufficiently controlled with diet and sulfonylureas: A randomized, placebo-controlled study. Diabetic Medicine 1999; 16: 755-761 Evidence class Ib

272 Wolfenbuttel BH, Sels JP, Huijberts MS. Rosiglitazone. Expert Opin Pharmacother 2001; 2: 467-478 Evidence class IV

273 Wright A, Burden ACF, Paisey RB et al. Sulfonylurea inadequacy Efficacy of addition of insulin over 6 years in patients with type 2 diabetes in the UK Prospective Diabetes Study (UKPDS 57). Diabetes Care 2002; 25: 330-336 Evidence class Ib

274 Yang WS, Jeng CY, Wu TJ et al. Synthetic peroxisome proliferatoractivated receptor- $\gamma$ agonist, rosiglitazone, increases plasma levels of adiponectin in type 2 diabetic patients. Diab Care 2002; 25: 376-380 Evidence class Ib

275 Yanagawa T, Araki A, Sasamoto K et al. Effect of antidiabetic medications on microalbuminuria in patients with type 2 diabetes. Metabolism 2004; 53: 353-357 Evidence class Ib 
276 Yki-Järvinen H, Kauppila M, Kujansuu E et al. Comparison of insulin regimens in patients with non-insulin-dependent diabetes mellitus. N Engl J Med 1992; 327: 1426-1433 Evidence class Ib

277 Yki-Järvinen H, Rysy L, Nikkiä K et al. Comparison of bedtime insulin regimens in patients with type 2 diabetes mellitus. Ann Intern Med 1999; 130: 389-396 Evidence class Ib

278 Yki-Järvinen H, Dressler A, Ziemen M et al., HOE 901/3002 Study Group. Less nocturnal hypoglycemia and better post-dinner glucose control with bedtime insulin glargine compared with bedtime NPH insulin during insulin combination therapy in type 2 diabetes. HOE 901/3002 Study Group. Diabetes Care 2000; 23: 1130-1136 Evidence class Ib

279 Yki-Järvinen H. Combination therapies with insulin in type 2 diabetes. Diabetes Care 2001; 24: 758-767 Evidence class IV

280 Yki-Järvinen H, Kauppinen-Mäkelin R, Tiikkainen $M$ et al. Insulin glargine or NPH combined with metformin in type 2 diabetes: The LANMET study. Diabetologia 2006; 49: 442-451 Evidence class Ib

281 Yki-Järvinen H. Thiazolidinediones. N Engl J Med 2004; 351: 11061118 Evidence class IV
282 Yki-Järvinen $H$, Juurinen L, Alvarsson $M$ et al. Initiate Insulin by Aggressive Titration and Education (INITIATE): A randomized study to compare initiation of insulin combination therapy in type 2 diabetic patients individually and in groups. Diabetes Care 2007; 30: 1364-1369 Evidence class IV

283 Yosefy C, Magen E, Kiselevich A et al. Rosiglitazone improves, while glibenclamide worsens blood pressure control in treated hypertensive diabetic and dyslipidemic subjects via modulation of insulin resistance and sympathetic activity. J Cardiovasc Pharmacol 2004; 44: 215-222 Evidence class Ib

284 Zhu XX, Pan CY, Li GW et al. Addition of rosiglitazone to existing sulfonylurea treatment in Chinese patients with type 2 diabetes and exposure to hepatitis B or C. Diab Tech Ther 2003; 5: 33-42 Evidence class Ib.

285 Zinman B, Hoogwerf BJ, Duran Garcia $S$ et al. The effect of adding exenatide to a thiazolidinedione in suboptimally controlled type 2 diabetes: A randomized trial. Ann Intern Med 2007; 146: 477-485 Evidence class Ib 


\section{Appendix 1}

$\nabla$

Statement by the DDG regarding the results of the ACCORD and ADVANCE studies

\subsection{Introduction}

The effect of near normoglycaemic metabolic control on the reduction of microvascular complications (e.g. nephropathy, retinopathy) in patients with type 2 diabetes is well documented [286, 287].

On the other hand, the number of studies on the effect of near normoglycaemic metabolic control on macrovascular complications (e.g. myocardial infarction, stroke) is comparatively less extensive and is essentially based on the results of the UKPDS, which after 10 years revealed a clear downward trend in myocardial infarctions, which however did not quite reach the level of significance ( $p=0.052$ [286]). On the other hand a non-significant rise in strokes, by $11 \%$ in relative terms, was observed in the intensified arm of blood glucose reduction. The 10-year followup review of the results of the UKPDS are will be presented at this year's EASD Congress.

In this context, the results of two large studies that examined the effect of close to normal glucose metabolism control on macrovascular (ACCORD) and macro- and microvascular (ADVANCE) complications were presented at this year's Congress of the American Diabetes Association (6.-10.6.). Both studies were published in the New England Journal of Medicine to coincide with the presentation $[288,289]$.

\subsection{Design and results of the ACCORD study}

The Action to Control Cardiovascular Risk in Diabetes (ACCORD) study examined the effect of intensifying control of blood glucose, blood pressure and lipids on macrovascular complications compared with standard therapy. The results of the blood pressure and lipid therapy are expected to be published in 2010. The increased rate of mortality in the group receiving intensified antihyperglycaemic therapy caused this therapy arm of the study to be discontinued prematurely in February 2008, after 3.5 years, and the results thereof were published in June 2008 [288].

A total of 10,251 patients were recruited at 77 centres in the USA and Canada. In the group receiving intensified treatment the HbA1c target value was $<6.0 \%$, in the group receiving standard therapy the target $\mathrm{HbA1c}$ value was in a range from $7.0-7.9 \%$.

All approved substances with antihyperglycaemic effects (OADs, exenatde, insulin) could be used to achieve these targets, even combination therapies were unrestricted, in terms of either the number or type of substances used.

\section{Definition of the primary endpoint:}

- Non-fatal myocardial infarction,

- Non-fatal stroke,

- Death from cardiovascular causes. 


\subsubsection{Results of the ACCORD study (Table 1)}

\section{Parameter}

$\operatorname{HbA1c}(\%)$

Antihyperglycaemic therapy used

combination therapies for patients w/o

insulin (no. of substance groups*)

1 or 2 (n pat. (\%))

3 (n pat.(\%))

4 or 5 (n pat.(\%))

combination therapies for patients with

insulin (no. of substance groups *)

0 (n pat. $(\%))$

1 or 2 (n pat. (\%))

3 (n pat.(\%))

4 or 5 (n pat.(\%))

Side effects (selection)

severe hypoglycaemia requiring external

assistance (n pat.(\%))

severe hypoglycaemia requiring assistance

from medical staff (n pat.(\%))

Parameter

weight gain (kg)

weight gain $>10 \mathrm{~kg}$ (n pat.(\%))

Primary and secondary endpoints

primary endpoint (n pat. (\%))

all-cause mortality (n pat. (\%))

cardiovascular death (n pat. (\%))

non-fatal myocardial infarction (n pat. (\%))

non-fatal stroke (n pat. (\%))

heart failure (fatal / non-fatal) (n pat. (\%))

* the following substance groups were defined:

Metformin

Secretogogues (sulphonylureas, glinides)

Thiazolidindione (preferably rosiglitazone)

Alpha-glucosidase inhibitors

Incretins (exenatide, sitagliptin)

\section{Intensified $(n=5128)$ (at end of study)}

6.4

Standard ( $n=5123)$
(at end of study)

Relative riskreduction (\%)

7.5

$<0.001$
3224 (62.9)

$1681(32.8)$

$109(2.1)$

$892(17.4$

$2375(46.4)$

$834(16.3)$

$64(1.2)$

$526(10.3)$

$830(16.2)$

$538(10.5)$

intensified $(\mathrm{n}=5,128)$

(at end of study)

3.5

$1399(27.8)$

$352(6.9)$

$257(5.0)$

$135(2.6)$

$186(1.1)$

$67(1.3)$

$152(3.0)$
$261(5.1)$

$179(3.5)$

standard ( $\mathrm{n}=5,123)$
(at end of study)

0.4

$713(14.1)$

$371(7.2)$

$203(4.0)$

94 (1.8)

235 (4.6)

$61(1.2)$

124 (2.4)
$<0.001$

$<0.001$

relative

p-value

riskreduction (\%)

$<0.001$

$<0.001$

0.16

0.04

0.02

0.004

0.74

0.17

\subsubsection{Summary}

The primary endpoint was reduced non-significantly by $10 \%$ in relative terms $(p=0.16)$. The main reason for this trend was a significant relative reduction of $24 \%(p=0.004)$ in the risk of non-fatall myocardial infarctions.

The cause(s) of the significantly increased mortality (relative increase $22 \%, \mathrm{p}=0.04$ ) is (are) currently unknown and must be investigated in subsequent analyses. It is still unclear whether

- undetected hypoglycaemia (increased sympathotonus >> arrythmias > > death) against the background of hyperglycaemias requiring external assistance experienced by $16.2 \%$ of patients (3.1 times greater than standard therapy),

- the marked weight gain in a large subgroup of the patients ( $27.8 \%$ gained $>10 \mathrm{~kg}$ over the course of the study; $>70 \%$ of the patients in the group receiving intensified treatment received insulin + thiazolidindione combination therapy),

- interferences within the polypharmacotherapy used (at the end of the study $\sim 70 \%$ of the patients who were not treated

with insulin and $\sim 60 \%$ of those who were treated with insulin were receiving combination therapy consisting of 3,4 , or 5 OADs,

- or the speed with which the HbA1c target value was achieved

might have been a factor in this respect.

\subsection{Design and results of the ADVANCE study}

The Action in Diabetes and Vascular disease: Preterax and Diamicron-MR Controlled Evaluation (ADVANCE) study examined the effect of intensifying control of blood sugar and blood pressure on macrovascular and microvascular complications in comparison with a standard therapy. The results of the intensified blood pressure therapy were published in 2007 [290]. In all, 11,140 patients were recruited at 215 centres in 20 countries (particularly in Australia, Asia, Europe, Canada).

The HbA1c target value in the group receiving intensified treatment was $<6.5 \%$, the target value for the standard treatment 
group was $7.5 \%$. In order to achieve these targets, the following procedure was established for the intensified treatment group:

- Intensification of non-pharmacological therapy options

- Escalation of therapy by attending physision on the basis of HbA1c and fasting blood sugar levels, taking into account the following recommendations:

- Escalation of the gliclazid-MR dose

- Supplementing with other OADs

- Supplementing with a long-acting insulin

- Intensified insulin therapy (multiple insulin injection therapy)

\subsubsection{Results of the ADVANCE study (Table 2)}

Parameter

$\operatorname{HbA1c}(\%)$

Antihyperglycaemic therapy used

gliclazid (n pat. (\%))

other SU (n pat. (\%))

metformin (n pat. $\%)$ )

thiazolidindione (n pat.(\%))

acarbose (n pat. (\%))

glinide (n pat. (\%))

insulin (n pat.(\%))

Side effects (selection)

severe hypoglycaemia (\%/year)

weight gain $(\mathrm{kg})$

Primary and secondary endpoints

primary endpoint (n pat. (\%))

all-cause mortality (n pat. (\%))

cardiovascular death (n pat. (\%))

non-fatal myocardial infarction (n pat. (\%))

non-fatal stroke (n pat. (\%))

heart failure (n pat. (\%))

nephropathy (recurrence or progression) (n pat (\%))

retinopathy (recurrence or progression) (n pat. (\%))
Intensified ( $\mathrm{n}=4828)$
(at end of study)

6.5

4209 (90.5)

89 (1.9)

3455 (73.8)

$788(16.8)$

$891(19.1)$

$58(1.2)$

1953 (40.5)

0.7

0.0

1009 (18.1)

$498(8.9)$

$253(4.5)$

$153(2.7)$

$214(3.8)$

$220(3.9)$

$230(4.1)$

$332(6.0)$
Definition of the primary endpoint:

- Non-fatal myocardial infarction

- Non-fatal stroke

- Death from cardiovascular causes

- Nephropathy

- Retinopathy
Standard ( $\mathrm{n}=4741)$
(at end of study)

7.3

Relative risk p-value reduction (\%)

$<0.001$

80 (1.6)

2606 (57.1)

3057 (67.0)

495 (10.9)

$576(12.6)$

127 (2.8)

1142 (24.1)

0.4

$-1.0$

$<0.05$

$<0.05$

1116 (20.0)

$533(9.6)$

$289(5.2)$

$156(2.8)$

209 (3.8)

$231(4.1)$

$292(5.2)$

$349(6.3)$ 


\subsubsection{Summary}

The primary endpoint was lowered by $10 \%$ in relative terms $(\mathrm{p}=0.01)$.

The main reason for this effect was a significant reduction in nephropathy, by $21 \%$ in relative terms $(p=0.006)$.

Overall mortality was lowered non-significantly, by $7 \%$ in relative terms $(p=0.28)$. Macrovascular events were lowered nonsignificantly, by $6 \%$ in relative terms $(p=0.32)$.
The number of severe hypoglycaemia in the group receiving intensified therapy was $0.7 \% / y e a r$, higher than in the group receiving standard therapy $(0.4 \% /$ year $)$.

The group receiving intensified therapy experienced no weight gain, the group receiving standard therapy experienced an average weight loss of $1.0 \mathrm{~kg}$.

\subsection{Comparative consideration of ACCORD and ADVANCE}

Study characteristics

Patient characteristics at start of study

number of study participants

age (in years)

duration of diabetes (in years)

HbA1c (average) (\%)

percentage with prior macrovascular diseases (\%)

Intervention data

Definition of primary endpoint

HbA1c target value (\%)
Average duration of study (in years)
Pharmacotherapy at end of study (intensified vs. standard) (\%)
insulin
metformin
secretagogues (sulphonylurea / glinide)
thiazolidinedione
incretin based therapies (exenatide, sitagliptin)
statin
any antihypertensive medication
ACE inhibitors
aspirin
Results (intensified vs. standard)
HbA1c (average at end of study (\%))
mortality
all-cause
cardiovascular (\%)
non-fatal myocardial infarction (\%)
non-fatal stroke (\%)
severe hypoglycaemia requiring external assistance (ACCORD), or
severe hypoglycaemia (ADVANCE) (\%/year)
weight gain (kg)
nicotine abuse (\%)

$\begin{array}{ll}\text { ACCORD } & \text { ADVANCE } \\ & \\ 10,251 & 11,140 \\ 62 & 66 \\ 10 & 8 \\ 8.3 & 7.3 \\ 35 & 32\end{array}$

non-fatal myocardial non-fatal myocardial infarction, infarction, non-fatal non-fatal stroke, death due to stroke, death due to cardiovascular causes, cardiovascular causes nephropathy, retinopathy $<6.0$ $\leq 6.5$

3.4

5.0

$\begin{array}{ll}77 \text { vs. } 55 & 41 \text { vs. } 24 \\ 95 \text { vs. } 87 & 74 \text { vs. } 67 \\ 87 \text { vs. } 74 & 94 \text { vs. } 62 \\ 92 \text { vs. } 58 & 17 \text { vs. } 11 \\ 18 \text { vs. } 5 & \text { Not reported } \\ 88 \text { vs. } 88 & 46 \text { vs. } 48 \\ 91 \text { vs. } 92 & 89 \text { vs. } 88 \\ 70 \text { vs. } 72 & \text { Not reported } \\ 76 \text { vs. } 76 & 57 \text { vs. } 55 \\ & \\ 6.4 \text { vs. } 7.5+ & 6.5 \text { vs. } 7.3+ \\ & (\%) 8.9 \text { vs. } 9.6 \\ 5.0 \text { vs. } 4.0+ & 4.5 \text { vs. } 5.2 \\ 2.6 \text { vs. } 1.8+ & 2.7 \text { vs. } 2.8 \\ 3.6 \text { vs. } 4.6+ & 3.8 \text { vs. } 3.8 \\ 1.3 \text { vs. } 1.2 & 0.7 \text { vs. } 0.4 \\ 3.1 \text { vs. } 1.0+ & \\ 3.5 \text { vs. } 0.4 & 0.0 \text { vs. }-1.0+ \\ 10 \text { vs. } 10 & 8 \text { vs. } 8\end{array}$

+ The comparison of the intervention with the standard therapy was significant. Modified according to (6)

Table 3 shows a comparison summary of the essential parameters of the two studies.

\subsubsection{Note on patient characteristics}

The patient characteristics show that the patient cohorts recruited in both studies displayed similarities in terms of age, duration of diabetes and percentage with pre-existing macrovascular diseases. The HbA1c target values achieved were comparable.

\subsubsection{Note on intensifying antihyperglycaemic therapy} The ways in which antihyperglycaemic therapy was intensified present marked differences: Whereas a polypharmacotherapeutic approach was adopted in the ACCORD study (by the end of the study $\sim 70 \%$ of patients not treated with insulin and $\sim 60 \%$ of those treated with insulin were receiving combination therapies with 3, 4, or 5 OADs), the ADVANCE study used an algorithm to determine a supplementary regimen of insulin with lasting effects if the HbA1c target value of $<6.5 \%$ was not achieved using OADs alone. If a further escalation in therapy became necessary 
in order to achieve the HbA1c target value, intensified insulin therapy using basal and prandial insulin was recommended. 4.4.3 Note on results regarding effect on mortality

The conspicuous effect of increased mortality in the group receiving intensified treatment in the ACCORD study was not observed in the ADVANCE study, which recorded comparable results for $\mathrm{HbA1c}$ target value achievement.

\subsubsection{Note on side effects of intensified therapy \\ 4.4.4.1 Hypoglycaemia}

The group receiving intensified treatment in the ACCORD study experienced severe hypoglycaemia at a rate 3.1 times greater than the standard treatment group, overall $16.2 \%$ of the patients in this group suffered a severe hypoglycaemia episode In the ADVANCE study, the rate of severe hypogylycaemia was $0.7 \% / y e a r$, slightly higher than in the standard therapy group ( $0.4 \% / y e a r)$, but lower than in the standard therapy group of the ACCORD study (1.0\%/year) - with a difference of 1.0\% (6.5\% (ADVANCE (int.) vs. $7.5 \%$ (ACCORD (std.))) in the average HbA1c value.

\subsubsection{Weight gain}

The average weight gain of patients in the ACCORD study was $3.5 \mathrm{~kg}, 27.8 \%$ of the patients experienced a weight gain of $>10 \mathrm{~kg}$.

The patients in the group receiving intensified treatment in the ADVANCE study experienced no weight gain $(+/-0.0 \mathrm{~kg})$.

\subsection{Conclusions}

The results of the ADVANCE study show that intensified antihyperglycaemiec therapy that aims to achieve an HbA1c target value of $<6.5 \%$ while avoiding side effects (hypoglycaemia, weight gain) is associated with significantly reduced recurrence or progression of nephropathy, by $21 \%$ in relative terms (NNT 91 for 5 years). Macrovascular endpoints were not significantly reduced by the end of the 5 -year study.

The results of the ACCORD study show that lowering the HbA1c to below $6.5 \%$ - under the conditions of this study - can increase mortality due to myocardial infarction. The differing results from these two studies indicate that the way in which antihyperglycaemic therapy is intensified is of crucial importance to the success of the therapy.

The conclusion derived from the studies for application in practical therapy is that lowering HbA1c to $6.5 \%$ as compared with a target value of $7.0 \%$ can be beneficial for the patient, but should only be aimed for provided that

- hypoglycaemia (particularly severe hypoglycaemia) can be largely prevented,

- the therapeutic effect is not associated with significant weight gain,

- inadequately documented combinations of multiple oral diabetics (i.e., generally more than two) are avoided, and particularly that such multiple combinations are discontinued if treatment with insulin is begun.

The polypharmacotherapeutic procedure adopted in the ACCORD study (with the side effects described above) is not recom- mended in the territory for which the DDG guideline is authoritative. Instead, the guideline recommends a procedure with preferential use of a non-hypoglycaemia inducing substance (metformin) as the medium of first choice [292] and also the use of insulin, if the HbA1c target value is no longer reached with a combination therapy consisting of no more than two OADs.

In the light of the results of the ACCORD and ADVANCE studies, the DDG guideline on "Antihyperglycaemic treatment of type 2 diabetes" has been supplemented with a statement to the effect that avoidance of side effects (hypoglycaemia, significant weight gain) is a primary objective, even at the cost of allowing the HbA1c target value to remain at 7.0, if a target value of $<6.5 \%$ can only be achieved with the side effects described above.

The guidelines commission will respond promptly to the publications on this subject that are expected soon (e.g. further analyses of the ACCORD study, VADT, results of the 10-year follow-up review of the UKPDS (presentation on 10.9.08 on the EASD, BARI-2D etc.), and will adapt its recommendations for treating type 2 diabetes to the latest status of published evidence as necessary, in keeping with the guidelines of the the EASD and IDF.

DDG President

DDG Managing Board

DDG Pharmacotherapy Committee

DDG Guidelines Commission

(Antihyperglycaemic treatment of type 2 diabetes mellitus)

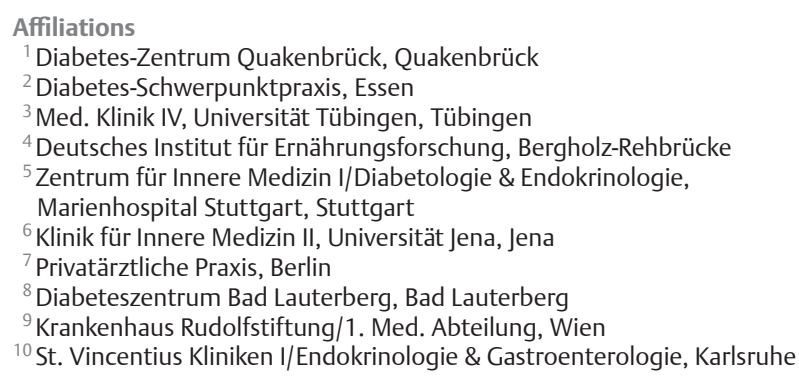

\subsection{References}

1 UK Prospective Diabetes Study (UKPDS) Group. Intensive blood-glucose control with sulphonylureas or insulin compared with conventional treatment and risk of complications in patients with type-2 diabetes. (UKPDS 33). Lancet 1998; 352: 837-853

2 Shichiri $M$, Kishikawa $H$, Ohkubo $Y$ et al. Long-term results of the Kumamoto Study on optimal diabetes control in type 2 diabetic patients. Diabees Care 2000; 23 (Suppl.2): B21-B29

3 The Action to Control Cardiovascular Risk in Diabetes Study Group. Effect of Intensive Glucose Lowering in Type 2 Diabetes. N Eng J Med 2008; 358: $2545-2559$

4 The ADVANCE Collaborative Group. Intensive Blood Glucose Control and Vascular Outcomes in Patients with Type 2 Diabetes. N Eng J Med 2008; 358: $2560-2572$

5 Patel A, McMahon S, The ADVANCE Collaborative Group. Effect of a fixed combination of perindopril and indapamide on macrovascular and microvascular outcomes in patients with type 2 diabetes mellitus. Lancet 2007; 370: 829-840

6 Dluhy RG, McMahon GT. Intensive Glycemic Control in the ACCORD and ADVANCE Trials. N Eng J Med 2008; 358: 2630-2633

7 UKPDS Group. Effect of intensive blood-glucose control with metformin on complications in overweight patients with type 2 diabetes (UKPDS 34). Lancet 1998; 352: 854-865 